\title{
Contextual variability in early adolescents' state masculinity, femininity and peer interaction goals
}

Jennifer Kristen Pickard

West Virginia University

Follow this and additional works at: https://researchrepository.wvu.edu/etd

\section{Recommended Citation}

Pickard, Jennifer Kristen, "Contextual variability in early adolescents' state masculinity, femininity and peer interaction goals" (2003). Graduate Theses, Dissertations, and Problem Reports. 1886.

https://researchrepository.wvu.edu/etd/1886

This Dissertation is protected by copyright and/or related rights. It has been brought to you by the The Research Repository @ WVU with permission from the rights-holder(s). You are free to use this Dissertation in any way that is permitted by the copyright and related rights legislation that applies to your use. For other uses you must obtain permission from the rights-holder(s) directly, unless additional rights are indicated by a Creative Commons license in the record and/ or on the work itself. This Dissertation has been accepted for inclusion in WVU Graduate Theses, Dissertations, and Problem Reports collection by an authorized administrator of The Research Repository @ WVU.

For more information, please contact researchrepository@mail.wvu.edu. 
Contextual Variability in Early Adolescents'

State Masculinity, Femininity and Peer Interaction Goals

Jennifer Kristen Pickard, M.A.

Dissertation submitted to the Eberly College of Arts and Sciences

at West Virginia University in partial fulfillment of the requirements

for the degree of

Doctor of Philosophy

in

Developmental Psychology

JoNell Strough, Ph.D., Chair

Deborah Jones, Ph.D.

Kevin Larkin, Ph.D.

Jennifer Margrett, Ph.D.

Carol Markstrom, Ph.D.

Department of Psychology

Morgantown, West Virginia

2003

Keywords: Gender, Gender roles, Masculinity, Femininity, Goals 


\author{
ABSTRACT \\ Contextual Variability in Early Adolescents' \\ Masculinity, Femininity, and Peer Interaction Goals
}

Jennifer Kristen Pickard

The purpose of the study was to investigate how early adolescents' gender-typed behaviors (i.e., masculinity, femininity, goals for interacting with peers) changed as a function of the social context. Eighty early adolescents (40 boys and 40 girls, $7^{\text {th }}-8^{\text {th }}$ graders; Mean age $=13.14 ; S D=$ .65) worked with both a same- and an other-sex peer on a collaborative or a competitive block building task. Individual attributes such as participant sex, and contextual features such sex of partner affected early adolescents' reported masculinity, femininity, and their goals for a peer interaction. Boys reported greater femininity when interacting with an other-sex peer than when interacting with a same-sex peer. On an open-ended goals assessment, both boys and girls reported a greater proportion of task-performance goals when interacting with a same-sex peer than when interacting with an other-sex peer. The type of task (collaborative, competitive) was found to influence participants' reported gender-typed behaviors. Participants who worked on a competitive task reported greater control goals compared to participants who worked on a collaborative task. Participants who worked on a collaborative task reported greater taskperformance goals and mutual-participation goals than participants who worked on a competitive task. Gender differences were more apparent in competitive situations than in collaborative situations. On a closed-ended goals assessment, among participants who had worked a competitive task, girls reported greater mutual-participation and task-performance goals than boys in the same condition. The results of the study highlighted the importance of examining a combination of individual attributes and contextual features when investigating issues related to early adolescence and gender. The study supported the contention that masculinity and femininity can vary according to social contextual demands. The findings added to the literature by supporting the idea that gender is socially constructed and illustrated the importance of examining the contextual specificity of gender-typed behaviors. 


\section{ACKNOWLEDGEMENTS}

The author would like to thank her fiance, Marek Leszczynski, and her parents, Rick and Connie Pickard, for all of their love and support during the dissertation process. She would not have been so successful without each one of them in her life. The author also wishes to acknowledge Dr. JoNell Strough for her advisory role during this research project. 


\section{TABLE OF CONTENTS}

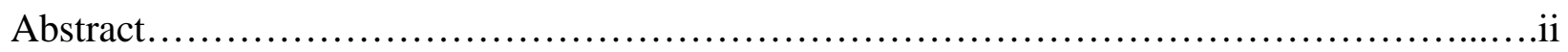

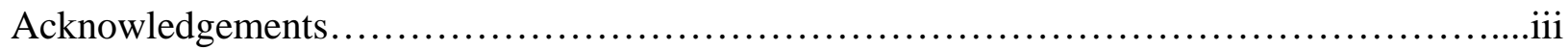

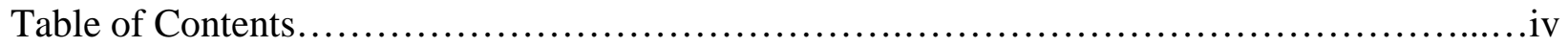

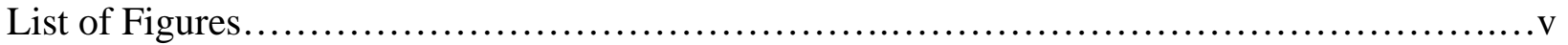

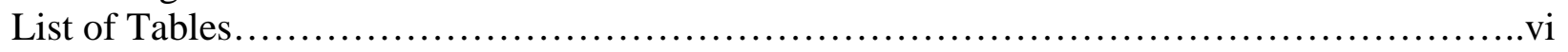

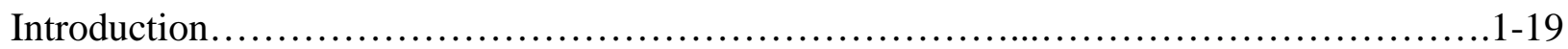

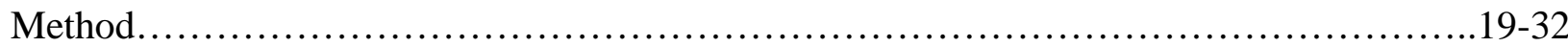

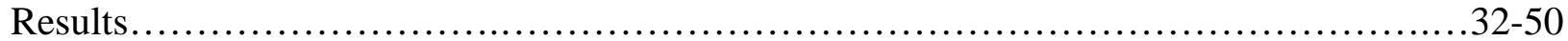

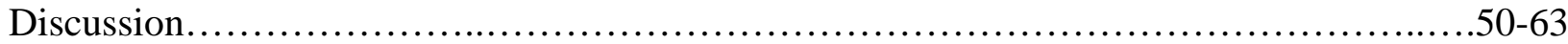

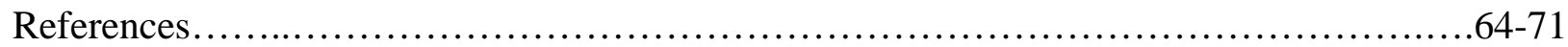

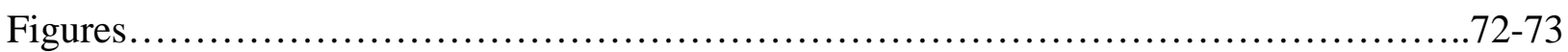

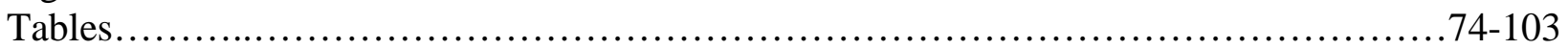

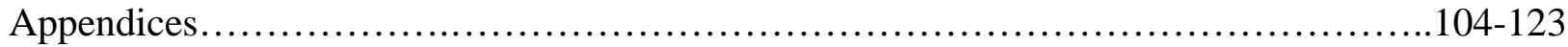




\section{LIST OF FIGURES}

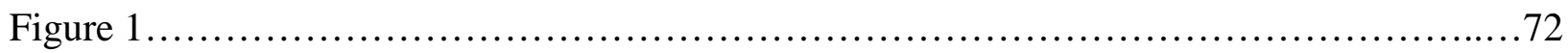

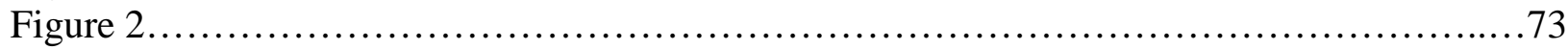




\section{LIST OF TABLES}

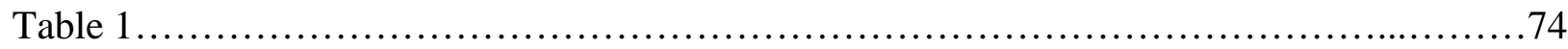

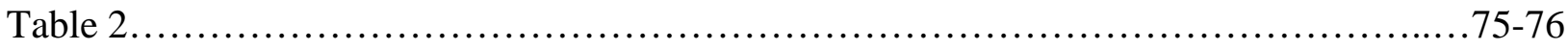

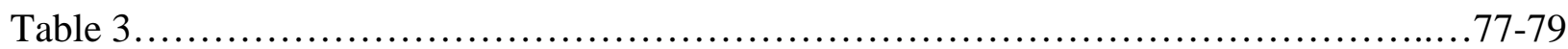

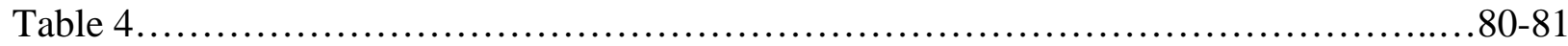

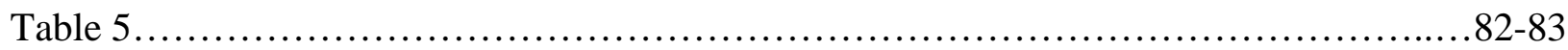

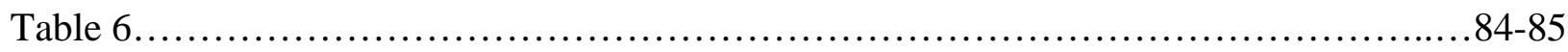

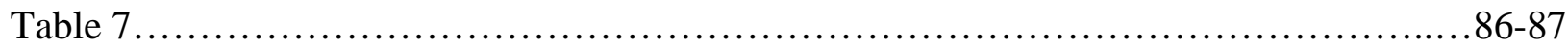

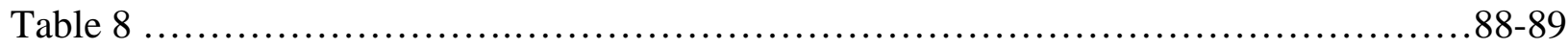

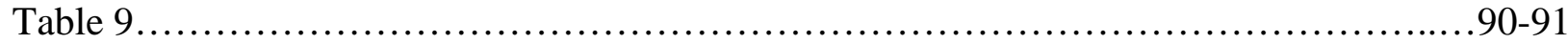

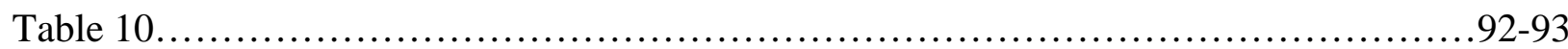

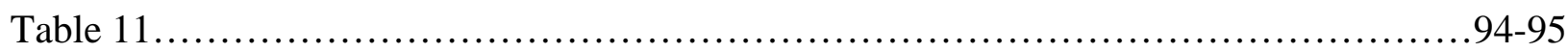

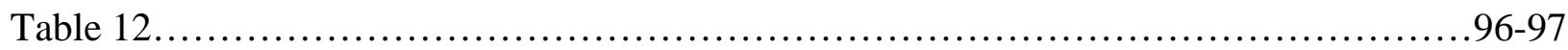

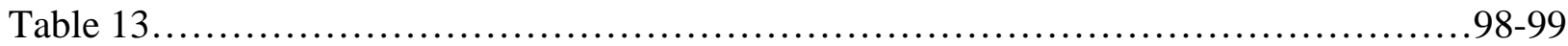

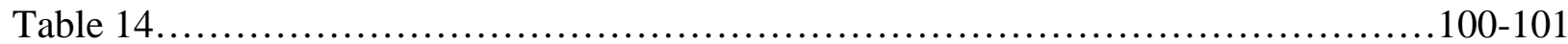

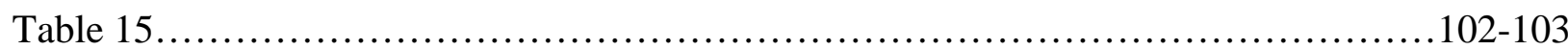


Contextual Variability in Early Adolescents' State

Masculinity, Femininity and Peer Interaction Goals

Individuals' genders are reflected in the degree to which their behaviors are stereotypically masculine or feminine and in their orientations for viewing the world. The term "gender" refers to differences and similarities between males and females resulting from socialization, whereas the term "sex" refers to biological differences and similarities (Anselmi \& Law, 1998). Aspects of gender such as masculinity and femininity are often conceptualized as stable personality characteristics (Ruble \& Martin, 1998). However, some researchers suggest that masculinity and femininity can be viewed as expressive and instrumental behaviors (Spence \& Helmreich, 1981) that vary within different social contexts (Pickard \& Strough, 2003). Goals are important for understanding gender differences and similarities in social behavior (Strough \& Berg, 2000) and also vary as a function of social contexts (Pickard \& Strough, 2003; Strough \& Berg, 2000; Swenson \& Strough, 2002). Thus, it is important to examine contextual influences on masculinity, femininity and goals to gain insight as to how gender is socially constructed through interactions with other people. The current study compared the flexibility of males' and females' gender-typed behaviors when working with a same- or an other-sex peer on a collaborative or a competitive social task.

\section{Overview}

This paper begins with a discussion of conceptual theories that emphasize the contextual variability of gender-typed behaviors. This includes a conceptual model developed specifically for this study. Second, research indicating contextual variability in masculinity, femininity and goals for peer interactions is reviewed. Contextual variability is discussed as it relates to gender- 
typed behaviors, including how the sex of a partner (i.e., same- and other-sex), partner familiarity and the type of task (i.e., collaborative, competitive) may influence masculinity, femininity, and goals for the peer interaction. Third, age (i.e., early adolescence) is discussed as an individual attribute that may, through a series of developmental tasks and demands, influence masculinity, femininity and goals for the interaction.

\section{Definition of Key Terms}

The use of the terms "gender" and "sex" vary throughout the literature. In this paper, the term "sex" is used when referring specifically to biological sex and to denote contexts comprised of either two boys or two girls (same-sex) or a boy and a girl (other-sex; see also Strough, Berg \& Sansone, 1996). The term "gender" is used to describe differences and similarities between males and females that may reflect socialization and when referring to behaviors that vary by context (Anselmi \& Law, 1998). Consistent with past literature, this paper refers to individuals of the "other" sex rather than to individuals of the "opposite" sex. The term "opposite" sex implies that males and females are inherently different rather than emphasizing the similarities between the sexes. The term "gender-typed behaviors" is used when referring to expressive and instrumental behaviors that are consistent with masculine and feminine stereotypes, including individuals' goals for the peer interaction.

\section{Conceptual Framework}

Within the fields of developmental psychology and social psychology, researchers who adopt a social constructionist view of gender emphasize how gender stereotypical behaviors are contextually specific (e.g., Deaux \& Major, 1987; Leaper, 1991; Maccoby, 1990). Social constructionists conceptualize gender-typed behaviors as emerging from the intersection of the individual and the immediate context, rather than only from individuals' personality traits or 
socialization. The current study draws from the social constructionist view to examine how contextual factors and individual characteristics combine to affect individuals' state masculinity, femininity, and goals with a peer. Researchers (e.g., Pickard \& Strough, 2003; Pickard \& Strough, 2003; Strough \& Berg, 2000) have suggested that masculine and feminine behaviors and goals for working with others may differ according to contextual demands. Therefore, it is important to examine flexibility in gender-typed behaviors (i.e., masculinity, femininity, and goals) in a number of different social situations.

Individuals' gender-typed behaviors may reflect two distinct orientations for viewing the world. Agentic (i.e., instrumental) and communal (i.e., expressive) orientations have been of enduring interest throughout the gender literature (e.g., Bakan, 1966; Block, 1983; Gilligan, 1982; Sheldon, 1990). Communal orientations reflect concerns with interpersonal issues (e.g., peers, family, relationships, and other people's interests); whereas agentic orientations reflect concerns about meeting one's own needs such as accomplishing a specific task (Bakan, 1966; Block, 1983). Within the gender literature, a number of researchers (e.g., Stake, Zand, \& Smalley, 1996) have examined agentic and communal concerns. Individuals' goals for interacting with other people (Sheldon, 1990; Strough et al., 1996) and their masculine and feminine behaviors (e.g., Stake et al., 1996) are thought to reflect agentic and communal orientations. Agentic qualities are associated with masculine traits and communal qualities are associated with feminine traits (Marsh, 1987).

Masculinity and Femininity. Regardless of a person's biological sex, masculinity and femininity may vary within an individual; males and females may exhibit both masculine and feminine behaviors. That is, masculinity and femininity are not constructs at either end of a single dimension, but rather, each consists of a separate dimension and should be measured 
separately (Constantinople, 1973). Using masculinity and femininity in research in addition to biological sex allows researchers to study variations in gender-typed behaviors in both males and females (Anselmi \& Law, 1998). Investigators have often conceived masculinity and femininity to be fairly rigid in that they are often described as being stable over time (Ruble \& Martin, 1998). This is a conceptualization of masculinity and femininity as fixed personality traits. For example, a man who is categorized as masculine is thought to exhibit consistently high levels of masculinity across various contexts. The trait conceptualization often uses masculinity and femininity as categorical variables. That is, individuals who describe themselves as having high levels of masculinity and low levels of femininity are categorized as masculine and individuals having high levels of femininity and low levels of masculinity are categorized as feminine (Bem, 1974).

Pickard and Strough (2003) conceptualized changes in behaviors according to situational demands as a state component of masculinity and femininity. In their research, masculinity and femininity are thought to be comprised of both a trait and a state component. That is, there are stable differences between individuals in the extent to which they view themselves as masculine or feminine (trait component). However, there is within-person variation (state component). Within-person variation is conceptualized as a potential range in the degree to which state masculinity and femininity (or expressive and instrumental behaviors) can be expressed. This state aspect of masculinity and femininity may be sensitive to contextual demands. Thus, high or low state masculinity and femininity are thought to depend on individual differences in the trait aspect and the salience of gender within the context.

Bem's (1974) notion of androgyny can be extended to include a state component. Androgynous individuals exhibit both masculine and feminine traits. Bem suggested that 
androgynous individuals have a wider repertoire of behaviors from which to choose. That is, androgynous individuals may draw upon both masculine and feminine behaviors. Androgyny as it is conceptualized in Bem's theory is a personality trait. However, it is consistent with Bem's conceptualization to include a state component that varies according to situational constraints. For instance, as a result of their more extensive behavioral repertoire, androgynous individuals' masculinity and femininity may vary more as a function of situational demands compared to individuals with traditional gender-typed behaviors.

Goals for the Peer Interaction. Individuals have a number of different goals in their everyday lives (Strough et al., 1996). Goals differ in both their level and specific content. Lifetask goals include goals for the future, planning ahead, making new friends and finding romantic partners (Wrosch \& Heckhausen, 1999; Zirkel \& Cantor, 1990). There are also goals specific to certain domains or situations. For example, individuals may have purpose goals when accomplishing a specific task (Sansone \& Harackiewicz, 1996). When solving everyday problems, individuals' goals are often focused on a specific task or managing relationships with other people (Strough et al., 1996). Specific goals have been found to emerge within certain social contexts. For example, in academic contexts, individuals may be concerned with performance (i.e., judgments of current competence) or may have goals for learning (i.e., wanting to increase competence; Dweck \& Leggett, 1988). At school, adolescents have a number of different goals including task-mastery, evaluation, academic and social responsibility goals (Wentzel, 1991; 1993). When interacting with friends, Rose and Asher (1999) suggest that relationship and morality goals become important. In situations where individuals work with others to complete a task, their goals may focus on the task, the relationship, or both (Strough, Berg, \& Meegan, 2000). Accordingly, individuals' concerns with mutual-participation, task- 
performance and partner control goals have been investigated when working with a peer on a task (Strough \& Berg, 2000).

Mutual-participation goals reflect individuals' motivations to work together with others to perform a task (Strough \& Berg, 2000). Therefore, mutual-participation goals reflect aspects of both communal and agentic orientations. Sheldon (1990) suggests that girls are more likely than boys to adopt this dual orientation, accomplishing instrumental goals while simultaneously taking others' needs into account. Control goals have been defined as goals for exerting authority; task-performance goals are goals for completing or performing well on a task. Control and task-performance goals are consistent with agentic orientations (Strough \& Berg, 2000). Males are thought to be relatively more motivated by instrumental or agency concerns than are females (Bakan, 1966; Block, 1983).

Consistent with theoretical work on gender differences in communal and agentic concerns, research with children, preadolescents, and college students indicates gender differences in goals. When working with a peer on a task, female college students (Pickard \& Strough, 2003), adolescents (Swenson \& Strough, 2002), and preadolescents (Strough \& Berg, 2000) rate mutual-participation goals higher than do males. Rose and Asher (1999) found that girls reported more relationship maintenance goals compared to boys and boys reported more instrumental-control goals compared to girls. Similarly, compared to adolescent girls, adolescent boys report more control goals when interacting with same-sex peers (Swenson \& Strough, 2002). However, it is not only the gender of the person that is important to examine. Research suggests that individuals' goals vary according to the surrounding context.

Conceptual Model. A conceptual model was devised specifically for the current study. The model is based on a contextual worldview, research within the gender literature, and 
Sansone and Berg's (1993) model. Researchers who adopt a contextual worldview examine the combination of individual and contextual factors (Pepper, 1966). Within the gender literature, these researchers emphasize the contextual specificity of social behaviors and the social construction of gender (e.g., Deaux \& Major, 1987; Leaper, 1991; Maccoby, 1990). Sansone and Berg's (1993) model suggests that contextual features and individual attributes combine to affect individuals' interpretations of situations. Figure 1 shows how contextual features (i.e., sex of partner and type of task) and individual attributes (i.e., sex and age of participant) combine to influence how gender is constructed within the social context. The contextual and individual attributes examined in the study were selected because previous research indicates that they are associated with individuals' communal and agentic orientations. Masculinity (i.e., instrumental behaviors), femininity (i.e., expressive behaviors), mutual-participation, control, and taskperformance goals were chosen as dependent variables in the study because they reflect the communal and agentic orientations people have for viewing the world.

In the current study, sex of partner is a contextual feature that combines with the individual characteristics participant age and sex to influence gender-typed behaviors. For example, when early adolescent boys and girls work on a task, based on their own gender and experiences, they bring beliefs about males and females into the context. These beliefs (or stereotypes) may influence their behaviors in a number of different situations. Krauss (1977) found that adolescent girls reported more masculinity when working with a boy on a competitive task than when working with another girl on a competitive task. Within a collaborative context and examining college students, Pickard and Strough (2003) found that male college students reported more femininity when interacting with a female compared to another male. Thus, both 
individual attributes and contextual features combine to affect individuals' gender-typed behaviors.

The current study continues Pickard and Strough's (2003) work examining the contextual variability of masculine and feminine behaviors. The Bem Sex Role Inventory (BSRI; Bem, 1974) is often used to assess an individual's trait masculinity and femininity. However, some researchers suggest that the BSRI may actually be measuring expressive and instrumental behaviors (Spence \& Helmreich, 1981). If the BSRI assesses expressive and instrumental behaviors, then researchers could use the instrument to examine behavioral change in different social situations.

\section{Variability in Gender-typed Behaviors}

Masculinity and Femininity. Research examining undergraduate college students indicates that the behaviors that constitute masculinity and femininity change according to the social context. Several studies have found that masculine attributes change according to contextual demands. Miller, Lewy, and Peckham (1997) found that males' and females'

masculinity (as measured by the Bem Sex Role Inventory; BSRI) increased in instrumental conditions as compared to expressive conditions. Smith, Noll, and Becker-Bryant (1999) found that, for both males and females, higher masculinity (as measured by the BSRI) was reported in an employment context compared to a social context where the participant did not know many people. The workplace is often viewed as an arena for competition and dominance, two stereotypically masculine traits. Therefore, it may be effective for an individual to express masculine behaviors within an employment context. Together, this empirical research suggests that individuals are more likely to report masculinity in instrumental/employment contexts than in expressive/social contexts. 
Results also indicate variation in femininity as assessed by Bem's (1974) instrument in relation to contextual influences. Miller et al. (1997) found that participants' state femininity increased in expressive conditions. Using vignettes to manipulate the same-sex and other-sex contexts, Smith et al. (1999) found that males reported more femininity when told to imagine themselves in an other-sex context (interacting with a female) than when told to imagine themselves in a same-sex context (interacting with a male). Thus, the authors suggested that males avoid feminine behaviors when interacting with male peers. Females' femininity did not vary between same-sex and other-sex contexts in Smith and colleagues' study. However, when Pickard and Strough (2003) used actual interactions to manipulate same-sex and other-sex contexts, they found that both males and females reported more femininity in other-sex contexts compared to same-sex contexts. Thus, there is evidence that both males' and females' femininity varies when interacting with either same-sex or other-sex peers.

Androgyny. Androgynous individuals are able to draw from both feminine and masculine behavioral repertoires. Bem (1975) argues that androgynous individuals vary their expressive or instrumental behaviors in different situations. However, few studies have actually assessed how androgynous individuals change their behaviors according to contextual demands. One exception is Pickard and Strough's (2003) work which examined whether androgynous individuals' gender-typed behaviors changed when working with a same- or an other-sex peer. The study compared individuals high on androgyny to those low on androgyny and did not find significant differences in the amount of behavioral flexibility between the two groups. Thus, the findings did not support Bem's theory of androgynous flexibility.

It could be argued that the ability to vary their behaviors according to situational demands makes androgynous individuals more adaptive than sex-typed individuals (Bem, 1975). Many 
studies have examined the adaptability of androgyny by comparing the psychological well-being of androgynous individuals to that of sex-typed individuals (e.g., Flaherty \& Dusek, 1980; Massad, 1981). Empirical support for Bem's theory of androgynous flexibility has focused on differences between masculine, feminine, and androgynous individuals in self-esteem, psychological adjustment (Taylor \& Hall, 1982), self-reported traits (Flaherty \& Dusek, 1980), and peer acceptance (Massad, 1981). Some studies suggest that higher levels of androgyny are associated with greater social and psychological functioning (e.g., Flaherty \& Dusek, 1980). However, support for an androgynous theory of adjustment is often qualified by gender differences. It is only for girls that higher levels of androgyny are associated with greater peer acceptance and self-esteem (Flaherty \& Dusek, 1980; Massad, 1981). Studies suggest that masculinity, rather than androgyny or femininity, is related to psychological well-being in boys (Taylor \& Hall, 1982). Thus, these studies suggest that androgyny may be more adaptive for females than for males.

Goals for the Peer Interaction. The contextual attributes highlighted in Figure 1 (i.e., sex of partner and type of task) have also been found to influence individuals' reported goals. For example, compared to males, females report more goals for solving everyday problems that focus on the needs of others. However, when other people are central to the problem, males and females are equally concerned with other-focused goals (Strough et al., 1996). Children's gender-typed behaviors are more prevalent in same-sex peer interactions and less prevalent in other-sex peer interactions (Maccoby, 1998). Preadolescents' goals vary according to the sex of others in the social context. Strough and Berg (2000) found that, in contrast to the gender differences in same-sex dyads, within mixed-sex dyads, boys' and girls' concern with mutualparticipation goals was not significantly different. Research on adults' communication also 
suggests that gender differences are greatest in same-sex interactions and less apparent in othersex interactions (Carli, 1989; Carli \& Bukatko, 2000; Strough, Swenson, Pickard \& Owens, 2002). Pickard and Strough (2003) found that males reported a greater proportion of mutualparticipation goals in an other-sex context (i.e., when interacting with a female) compared to a same-sex context. As for task-performance goals, both males and females reported a greater proportion of task-performance goals in a same-sex context than in an other-sex context. Thus, sex of partner is an aspect of the situation associated with gender differences and similarities in individuals' goals. Together this research suggests that goals vary according to aspects of the immediate social context, including the sex of an interactional partner.

Collaborative and Competitive Tasks. Fisher (1983) suggests that task structure (competitive/collaborative) may be more influential to individuals' behaviors than the sex of their interactional partner. Expressive and collaborative tasks are often defined as feminine and may elicit a communal orientation. When interacting collaboratively, individuals work together to complete a task. In collaborative contexts, individuals are likely to trust each other and share their resources (Tjosvold, 1981). Instrumental and competitive tasks are described as being masculine and are may elicit an agentic orientation. When working on a competitive task, individuals compete against one another. Competitive tasks are characterized by mistrust and a struggle for resources (Tjosvold).

Research suggests that males and females exhibit different behaviors when working on collaborative and competitive tasks. For instance, working on a gender-stereotypically feminine task may increase the likelihood that an individual is more expressive and interdependent during the interaction. Conversely, working on a masculine task may increase the likelihood that an individual will exhibit more instrumental and independent behaviors (Hannover, 2002). In 
research with adults, Miller et al. (1997) found that males' and females' masculinity increased in instrumental conditions that could assess participants' agentic concerns (i.e., a job interview for an authoritative leader) and their femininity increased in expressive conditions that could assess participants' communal concerns (i.e., a job interview for an individual concerned with his/her coworkers' needs). Schmidt, Ollendick, and Stanowicz (1988) found that, when playing an individualistic (i.e., competitive) game, $5^{\text {th }}$ and $6^{\text {th }}$ grade children compared to $4^{\text {th }}$ grade children were more likely to use combative moves than cooperative moves. Thus, it is important to examine both collaborative (or expressive) and competitive (or instrumental) tasks as males' and females' behaviors tend to vary according to this particular nature of the context.

Research indicates that there are several types of competition, for instance, interference competition (see Roy \& Benenson, 2002); intragroup competition (see Krauss, 1977) and intergroup competition (see Johnson, Johnson, \& Stanne, 1986). Interference competition occurs when individuals attempt to hurt someone else's chances of doing well on the task. When one group is competing against another group, it is considered intergroup competition. Intragroup competition occurs when individuals within a group or dyad compete for resources. For example, when individual children are playing a game against their peers it is defined as intragroup competition (Goldman, Stockbauer, and McAuliffe, 1977). The current study focuses on intragroup competition in which an individual's performance is measured in relation to the performance of a partner. Since the current study compares collaborative and competitive tasks, it is important that the tasks are distinct in their demands and the interpersonal processes that may emerge. Intragroup competition was chosen over intergroup competition because of a concern that intergroup (i.e., between group) competition could lead to collaboration within dyads (Bornstein \& Erev, 1994) 
Partner Familiarity. In addition to the structure of the task, aspects of the situation such as the friendship between two people, may affect how individuals interact when working with a peer. Previous research has examined the variability in college students' gender-typed behaviors using unacquainted dyads (e.g., Pickard \& Strough, 2003; Pickard \& Strough, 2003; Strough et al., 2002). Work with children (e.g., Azmitia \& Montgomery, 1993), early adolescents (Strough, Swenson \& Cheng, 2001) and adults (e.g., Margrett \& Marsiske, 2002) indicates that partner familiarity may affect task expectations. In addition, some studies indicate that friendship leads to more effective task performance (Azmitia \& Montgomery, 1993; Newcomb \& Bagwell, 1995; Newcomb \& Brady, 1982). Friendship has also been found to relate to conflict resolution in that friends are more likely to resolve conflicts that occur during an interaction compared to nonfriends (for a review see Zajac \& Hartup, 1997). When working on collaborative problemsolving tasks, adolescents prefer to work with friends than non-friends (Strough et al., 2001). Similarly, older married couples rate their satisfaction higher when working collaboratively with a familiar partner than when working collaboratively with an unfamiliar partner (Margrett \& Marsiske, 2002). In fact, greater friendship relates to higher expectations concerning task enjoyment, more perceptions of affiliation during the task (Strough, Swenson, \& Cheng, 2001) and more shared mutual-participation goals (Strough \& Cheng, 2000).

Some researchers have examined contextual variability in instrumental behaviors between friends and non-friends. For instance, Moskowitz (1993) found that men engaged in more dominance (i.e., made attempts to make his partner accept his solution to a problem) when interacting with a friend than when interacting with a stranger. Conversely, women engaged in less dominance when working with a friend compared to a stranger. Thus, partner familiarity had different consequences for men's and women's instrumental behaviors. 
Overall, the literature suggests that how well people know each other affects different aspects of the interaction. Thus, it may be important to control for friendship when examining interactions between peers. Friendship was used as a covariate in the current study in order to adjust for the potential influence of dyadic friendship on gender-typed behaviors.

\section{Developmental Influences on Gender-typed Behaviors}

Figure 1 shows how the contextual features discussed above combine with individual attributes to influence gender-typed behaviors. The current study focuses on the individual attribute age by examining variability in early adolescents' masculinity, femininity, and peer interaction goals.

Identity exploration, making new friends and the search for romantic partners are important tasks during early adolescence (Strough, Swenson, Owens, \& Pickard, 2002) and may influence peer interaction goals and the flexibility or rigidity of gender-typed behaviors. For example, Strough et al. (2002) found that making friends and getting along with others were more important to early adolescents than to late adolescents and college students. The importance of the peer group may result from transitions from elementary to middle school and middle to high school in which early adolescents are exposed to peer groups consisting of new individuals. In addition, friendships become much more intimate between the ages of 12-17 years and adolescents find themselves seeking much more support from their friends than from their parents (Craig, 1996). These developmental tasks and contexts may influence early adolescents' goals for social interactions. For instance, the importance of peer group formation may make it likely that early adolescents will have communal concerns and mutual-participation goals when interacting with a peer. 
Developmental demands during adolescence may lead to different social interactions between males and females than those established in childhood. During childhood, boys and girls segregate into same-sex groups and have few other-sex interactions (Maccoby, 1998). It is around the eighth grade that other-sex peers become much more prevalent in peer groups (Buhrmester \& Furman, 1986, 1987) and same-sex peer nominations become less common than earlier in the life-span (Strough \& Covatto, 2002). The move from segregated same-sex peer networks to other-sex relationships may arise from the search for potential romantic partners (Maccoby, 1998). It is important to examine early adolescents (ages 12-15 years) in order to study how this move from same-sex peer groups to other-sex peer relationships may influence variation in individuals' displays of gender-typed behaviors.

Work with preadolescents suggests that, when working on a collaborative task, girls' interactions with other girls are highly affiliative, whereas girls' interactions with boys are low in affiliation (Strough \& Berg, 2000). Conversely, studies examining young adults suggest that it is men who alter their behaviors when interacting with women. Studies indicate that men report more expressive behaviors when working with women (Pickard \& Strough, 2003) and alter their verbal behavior (i.e., speaking more warmly when interacting with women than with other men; see Carli \& Bukatko, 2000). Leaper's (1994) work suggests that male college students are more disclosing with female friends than with male friends. These findings are important to the current study because it suggests that both men and women may vary their feminine behaviors when interacting with peers.

Developmental tasks during adolescence may influence the flexibility or rigidity of individuals' masculinity and femininity. Establishing an identity is an important task encountered by adolescents (Erikson, 1950; Grotevant, 1998; Nurmi, 1993). Identity is highly 
rooted in both historical and immediate contexts and has the potential to fluctuate when contextual and individual changes are encountered (Grotevant, 1998). Early adolescents encounter a number of new contexts (e.g., transition from junior high to high school, making new friends) in which their identity may fluctuate. Thus, instability in identity formation may lead to an increased flexibility in masculinity and femininity between different contexts and tasks during this point in the life-span. However, several authors have argued that even though identity may be changing, trait masculinity and femininity is rigid during adolescence. Considering the increased importance of peers during this time, social pressures may lead to more gender conformity. Massad (1981) found that males were more accepted by their sameand other-sex peers if they exhibited masculine behaviors compared to feminine or androgynous behaviors. Females had a higher peer acceptance from their same- and other-sex peers when they exhibited both masculine and feminine behaviors. Similarly, Galambos, Almeida and Petersen (1990) examined the gender intensification hypotheses which states that gender differences increase during early adolescence. These gender differences are thought to reflect peer pressure during early adolescence to exhibit traditional sex role stereotypes. Consistent with the hypothesis, Galambos et al., found that boys consistently reported more masculinity than did girls across the $6^{\text {th }}, 7^{\text {th }}$, and $8^{\text {th }}$ grades. In fact, the gender difference was especially pronounced during the $8^{\text {th }}$ grade, suggesting an increased importance of gender stereotypical behaviors during early adolescence.

In sum, previous work suggests that developmental demands during adolescence influence individuals' communal and agentic concerns, their social interactions with peers, and the formation of a gendered identity. Therefore, it is important to examine the malleability or stability of gender-typed behaviors during this point in the life-span. 


\section{Statement of the Problem}

The current study addresses some of the limitations in past research. First, the research base concerning the contextual specificity of masculinity, femininity and goals has focused on a limited number of contexts (e.g., collaborative and peer contexts; Strough \& Berg, 2000; Pickard \& Strough, 2003, 2003). The current study compared participants' state masculinity, femininity, and goals within several social contexts (i.e., same-sex and other-sex peer contexts, collaborative and competitive contexts). Thus, the study adds to the current literature by examining both collaborative and competitive contexts. Second, previous research has primarily used vignettes to examine contextual influences on feminine and masculine behaviors (e.g., Brody, Lovas \& Hay, 1995; Kelly \& Hutson-Someaux, 1999). The examination of actual interactions is important to determine how gender-typed behaviors may vary systematically across contexts (Pickard \& Strough, 2003). Third, past research examining the flexibility of gender-typed behaviors using participants interacting with a same-sex or other-sex partner has focused on college students (Pickard \& Strough, 2003; 2003; Smith et al., 1999). College students' and early adolescents' gender-typed behaviors may differ when working with same- and other-sex peers. A major goal during young adulthood is the search for romantic partners (Zirkel \& Cantor, 1990) and it is during early adolescence that individuals begin to have more frequent interactions with other-sex peers (Buhrmester \& Furman, 1986, 1987; Strough \& Covatto, 2002). It is important to examine early adolescents because prominent developmental issues (e.g., identity formation, peer and romantic relationships) may affect the flexibility of their gendertyped behaviors. Therefore, the current study examined individuals between the ages of 12-14 years.

Hypotheses 
Hypothesis 1. For state femininity, a three-way interaction between sex of participant (boy, girl), sex of partner (same-sex, other-sex), and type of task (collaborative, competitive) was hypothesized. Based on Pickard and Strough's (2003) work, when performing a collaborative task, it was expected that boys would rate femininity higher in the other-sex context (when working with a girl) than in the same-sex context. Girls would rate femininity similarly in the same-sex and other-sex contexts. In competitive contexts, no significant sex of participant and context effects were hypothesized for femininity.

Hypothesis 2. For state masculinity, a three-way interaction between sex of participant (boy, girl), sex of partner (same-sex, other-sex), and type of task (collaborative, competitive) was hypothesized. Based on Krauss's (1977) work with adolescents and Pickard and Strough's (2003) study, on the competitive task but not the collaborative task, it was expected that girls would report greater masculinity in the other-sex context (working with a boy) compared to the same-sex context. Conversely, on the competitive task but not the collaborative task, it was expected that boys would report greater masculinity in the same-sex context (working with another boy) compared to the other-sex context.

Hypothesis 3. Bem (1974) contends that androgynous individual have an extensive behavioral repertoire including both masculine and feminine behaviors. However, Pickard and Strough's (2003) study did not find differences in gender-typed behavioral flexibility between individuals having high or low androgyny scores. Therefore, it was expected that participants who reported high androgyny would not differ from participants who reported low androgyny in their state masculinity and femininity when working with same- and other-sex peers.

Hypothesis 4. For mutual-participation goals, a three-way interaction between sex of participant (boy, girl), sex of partner (same-sex, other-sex), and type of task (collaborative, 
competitive) was hypothesized. Based on Pickard and Strough's (2002) study, on the collaborative task as compared to the competitive task, boys were expected to rate mutualparticipation goals higher (closed-ended assessment) and report more mutual-participation goals (open-ended assessment) in the other-sex context (working with a girl) than in the same-sex context. Girls were expected to rate mutual-participation goals similarly in the same-sex and other-sex contexts and on the collaborative and competitive tasks.

Hypothesis 5. For control and task-performance goals, a two-way interaction between sex of partner (same-sex, other-sex), and type of task (collaborative, competitive) was hypothesized. Based on Pickard and Strough's (2003) work with college students, it was expected that both boys and girls would rate control and task-performance goals higher (closed-assessment) and report more control and task-performance goals (open-ended assessment) in the same-sex context than in the other-sex context on the collaborative task, but not on the competitive task.

Method

\section{Participants}

The participants were 80 early adolescents $\left(7^{\text {th }}-8^{\text {th }}\right.$ graders; 40 boys, 40 girls; Mean age $=13.14 ; S D=.65)$ who were recruited from a middle school in Harrison County, West Virginia. The school enrollment was approximately 650 students in the $6^{\text {th }}, 7^{\text {th }}$, and $8^{\text {th }}$ grades. The city population was approximately 7,000 residents. The age group was defined as "early adolescence" based on the work by Galambos et al. (1990). The majority of the participants were European American (86\% European American, 1\% African American, 4\% other and 9\% unknown). Fifty-percent of students reported that they did not know their parents' average yearly income. However, when participants did report their parents' average yearly incomes, the majority were greater than $\$ 60,000$. The majority of the students were eighth graders (68 eighth 
graders, 12 seventh graders). Seventy-five percent of participants reported having played the game Jenga ${ }^{\circledR}$ prior to the study; $8 \%$ had never played the game (17\% of the data was missing because of incomplete demographic questionnaires). Of those participants who reported that they had played Jenga ${ }^{\circledR}$ before, $17 \%$ had played the game less than 5 times, $30 \%$ had played 5 10 times, $20 \%$ had played 10-20 times and 33\% had played Jenga® more than 20 times. As a result of the missing data from incomplete demographic questionnaires, participants also were asked prior to beginning the task if they had every played the game Jenga® before. The vast majority of participants responded verbally that they had played the game prior to their participation in the study. Boys and girls did not differ on the demographic variables of age, parents' yearly income, and task familiarity.

Approximately six months to beginning the data collection phase of the study, several school superintendents were contacted. After the superintendent gave consent for the school district to participate in the study, meetings were held between the researcher, the school principal, several teachers and the guidance counselor. The guidance counselor organized the distribution and collection of consent, assent, and demographic questionnaires. Letters were sent home with each student explaining the study to both the student and his/her parent(s).

Participants were selected from those students who gave assent and also had parental consent to complete the study. Approximately 175 consent and assent forms were given to students and 83 forms were returned. Thus, the participation rate for the study was approximately $47 \%$. With the exception of one boy who was dropped from the study because of absences from school (after completing a same-sex interaction), all of the participants who began the study completed the study. Each participant received a small prize (i.e., school supplies) for taking part in the study and the students were entered into a raffle for a chance to win one of 9 Jenga ${ }^{\circledR}$ games. 
Measures

During a baseline assessment, participants completed the following measures: Demographic Questionnaire, the Bem Sex Role Inventory (BSRI), and the Children's Sex Role Inventory (CSRI). Prior to starting each interaction, participants completed the Expectations Questionnaire. Following each interaction, participants completed the State Gender Role Inventory (SGRI), the Children's State Gender Role Inventory (CSGRI), the Perceptions Questionnaire, the Open-ended Goals Questionnaire, the Closed-ended Goals Questionnaire, and the Friendship Questionnaire. Each measure is described below and the procedure is outlined in Table 1.

Both a closed-ended and an open-ended assessment of participants' goals were used in the current study. The open-ended assessment allowed participants to report any type of goal that they had for the interaction. A closed-ended measurement of goals based on Strough and Berg's (2000) and Pickard and Strough's (2003) work was included in order to specifically assess participants' mutual-participation goals, control goals, and task-performance goals. Conceptually, researchers believe that goals guide behaviors (e.g., Strough and Berg, 2000). If so, goals ought to be measured prior to an interaction. However, the primary purpose of the current study was to examine differences in goals between various situations (e.g., working with a same- or other-sex partner). Therefore, participants completed the goal assessments following the task.

Demographic Questionnaire. The Demographic Questionnaire (see Appendix A) assessed participants' age, sex, race, years of education, current grade point average, parents' income, number of siblings, sex of siblings, birth order, religious affiliation, extra-curricular activities, and familiarity with the task. 
Bem Sex Role Inventory. The Bem Sex-Role Inventory (BSRI; Bem, 1974) was used to measure individuals' trait masculinity and femininity. The BSRI consists of a list of 60 adjectives: 20 feminine (e.g., compassionate, gentle, cheerful), 20 masculine (e.g., aggressive, competitive, independent), and 20 neutral (e.g., truthful, friendly, moody). Participants rated on a 7 -point Likert scale $(1=$ never or almost never true to $7=$ always or almost always true $)$ how true each adjective was for themselves.

A continuous masculinity and femininity score was computed for each participant by adding the total item ratings for each category. The potential range for each score was $20-140$; actual masculinity scores ranged from 56 - 130; femininity scores ranged from 48 - 130 . Participants’ BSRI masculinity and femininity scores are reported in Table 2.

Androgyny was computed using Bem's (1974) formula. Participants' average trait femininity score on the Bem Sex Role Inventory was subtracted from their average masculinity score on the Bem Sex Role Inventory. The absolute value of the difference between participants' average masculinity and their average femininity was then multiplied by 2.322 . Androgyny scores could potentially range from $0-7$; actual scores ranged from $0-5$. Androgyny scores at the baseline assessment are reported in Table 2.

Previous research indicates that the BSRI is valid for assessing gender roles (Holt \& Ellis, 1998), has a high degree of internal reliability for each of the sub-scales, and has high testretest reliability over 4 weeks (Bem, 1974). In the current sample, internal reliability was high (femininity $\alpha=.84$; masculinity $\alpha=.83$ ).

The State Gender Role Inventory. Pickard and Strough (2003) created the State Gender Role Inventory (SGRI; see Appendix B) to measure participants' reported masculine and feminine behaviors during a specific task. The SGRI (see Appendix B) uses the same items as 
the Bem Sex Role Inventory (Bem, 1974), however, the trait instructions, which ask participants to "report how true the adjective or statement is about yourself", were changed so that participants are asked to "report how true the adjective or statement was about yourself while you were working on the Jenga® task". Similar to the Bem Sex Role Inventory, the State Gender Role Inventory consisted of a list of 60 adjectives; 20 feminine (e.g., 'compassionate,' 'gentle,' 'cheerful'), 20 masculine (e.g., 'aggressive,' 'competitive,' 'independent'), and 20 neutral (e.g., 'truthful,' 'friendly,' 'moody'). Some items may have been unfamiliar to early adolescents; therefore each item also included a definition of the word. Item definitions were constructed from a widely used American dictionary (Oxford American Dictionary, 1980). Masculinity and femininity were conceptualized as independent constructs; therefore, the level of each was assessed. That is, each individual received a score for masculinity and femininity rather than classifying individuals as masculine, feminine, androgynous or undifferentiated.

Participants completed the State Gender Role Inventory twice; therefore internal reliability was computed for each time of measurement. Internal reliability was high when participants worked with a same-sex partner (femininity $\alpha=.85$, masculinity $\alpha=.86$ ) and when participants worked with an other-sex partner (femininity $\alpha=.83$, masculinity $\alpha=.86$ ). Masculinity and femininity scores could each potentially range from 20 -140; actual masculinity scores ranged from 40 - 136 in the same-sex context and 41 - 136 in the other-sex context. Actual femininity scores ranged from 29 - 134 in the same-sex context and $36-122$ in the othersex context.

The Children's Sex Role Inventory. The Children's Sex Role Inventory (CSRI; Boldizar, 1991) was also used to assess trait masculinity and femininity. The CSRI was developed for preadolescents between the ages of 8-12 years old and was included in order to have multiple 
indicators of masculinity and femininity. The CSRI contains 60 short statements; 20 are feminine (e.g., "I care about what happens to others," "I can usually tell when someone else is feeling bad"), 20 are masculine (e.g., "I'm willing to work hard to get what I want," "When a decision has to be made, it's easy for me to take a stand"), and 20 are neutral (e.g., "I have many friends," "I feel bad when other people have something that I don't have"). Participants rated on a 4-point Likert scale $(1=$ not at all true of me to $4=$ very true of me $)$ how true each of the statements were for themselves. Masculinity and femininity scores could each potentially range from 20 - 80; actual masculinity scores ranged from 37 - 71; femininity scores ranged from 39 75.

Boldizar's (1991) work indicates high internal reliability for each of the sub-scales and good test-retest reliability of the subscales over a 1-year period. The current sample also indicated high internal reliability (femininity $\alpha=.79$; masculinity $\alpha=.79$ ).

The Children's State Gender Role Inventory. The Children's State Gender Role Inventory (CSGRI; see Appendix C) was created by Pickard and Strough (2003) to measure state masculinity and femininity. The Children's Sex Role Inventory (Boldizar, 1991) was modified to create the state measure. The scale consists of 48 items (i.e., 16 Feminine, 16 Masculine, 16 Neutral). The CSGRI uses similar statements to those on the CSRI; however, the statements were revised to assess specific task behaviors. For instance, the items "I can control a lot of people", "I feel good when people say nice things about me", and "I like to help others" from the original CSRI were changed to "I could control my partner", "I felt good when my partner said nice things about me", and "I liked to help my partner" on the Children's State Gender Role Inventory. Masculinity and femininity each could potentially range from $16-64$. Actual masculinity scores ranged from $24-55$ in the same-sex context and $24-62$ in the other-sex 
context. Actual femininity scores ranged from $25-60$ in the same-sex and $22-61$ in the othersex context.

Participants completed the CSGRI twice, and internal reliability was computed for each time of measurement. Internal reliability was high when working with a same-sex partner (femininity $\alpha=.78$, masculinity $\alpha=.69$ ) and when working with an other-sex partner (femininity $\alpha=.83$, masculinity scale $\alpha=.75$ ).

Expectations Questionnaire. The Expectations Questionnaire (see Appendix D) was given prior to the task to assess what participants expected for the interaction. The scale consisted of 5 items (i.e.,' How well do you think you will do on the task?,' 'How much do you think you will compete against your partner so you can win the game?', 'How much do you think you will like the task?', 'How much will you like doing the task with a partner?', 'How much do you think that you will cooperate (work together) to build the highest tower possible?'). Participants rated each item on a 5-point Likert scale.

Perceptions Questionnaire. The Perceptions Questionnaire (see Appendix E) was used following the task to assess how participants perceived the actual interaction. The scale consisted of 5 items parallel to those on the Expectations Questionnaire. Participants rated each item on a 5-point Likert scale. Both the Expectations Questionnaire and the Perceptions Questionnaire were used as a manipulation check to examine whether the contexts (e.g., collaborative, competitive) had the desired effects.

Closed-ended Goals Questionnaire. The Closed-ended Goals Questionnaire (adapted from Pickard \& Strough, 2003; Strough \& Berg, 2000; see Appendix F) asked participants to rate the goals they had when working with a partner on the Jenga ${ }^{\circledR}$ task. The questionnaire consisted of thirty items (10 mutual-participation, 13 control, and 7 task-performance). Items were 
designed to assess mutual-participation goals (e.g., 'I wanted to work together with my partner to come up with the best way to do the task'), task performance goals (e.g., 'I wanted to make the highest tower possible'), and control goals (e.g., 'I wanted to get my partner to do what I wanted to do') for interacting with a partner. Scores for each goal category were computed by dividing the sum score of items for each category by the number of items in that category. Scores for mutual-participation, control, and task-performance goals can potentially range from 0 to 4. Actual scores for mutual-participation goals ranged from $1.1-4.0$ in the same-sex context and $.9-4.0$ in the other-sex context. Actual scores for control goals were $0.1-3.6$ in the samesex context and $0.0-3.5$ in the other-sex context. For task-performance goals, actual scores were $0.6-4.0$ in the same-sex context and $1.1-4.0$ in the other-sex context. Mutualparticipation goals were negatively correlated with control goals $r(80)=-.33$ and highly positively correlated with task-performance goals $r(80)=.72$. However, control and taskperformance goals were not significantly correlated with one another $r(80)=.06$. Mutualparticipation goals were moderately correlated when with same-sex and other sex-partners $r(79)$ $=.44$; control goals were highly correlated between the two contexts $r(79)=.79$, and taskperformance goals were also highly correlated when with same- and other-sex partners $r(79)=$ .65 .

Since participants completed the Closed-ended Goals Questionnaire twice (after interacting with a same-sex partner and after interacting with an other-sex partner), reliability was computed for each time of measurement. When working with a same-sex partner, reliability was high for each subscale (Mutual participation scale $\alpha=.91$; Control scale $\alpha=.86$; Task performance scale $\alpha=.83$ ). When working with an other-sex partner, reliability was also high (Mutual participation scale $\alpha=.89$; Control scale $\alpha=.91$; Task performance scale $\alpha=.83$ ). 
Open-ended Goals Questionnaire. The Open-ended Goals Questionnaire (see Appendix G) asked participants, "In about a paragraph, describe in your own words, what your goal was when completing the task".

A coding scheme based on Pickard and Strough's (2003) work was used to classify each goal into one of eight mutually exclusive and exhaustive categories (see Appendix $\mathrm{H}$ ). The categories included mutual participation, defined as a goal for a collaborative interaction ('I want(ed) to work together with my partner'); authority, defined as a goal for taking over the interaction ('I want(ed) my partner to do the task by following my instructions); competitive, defined as a goal for competitiveness between the participant and his/her partner ('I want(ed) to do better on the task than my partner'); task completion, defined as a goal for completing the task ('I want(ed) to build a tower'); task quality, defined as a goal for doing well on the task ('I want(ed) to come up with the best strategy'); other ('I want(ed) to have fun'); no goal, and missing data. Based on Pickard and Strough, the categories of authority and competitive were combined to make the category of control goals and the categories of task completion and task quality were combined to make the category of task-performance goals. The proportion of each category was computed by dividing the number of goals in each category by the total number of goals reported. This proportion score was used in the analyses. When working with a same-sex partner, participants total number of reported goals ranged from $0-5$. When working with an other-sex partner, participants total number of reported goals ranged from $0-4$. Total number of mutual-participation goals ranged from $0-3$ when with a same-sex partner and from $0-1$ when with an other-sex partner. Total number of control goals ranged from $0-3$ when working with a same-sex partner and from $0-2$ when working with an other-sex partner. Total number of task- 
performance goals ranged from $0-2$ when working with a same- and $0-2$ when working with an other-sex partner.

Coding was conducted by 2 individuals (the author and 1 undergraduate research assistant) who were blind to the sex of the participant and the assigned task. The coders first decided how many goals were included in each statement and then coded every goal into one of eight mutually exclusive and exhaustive categories. The reported reliabilities are based on coding after initial training sessions which took approximately 2 weeks to complete. During the training sessions, coders reviewed the data from 8 participants (10\% of the data).

To establish reliability on the number of goals, the coders identified the number of goals reported in each open-ended statement for 16 participants. The coders agreed $100 \%$ of the time on the number of goals. Twenty percent of the data (32 questionnaires) were used to establish reliability for coding each goal into one of the eight categories. Cohen's (1960) Kappa coefficients were: .83 for mutual-participation goals, 1.00 for authority goals, .74 for competitive goals, .70 for task completion goals, .75 for task quality goals, and .84 for other goals. Each person coded half of the remaining data within two weeks of the reliability coding.

Friendship Questionnaire. The Friendship Questionnaire (see Appendix I) assessed participants' friendship with their same-sex and other-sex peer partners. The scale consisted of 5 items including "How well do you know your partner" (ranging from $0=I$ have never met this person to 4 = I know them very well) and "Before today, how often have you talked to your partner (ranging from $0=I$ have never talked to them to $4=I$ talk to them several times a day). The question "How would you describe your relationship with your partner (ranging from $0=$ We really don't like each other to $4=$ We are best friends) was used as the covariate in the analyses. This item was chosen because it has been used in previous studies to assess partner 
friendship (Furman, 1987). The two additional items asked participants to report how long they have known their partner and where they met.

Task

During the experimental sessions, participants played the game Jenga® for 15 minutes with either a boy or a girl partner. The game Jenga® was chosen for several reasons. First, past research (Pickard \& Strough, 2003) found contextual variability in individuals' state masculinity and femininity using this task. Second, it is important to use a task that early adolescents may encounter in their everyday lives. Since peers are increasingly important during this time, early adolescents may get together with friends to play games and socialize.

In the game Jenga ${ }^{\circledR}$, players are given a wooden tower consisting of 18 levels of blocks (each level contains three blocks). The object of the game is to remove one block from a level at a time and stack it on top without knocking over the tower. Participants were instructed to alternate turns while playing the game. If the dyad knocked over the blocks before the end of 15 minutes, they were instructed to rebuild the tower and continue the game.

Collaborative and Competitive Task Structure. Past research indicates that task instructions impact cooperation and competition within an interaction (Schmidt et al., 1988). Thus, the task was constructed by instructing participants to either interact collaboratively or competitively during the task (see Appendix J). On the collaborative task, participants were told to work together with their partner so that the tower did not fall. That is, participants tried to construct the tower so that neither person made the tower fall. If the tower fell prior to the end of the 15 minutes, the participants were instructed to rebuild the tower together. On the competitive task, participants were instructed to compete against their partner. That is, participants tried to construct the tower so that their partner made the tower fall. For the 
competitive task, participants were told that there would be a winner and a loser. If the tower fell prior to the end of the 15 minutes, the loser had to rebuild the tower while the winner waited.

\section{Design and Procedure}

The type of task (competitive, collaborative) was a between-subject variable and the sex of the partner (same-sex, other-sex) was a within-subject variable, meaning that participants worked on either a collaborative or a competitive task with both a same-sex and an other-sex partner. Participants were randomly assigned to either the collaborative or the competitive condition. The same-sex and other-sex dyads were created from those participants who had given consent/assent to participate in the study. Partner order (same-sex partner first, other-sex

partner first) was counterbalanced. That is, in the competitive condition, 10 boys worked with a same-sex partner first, 10 boys worked with an other-sex partner first, 10 girls worked with a same-sex partner first and 10 girls worked with an other-sex partner first. In the collaborative condition, 10 boys worked with a same-sex partner first, 10 boys worked with an other-sex partner first, 10 girls worked with a same-sex partner first and 10 girls worked with an other-sex partner first. Figure 2 illustrates the number of participants in each condition. Participants in the current study were randomly assigned to partners. As a result, some participants may have been friends with their partner, whereas other participants may have been strangers.

Each participant completed the Demographic Questionnaire, the Bem Sex Role Inventory, and the Children's Sex Role Inventory approximately 2-3 weeks prior to the first experimental session. Immediately prior to playing the game with a same- or an other-sex partner, participants completed the Expectations Questionnaire. Immediately after playing the game with a same- or an other-sex partner, participants completed the Perceptions Questionnaire, the State Gender Role Inventory, the Children's State Gender Role Inventory, the Open-ended 
Goals Questionnaire, the Closed-ended Goals Questionnaire, and the Friendship Questionnaire. It took participants approximately 25 minutes to complete the questionnaires after finishing the task. After the Jenga ${ }^{\circledR}$ task, participants were verbally reminded to focus on the task just completed and to report their behaviors and thoughts during the interaction with their partner. The entire session, including questionnaire completion and the Jenga ${ }^{\circledR}$ task, took approximately 50-55 minutes. Participants completed two sessions (same-sex session, other-sex session). Same-sex and other-sex peer interactions occurred on different days, approximately 1 week apart.

The study took place in a large cafeteria at a middle school. There was approximately 10 feet of space between each dyad. The number of dyads playing Jenga ${ }^{\circledR}$ at one time ranged from $4-11$ (with an average of approximately 8 dyads interacting at one time). Within a session, all of the dyads were in either the collaborative or the competitive condition. During all but one of the sessions, there were both girl same-sex, boy same-sex and other-sex dyads interacting. One session consisted of all other-sex dyads. On some occasions, participants' assigned partners were not present on the day of their data session. The participants who were absent were then assigned a new partner and participated in a subsequent data collection session. As a result of both student absences and difficulty in recruiting, twelve students served as replacement participants ( 7 boys, 5 girls). These replacement students, who had already completed the study, interacted a third time with participants still involved in data collection. Of the twelve replacement students, 1 boy interacted with a same-sex partner on a collaborative task, 6 boys interacted with an other-sex partner on a competitive task, 1 girl interacted with a same-sex partner on a collaborative task, 1 girl interacted with an other-sex partner on a collaborative task, and 3 girls interacted with an other-sex partner on a competitive task. The replacement students 
did not complete the questionnaires. Their only purpose was to serve as partners for the Jenga® task. Following the study, all participants were told the purpose of the study.

The study was a 2 (sex of participant) x 2 (sex of partner) x 2 (type of task) mixed factorial design. The independent variables were sex of participant (boy, girl) and sex of partner (same-sex, other-sex), and type of task (collaborative, competitive). The dependent variables were masculinity and femininity scores from the two state measures (i.e., the State Gender Role Inventory and the Children's State Gender Role Inventory) and the three types of goals (e.g., mutual-participation, control, and task-performance) from the two goal measures (i.e., Openended Goals Questionnaire and Closed-ended Goals Questionnaire). In the analysis concerning androgyny, scores from the trait assessment of masculinity and femininity (Bem Sex Role Inventory) were used to compute an androgyny score, which was then used as an independent variable. One of the items from the Friendship Questionnaire was used as a covariate in the analyses.

Results

\section{Preliminary Analyses}

Order effects. Preliminary analyses were conducted to examine possible order effects of working with a same-sex or an other-sex partner first). Order effects were significant for several dependent variables; therefore, partner order (same-sex partner first, other-sex partner first) was added as a between-subject variable into most of the following analyses. Since friendship was not a variable of primary interest in the study, friendship was entered into the analysis as a varying covariate. One item from the Friendship Scale was used as a covariate in the analyses. The item asked participants to describe their relationship with their partner. The scale ranged from $(0)=$ we really don't like each other to $(4)=$ we are best friends. A varying covariate was 
used because participants had different friendship ratings for both same-sex and the other-sex peer partners. Eleven participants had missing data for the friendship rating; the missing data was replaced using the means from the appropriate group (i.e., boy with a same-sex partner, boy with an other-sex partner, girl with a same-sex partner, and girl with an other-sex partner). The mean replacement was used for all of the remaining analyses in the study.

Manipulation Check. The Expectations Questionnaire and the Perceptions Questionnaire were used to assess the collaborative and competitive task manipulation. A 2 (task) x 2 (partner order) x 2 (partner sex) repeated measures ANOVA was computed for participants' cooperative and competitive expectations and perceptions. Therefore, four repeated measures ANOVAs were computed. The between-subject factors were type of task (collaborative, competitive) and partner order (same-sex first, other-sex first). The within-subject factor was partner sex (samesex, other-sex).

On the Expectations Questionnaire, there was a significant three-way interaction between type of task (collaborative, competitive), partner order (same-sex partner first, other-sex partner first) and partner sex (same-sex, other-sex) for competitive expectations, $F(1,76)=12.44, p<$ .01. Follow-up ANOVAs indicated that, among participants who completed the competitive condition, there was no significant interaction between partner order and partner sex. However, there was a significant interaction between partner order and partner sex among participants who completed the collaborative task, $F(1,38)=13.36, p<.01$. When working with a same-sex partner, participants who worked with a same-sex partner first reported greater expectations for competition $(M=2.70, S E=0.26)$ than participants who worked with an other-sex partner first. $(M=1.80, S E=0.25), F(1,38)=6.23, p<.05$, see Table 3. 
On the Expectations Questionnaire, there was a significant main effect for partner sex (same-sex, other-sex) for collaborative expectations, $F(1,76)=10.53, p<.01$. When working with a same-sex partner, participants reported greater expectations for collaboration ( $M=4.05$, $S E=0.10)$ than when working with an other-sex partner $(M=3.63, S E=0.10$; see Table 3).

On the Perceptions Questionnaire, there was a significant main effect for type of task (collaborative, competitive) for competitive perceptions, $F(1,75)=80.35, p<.01$. Participants who worked on the competitive task reported greater perceptions for competition $(M=3.76, S E$ $=0.15)$ than participants who worked on the collaborative task. $(M=1.93, S E=0.14$; see Table $3)$.

On the Perceptions Questionnaire, there was a significant main effect for partner sex (same-sex, other-sex) for collaborative perceptions, $F(1,75)=4.48, p<.05$. When working with a same-sex partner, participants reported greater expectations for collaboration ( $M=4.21$, $S E=0.11)$ than when working with an other-sex partner $(M=3.94, S E=0.10$; see Table 3).

In sum, the significant findings from the expectations and perceptions measures suggest that participants perceived competition in the competitive condition. However, participants did not expect and perceive cooperation in the collaborative condition. Also, participants expected and perceived collaboration when working with a same-sex partner compared to working with an other-sex partner. In order to further explore distinctions between the collaborative and competitive tasks, dyadic performance was analyzed.

Performance on the Jenga ${ }^{\circledR}$ task was measured by the number of blocks each dyad moved during the 15 minute time period. The number of blocks moved indicated the height of the tower. If the dyad built more than one tower, the height of each tower was assessed. The dyads built approximately two towers $(M=2.06, S D=.64$, range from $1-3)$. A 2 (dyad type) x 2 
(type of task) ANOVA was conducted to examine whether performance differed between samesex and other-sex dyads on collaborative and competitive tasks. The between-subject factors were dyad type (same-sex, other-sex) and type of task (collaborative, competitive). The dependent variable was the number of towers built. There was a significant main effect for type of task, $F(1,83)=16.34, p<.01$. Participants who worked on the competitive task built more towers $(M=2.28 ; S D=0.09)$ compared to participants who worked on the collaborative task $(M$ $=1.76 ; S D=.10)$. This finding may suggest that there was a distinction between the collaborative and competitive task structures. Participants in the competitive condition were instructed to play the game so that their partner knocked down the tower. Participants in the collaborative condition were instructed to work with their partner so that the tower did not fall down. This analysis indicates that participants in both conditions followed instructions.

A 2 (dyad type) x 2 (type of task) ANOVA was conducted using the height of the first tower as the dependent variable. The between-subject factors were dyad type (same-sex, other-sex) and type of task (collaborative, competitive). Analyses did not indicate any significant differences between participants who had worked on the competitive $(M=25.56, S D=3.43)$ or on the collaborative task $(M=26.51 ; S D=3.26)$. Also, there were no differences in the height of towers built between same-sex $(M=25.78, S D=2.95)$ and other-sex dyads $(M=26.15, S D=$ 3.72).

Intraclass Correlation Coefficients. Intraclass correlation coefficients were computed to determine the degree of dependency between partners' masculinity, femininity, and goal ratings on each measure. The correlations are based on the data from sixty-eight dyads. Intraclass correlations were not significant for masculinity $r(67)=-.06$ and femininity $r(67)=.09$ on the State Gender Role Inventory or masculinity $r(67)=-.19$ and femininity $r(67)=.16$ on the 
Children's State Gender Role Inventory. On the Closed-ended Goals Questionnaire, the intraclass correlations were not significant for control $r(67)=.01$ and task-performance goals $r$ $(67)=.13$, but were significant for mutual-participation goals $r(67)=.42, p<.01$. On the Openended Goals Questionnaire, the intraclass correlations were not significant for mutualparticipation goals $r(61)=-.05$, but were significant for control goals $r(60)=.34, p<.01$ and task-performance goals $r(59)=.39, p<.01$. When examining other dependent variables, such as masculinity and femininity, dependency in the data may be viewed as problematic. However, in the current study, similarity between partner' reported goals was expected because partners were given the same task instructions (e.g., collaborative, competitive).

Correlations Between Multiple Measures. The following analyses focus on the correlations between different measures of the same construct. Trait masculinity and femininity were assessed using the Bem Sex Role Inventory and the Children's Sex Role Inventory. Masculinity on the BSRI was highly correlated with masculinity on the CSRI $r(80)=.82$; femininity on the BSRI was highly correlated with femininity on the CSRI $r(80)=.77$. State masculinity and femininity were assessed using the State Gender Role Inventory and the Children's State Gender Role Inventory. When working with a same-sex partner, masculinity on the SGRI was significantly correlated with masculinity on the CSGRI $r(80)=.71$; femininity on the SGRI was significantly correlated with femininity on the CSGRI. $r(80)=.71$. When working with an other-sex partner, masculinity on the SGRI was significantly correlated with masculinity on the CSGRI $r(80)=.62$; femininity on the SGRI was significantly correlated with femininity on the CSGRI $r(80)=.57($ see Table 4$)$.

The Open-ended and Closed-ended Goals Questionnaires were used to assess participants' mutual-participation, control, and task-performance goals. When working with a same-sex 
partner, goals on the open-ended assessment and closed-ended assessments were moderately correlated for mutual-participation $r(75)=.33$, and control goals $r(75)=.43$. Reported taskperformance goals on the open- and closed-ended assessments were not significantly correlated $r$ $(75)=.01$. When working with an other-sex partner, goals on the open-ended assessment and closed-ended assessments were moderately correlated for mutual-participation $r(75)=.27$, and control goals $r(75)=.31$. Reported task-performance goals on the open- and closed-ended assessments were not significantly correlated $\mathrm{r}(75)=.17$ (see Table 5).

Friendship Questionnaire. When asked "How well do you know your partner", on average participants reported that they knew their same-sex partners $(M=2.39, S D=1.02)$ better than they knew their other-sex partners $(M=1.61, S D=.98)$. On average, participants reported that they talked almost everyday to their same-sex partners $(M=2.27, S D=1.22)$ and that they had talked only once or twice to their other-sex partners $(M=1.22, S D=1.06)$. When asked "How would you describe your relationship with your partner", on average participants reported that they were friends with their same-sex partners $(M=2.60, S D=.83)$ and that they liked, but were not friends with their other-sex partners $(M=1.97, S D=.89)$. Sixty-nine participants met their same-sex partners in school, 7 participants through sports, and 2 participants had not met their partners before participating in the study (2 participants had missing data). Fifty-seven participants met their other-sex partners in school and 5 participants had not met partners before participating in the study (18 participants had missing data).

\section{Primary Analyses}

Localizing Significant Effects. For the following analyses, significant findings were localized according to several criteria. First, importance was given to sex of participant (i.e., boy, girl) and type of task (i.e., collaborative, competitive) effects rather than partner order (i.e., same-sex first, 
other-sex first) effects. Second, many interactions could not be localized when examining differences between collaborative and competitive tasks. Therefore, the majority of follow-up analyses examined gender differences.

\section{Masculinity, Femininity, and Context}

The first research question was whether boys' and girls' femininity and masculinity scores would change when working with a same- or an other-sex partner and when completing a collaborative or a competitive task. For state femininity, a three-way interaction between sex of participant (boy, girl), sex of partner (same-sex, other-sex), and type of task (collaborative, competitive) was hypothesized. When working on a collaborative task, it was expected that girls would rate femininity similarly in the same-sex and other-sex contexts, however it was expected that boys would rate femininity higher when working with a girl compared to working with a boy. For state masculinity, a three-way interaction between sex of participant (boy, girl), sex of partner (same-sex, other-sex), and type of task (collaborative, competitive) was hypothesized. On the competitive task, it was expected that girls would report more masculinity when working with a boy than when working with a girl. Conversely, it was expected that boys would rate masculinity higher when working with another boy than when working with a girl.

To address the question as to whether masculinity and femininity scores would change according to the context, a 2 (sex of participant) $\mathrm{x} 2$ (sex of partner) $\mathrm{x} 2$ (type of task) $\mathrm{x} 2$ (partner order) mixed factorial model ANCOVA was conducted. The within-subject factor was sex of partner (same-sex, other-sex). The between-subject factors were the sex of the participant (boy, girl), the type of task (collaborative, competitive) and partner order (same-sex partner first, other-sex partner first). Four separate analyses were conducted; two using the masculinity and 
femininity scores from the State Gender Role Inventory and two using scores from the Children's State Gender Role Inventory.

State Gender Role Inventory. The covariate, partner friendship, was not significantly associated with femininity and masculinity on the SGRI.

The interaction between sex of participant (boy, girl) and partner order (same-sex partner first, other-sex partner first) was significant for femininity on the State Gender Role Inventory, $F$ $(1,143)=6.47, p<.05$. Follow-up LSD tests compared boys' and girls' femininity with either a same-sex partner first or an other-sex partner first. Results indicated that there was no significant difference between boys' and girls' femininity for those participants who had worked with an other-sex partner first. However, girls who worked with a same-sex partner first reported greater femininity $(M=102.15, S E=2.69)$ than did boys who worked with a same-sex partner first $(M=$ 83.23, $S E=2.72), p<.01$ (see Table 6).

The interaction between sex of participant (boy, girl) and type of task (collaborative, competitive) was significant for masculinity on the SGRI, $F(1,143)=6.93, p<.01$. Follow-up LSD tests compared boys' and girls' masculinity when working on a collaborative or a competitive task. Results indicated that there was no significant difference between boys' and girls' reported masculinity for those participants who had worked on a competitive task. However, among participants who had worked on the collaborative task, boys reported greater masculinity $(M=103.50, S E=2.75)$ compared to girls $(M=88.80, S E=2.74, p<.01$ (see Table 7).

The interaction between type of task (collaborative, competitive) and partner order (samesex partner first, other-sex partner first) was significant for masculinity on the SGRI, $F(1,143)=$ $6.77, p<.05$. Follow-up LSD tests compared participants' masculinity on a collaborative or a 
competitive task in the same-sex partner first or other-sex partner first conditions. Results indicated that, among participants who had worked with a same-sex partner first, there was no significant difference between participants' who worked on the collaborative or competitive tasks. However, among participants who interacted with an other-sex partner first, participants who worked on a collaborative task reported greater masculinity $(M=98.25, S E=2.74)$ compared to participants who worked on a competitive task $(M=89.01, S E=2.77), p<.05$ (see Table 7).

In sum, there were significant effects for the sex of the participant, the type of task and partner order. Gender differences were found only among participants who worked on a collaborative task. That is, boys reported greater masculinity compared to girls. Partner order seemed to exert some degree of influence on femininity and masculinity as measured by the SGRI. For instance, girls who worked with a same-sex partner first reported greater femininity than did boys who worked with a same-sex partner first. Among participants who interacted with an other-sex partner first, individuals who worked on a collaborative task reported greater masculinity than individuals who worked on a competitive task.

Children's State Gender Role Inventory. The covariate, partner friendship, was not significantly associated with masculinity on the CSGRI. However, partner friendship was significantly associated with femininity, $F(1,143)=15.26, p<.01$.

For femininity on the Children's State Gender Role Inventory, the interaction between sex of participant (boy, girl) and sex of partner (same-sex, other-sex) was significant, $F(1,141)=$ $5.90, p<.05$. Follow-up LSD tests compared femininity when working with a same-sex or an other-sex partner for both boys and girls. Results indicated that, for girls, there was no significant difference in femininity between working with a same-sex partner and working with 
an other-sex partner. However, boys reported greater femininity when working with an othersex partner $(M=44.90, S D=1.18)$ than when working with a same-sex partner $(M=41.49, S D$ $=1.03), p<.05($ see Table 8$)$.

For femininity on the Children's State Gender Role Inventory, the three-way interaction between sex of participant (boy, girl), type of task (collaborative, competitive), and partner order (same-sex partner first, other-sex partner first) was significant, $F(1,141)=7.65, p<.01$. Follow-up LSD tests compared boys' and girls' femininity scores with either a same- or an othersex partner first on collaborative or competitive tasks. The tests indicated a significant effect only for those participants who had worked with a same-sex partner first on a competitive task. Girls who worked with a same-sex partner first on a competitive task reported greater femininity $(M=46.99, S E=1.55)$ compared to boys who worked with a same-sex partner first on a competitive task $(M=37.63, S E=1.55), p<.01$; see Table 8$)$.

The interaction between sex of participant (boy, girl) and type of task (collaborative, competitive) was significant for masculinity on the CSGRI, $F(1,141)=5.45, p<.05$. Followup LSD tests compared boys' and girls' masculinity on collaborative or competitive tasks. Results indicated that there was not a significant difference between boys' and girls' reported masculinity for those participants who had worked on the competitive task. However, among participants who had worked on a collaborative task, boys reported greater masculinity $(M=$ 43.97, $S E=1.04)$ compared to girls $(M=37.43, S D=1.03), p<.01$ (see Table 6).

The interaction between type of task (collaborative, competitive) and partner order (samesex partner first, other-sex partner first) was significant for masculinity on the CSGRI, $F(1,141)$ $=5.07, p<.05$. Follow-up LSD tests compared participants' masculinity who had worked on a 
collaborative or a competitive task with a same-sex or an other-sex partner first. Results did not indicate any significant effects (see Table 9).

In sum, boys reported greater femininity when working with an other-sex partner than when working with a same-sex partner. Gender differences were found only among participants who worked on a collaborative task. Boys who worked on a collaborative task reported greater masculinity compared to girls who worked on a collaborative task. Similar to the SGRI, partner order effects were significant only when examining participants who had worked with a samesex partner first. That is, girls who worked with a same-sex partner first on a competitive task reported greater femininity than boys who worked with a same-sex partner first on a competitive task.

\section{Trait Masculinity, Femininity, and Context}

The second question was whether participants who reported higher androgyny scores (i.e., reporting both masculine and feminine characteristics) would change more according to the situation (i.e., when working with a same- or other-sex partner) than participants who reported lower androgyny scores. To address this question, the sample was divided into two groups; those having androgyny scores above the median and those having androgyny scores below the median.

Two sets of analyses were conducted. For the first set of analyses, a 2 (androgyny group) x 2 (type of task) x 2 (partner order) ANOVA was computed to examine whether participants with higher androgyny scores would differ from participants with lower androgyny scores in their state masculinity and femininity when working with same- and other-sex peers. The between-subject factors were androgyny group (low androgyny, high androgyny), type of task (collaborative, competitive), and partner order (same-sex partner first, other-sex partner first). 
Low androgyny and high androgyny groups were constructed using a median split. For this set of analyses, a change score was computed for both masculinity and femininity. Change scores for masculinity were the absolute value of the difference in state masculinity when working with a same-sex or an other-sex partner. Change scores for femininity were the absolute value of the difference in state femininity when working with a same-sex or an other-sex partner. Change scores were computed for both the SGRI and the CSGRI. Participants actual change scores on the SGRI ranged from 0 to 63 (masculinity $M=9.58, S D=9.13$; femininity $M=10.13, S D=$ 10.88). On the CSGRI, participants actual change scores ranged from 0 to 31 (masculinity $M=$ 4.60, $S D=3.79$, femininity $M=5.13, S D=3.79$ ). Four ANOVAs were conducted using participants' masculinity and femininity change scores on the SGRI and the CSGRI. Androgyny group (i.e., low, high) was used as the independent variable and participants' change scores for masculinity or femininity was used as the dependent variable. No significant results were found between the two groups. Therefore, ANOVAs were computed dividing the participants into quartile groups. Again, there were no significant differences.

For the second set of analyses, a 2 (androgyny group) x 2 (type of task) x 2 (partner order) ANOVA was computed to examine the change in participants' trait masculinity and femininity at baseline and their state masculinity and femininity when working with a same-sex or an othersex partner. The between-subject factors were androgyny group (low androgyny, high androgyny), type of task (collaborative, competitive) and partner order (same-sex partner first, other-sex partner first). Low androgyny and high androgyny groups were constructed using a median split. For this set of analyses, a change score was computed between participants' trait assessment at baseline and their state assessment after each task. Change scores for masculinity were the absolute value of the difference between participants' baseline Bem Sex Role Inventory 
masculinity scores and their same-sex or other-sex State Gender Role Inventory masculinity scores. Change scores for femininity were the absolute value of the difference between participants' baseline BSRI femininity scores and their same-sex or other-sex SGRI femininity scores. Participants actual masculinity change scores ranged from 0 to 51 (same-sex partner $M=$ 11.21, $S D=9.25$; other-sex partner $M=10.03, S D=9.86)$. Participants actual femininity change scores ranged from 0 to 73 (same-sex partner $M=13.79, S D=12.77$; other-sex partner $M=$ 13.40; $S D=13.74)$. Four ANOVAs were conducted using participants' masculinity and femininity change scores when they were working with both a same-sex or an other-sex partner.

There were no significant effects of type of task, androgyny group, or partner order for the majority of the analyses. However, there was a significant main effect for type of task (collaborative, competitive) when examining the change in participants' femininity from baseline to working with a same-sex partner, $F(1,72)=5.83 p<.05$. Participants who worked on a competitive task reported a greater change in femininity from baseline to the same-sex partner interaction $(M=16.73, S E=2.07)$ than participants who worked on a collaborative task $(M=$ 9.74, $S E=2.02$ ). None of the other effects were significant in the analysis.

\section{Peer Interaction Goals and Context}

The third research question was whether boys' and girls' goals for the peer interaction would change when working with same-sex and other-sex partners and when completing a collaborative or a competitive task. For mutual-participation goals, a three-way interaction between sex of participant (boy, girl), sex of partner (same-sex, other-sex), and type of task (collaborative, competitive) was hypothesized. On the collaborative task, boys were expected to rate mutual-participation goals higher when working with a girl than when working with a boy. For control and task-performance goals, a two-way interaction between sex of partner (same-sex, 
other-sex), and type of task (collaborative, competitive) was hypothesized. It was expected that both boys and girls would rate control and task-performance goals in the same-sex context than in the other-sex context on the collaborative task but not on the competitive task.

To address this question, a 2 (sex of participant) x 2 (sex of partner) x 2 (type of task) x 2 (partner order) mixed factorial model ANCOVA was conducted. The within-subject factor was sex of partner (same-sex, other-sex). The between-subject factors were the sex of the participant (boy, girl), the type of task (collaborative, competitive) and partner order (same-sex partner first, other-sex partner first). The friendship rating was used as a varying covariate in the analyses. Six separate analyses were conducted; three using participants' mutual-participation goals, control goals and task-performance goals on the Closed-ended Goals Questionnaire and three using participants' mutual-participation goals, control goals and task-performance goals on the Open-ended Goals Questionnaire.

Closed-ended Goals Questionnaire. On the Closed-ended Goals Questionnaire, partner friendship was not significantly associated with control goals; however, the friendship rating was associated with participants' reported mutual-participation goals, $F(1,143)=19.72, p<.01$, and task-performance goals, $F(1,143)=5.42, p<.05$.

For mutual-participation goals, the three-way interaction between sex of participant (boy, girl), type of task (collaborative, competitive), and partner order (same-sex first, other-sex first) was significant, $F(1,137)=10.22, p<.01$. Follow-up LSD tests compared boys' and girls' mutual-participation goals with either a same- or other-sex partner first on a collaborative or a competitive task. Follow-up tests indicated a significant gender difference only among participants who worked with a same-sex partner first on a competitive task. Girls who worked with a same-sex partner first reported greater mutual-participation goals on a competitive task $(M$ 
$=3.54, S E=.14$ ) compared to boys who worked with a same-sex partner first on a competitive task $(M=2.47, S E=.14), p<.01$. Among participants who worked on the collaborative task, boys' $(M=3.15, S E=.14)$ and girls' $(M=3.29, S E=.14)$ reported mutual-participation goals did not differ (see Table 10).

For control goals, there was a significant interaction between sex of participant (boy, girl) and partner order (same-sex partner first, other-sex partner first), $F(1,143)=7.82, p<.01$. Follow-up LSD tests compared boys' and girls' control goals in the same-sex partner first and the other-sex partner first conditions. For girls, there was no significant difference between the partner order conditions (i.e., same-sex first, other-sex first). However, boys who had worked with a same-sex partner first reported greater control goals $(M=2.03, S E=.12)$ than boys who had worked with an other-sex partner first $(M=1.68, S E=.12), p<.05$ (see Table 11).

For control goals, there was also a significant interaction between type of task (collaborative, competitive) and partner order (same-sex partner first, other-sex partner first), $F$ $(1,143)=9.48, p<.05$. Follow-up LSD tests compared participants' control goals on either a collaborative or a competitive task in the two order conditions (same-sex partner first, other-sex partner first). Among participants who worked with an other-sex partner first, there was no significant difference in control goals between collaborative and competitive tasks. However, participants who had worked with a same-sex partner first and on a competitive task reported greater control goals $(M=1.85 S E=.12)$ than participants who had worked with a same-sex partner first on a collaborative task $(M=1.13, S E=.12), p<.01$ (see Table 11$)$.

For task-performance goals, the three-way interaction between sex of participant (boy, girl), type of task (collaborative, competitive), and partner order (same-sex first, other-sex first) was significant, $F(1,142)=5.54, p<.05$. Follow-up LSD tests compared boys' and girls' task- 
performance goals with either a same- or other-sex partner first on a collaborative or a competitive task. Follow-up tests indicated a significant gender difference only for those participants who had worked with a same-sex partner first on a competitive task. Girls who worked with a same-sex partner first on a competitive task reported greater task-performance goals $(M=3.54, S E=.17)$ compared to boys who worked with a same-sex partner first on a competitive task $(M=2.80, S E=.17), p<.01$. Among participants who worked on a collaborative task, boys who worked with a same-sex partner first reported greater taskperformance goals $(M=3.24, S E=.17)$ compared to girls who worked with a same-sex partner first $(M=2.91, S E=.17$; see Table 12).

In sum, the partner order (same-sex first) and sex of participant had a significant effect on participants' mutual-participation, control, and task-performance goals. For instance, girls who worked with a same-sex partner first on a competitive task reported greater mutual-participation goals compared to boys in the same condition; boys and girls concern with mutual-participation goals were similar in the collaborative task condition. Similarly, among participants who worked with a same-sex partner first on a competitive task, girls reported greater taskperformance goals compared to boys, but on the collaborative task, boys reported greater taskperformance goals compared to girls. In addition, boys who had worked with a same-sex partner first reported greater control goals than boys who had worked with an other-sex partner first. The type of task also had a significant effect on participants' control goals. Participants who worked with a same-sex partner first on a competitive task reported greater control goals than participants who worked with a same-sex partner first on a collaborative task. 
Open-ended Goals Questionnaire. The covariate, partner friendship, was not significantly associated with mutual-participation, control, or task-performance goals on the Open-ended Goals Questionnaire.

For mutual-participation goals, there was a significant main effect for type of task (collaborative, competitive). Participants who worked on a collaborative task reported a greater proportion of mutual-participation goals $(M=.30, S E=.03)$ than participants who worked on a competitive task $(M=.07, S E=.03), F(1,129)=23.30, p<.01($ see Table 13$)$.

For control goals, there was significant interaction between sex of participant (boy, girl) and type of task (collaborative, competitive), $F(1,138)=6.76, p<.05$. Follow-up LSD tests compared boys' and girls' control goals on a collaborative or a competitive task. Results did not indicate differences between boys' and girl's control goals for those participants who had worked on a collaborative task. However, among participants who worked on a competitive task, boys reported a greater proportion of control goals $(M=.41, S D=.05)$ compared to girls $(M=.20, S D=.05), p<.01$ (see Table 14).

For control goals, there was a significant interaction between type of task (collaborative, competitive) and partner order (same-sex first, other-sex first), $F(1,138)=4.67, p<.05$. Follow-up LSD tests compared participants' control goals with an other-sex partner first or a same-sex partner first on the collaborative or competitive task. Results did not indicate differences in participants' control goals between the partner order groups (i.e., same-sex first, other-sex first) and among participants who had worked on a collaborative task. However, among participants who had worked on a competitive task, participants who worked with a same-sex partner first reported a greater proportion of control goals $(M=.41, S D=.05)$ than 
participants who worked with an other-sex partner first $(M=.20, S D=.05), p<.01$ (see Table 14).

For task-performance goals, there was a significant main effect for type of task (collaborative, competitive), $F(1,89)=9.97, p<.01$. Participants who worked on the collaborative task reported a greater proportion of task-performance goals $(M=.34, S E=.03)$ than participants who worked on the competitive task $(M=.19, S E=.03)$. There was also a significant main effect for sex of partner (same-sex, other-sex), $F(1,95)=48.79, p<.01$. Participants reported a greater proportion of task-performance goals when interacting with a same-sex partner $(M=.43, S E=.05)$ than when interacting with an other-sex partner $(M=.09$, $S E=.02 ;$ see Table 15).

In sum, participants' mutual-participation, control and task-performance goals varied according to the type of task and the sex of their partner. Only among participants who had worked on a competitive task was there a gender difference in control goals. Boys reported a greater proportion of control goals compared to girls when completing the competitive task, but not the collaborative task. Also, participants who worked on a collaborative task reported a greater proportion of mutual-participation goals than participants who worked on a competitive task. Participants who worked on the collaborative task reported a greater proportion of taskperformance goals than participants who worked on the competitive task. Participants' taskperformance goals not only varied according to the type of task, but also according to the sex of their interactional partner. Participants reported a greater proportion of task-performance goals when interacting with a same-sex partner than when interacting with an other-sex partner.

Partner order (same-sex partner first) had a significant effect on participants' reported control goals. Among participants who had worked on a competitive task, participants who had 
worked with a same-sex partner first reported a greater proportion of control goals than participants who had worked with an other-sex partner first.

\section{Discussion}

The current study examined how individual attributes and contextual features combine to influence individuals' gender-typed behaviors. Results indicated that individual attributes such as participant sex, and contextual features such type of task, sex of partner, and partner order affected early adolescents' reported state masculinity, femininity, and their goals for a peer interaction. The findings of the current study support the idea that gender-typed behaviors can vary according to immediate situational demands and the idea investigated by Pickard and Strough (2003) that masculinity and femininity may contain a flexible state component in addition to a stable trait component. In addition, the study contributes to a greater understanding concerning developmental issues during early adolescence. The findings add to the literature by supporting the social constructionist viewpoint and illustrate the importance of examining the contextual specificity of gender-typed behaviors.

\section{Contextual Variability in State Masculinity and Femininity}

Sex of Partner. As predicted, state masculinity and femininity changed according to aspects of the social context. The findings of the current study supported the hypothesis that boys would rate femininity higher in the other-sex context (when working with a girl) than in the same-sex context. On the Children's State Gender Role Inventory, boys reported greater femininity when interacting with an other-sex partner (i.e., girl) than when interacting with a same-sex partner (i.e., boy). This finding is consistent with Pickard and Strough's (2003) and Smith et al.'s (1999) work with college students suggesting that males are more likely than 
females to report changes in behavior (e.g., exhibit more feminine behaviors) when working with an other-sex partner than when working with a same-sex partner.

Several researchers (e.g., Maccoby, 1990) assert that it is girls, not boys that change their behaviors when interacting with an other-sex partner. The different findings between the current study and some past research may result from the investigation of different developmental lifestages and the tasks associated with each stage. Much of the work suggesting that girls change their behaviors in response to the sex of their partner has examined children (e.g., Fagot, 1985). During childhood, boys and girls segregate into same-sex groups and have few other-sex interactions (Maccoby, 1998). Girls discover that the interactional styles they have used with other girls are ineffective when interacting with boys. As a result, girls change their behaviors to be either be more communal (e.g., smile, show attentiveness) or more instrumental (e.g., interruptions, assertiveness; Maccoby, 1990). Studies suggesting that males change their behaviors when working with females have examined either college students (e.g., Smith et al., 1999) or adults (e.g., Carli \& Bukatko, 2000). Young adulthood and adulthood are times in the life-span when romantic relationships are already established. That is, males and females may have had experience interacting with one another. Early adolescence is a time in the life-span when other-sex interactions begin to increase (Buhrmester \& Furman, 1986; 1987; Maccoby, 1998). Therefore, it was important to examine early adolescents to investigate how the developmental changes during this transitional periods (i.e., moving from same-sex to other-sex relationships) may affect expressions of gender-typed behaviors. The current study found that adolescent boys' feminine behaviors varied according to the sex of their partner. Therefore, this study suggests that the move from same-sex to other-sex relationships may be especially influential for boys when they are interacting with girls. Future research should continue to 
examine males' and females' feminine and masculine behaviors in a number of different lifestages and situations. For instance, times of transition such as marriage, parenthood, and retirement may elicit higher femininity in men than at other times in the life-span. The current study examined only one period in the life-span. Cross-sectional and longitudinal designs are better apt to investigate life-stage and situational influences on individuals' expressive and instrumental behaviors.

Type of Task and Sex of Participant. The sex of their interactional partner was not the only contextual factor that influenced early adolescents' state masculinity and femininity. Early adolescents' reported masculine and feminine behaviors varied according to the type of task (collaborative, competitive). On the SGRI, among participants who worked on a collaborative task, boys reported greater masculinity compared to girls. No gender differences in masculinity were found for participants who worked on a competitive task. On the CSGRI, among participants who worked on a competitive task with a same-sex partner first, girls reported greater femininity compared to boys. No gender differences in femininity were found for participants who worked on a collaborative task. Past studies that have examined task structures suggest that participants who work on a gender-stereotypically feminine task exhibit expressive behaviors (i.e., feminine, communal orientation) and participants who work on a masculine task exhibit instrumental behaviors (i.e., masculine, agentic orientation; Hannover, 2002).

However, as Figure 1 shows, it is not simply the different task structure that may influence gender-typed behaviors. It is the combination of contextual (type of task) and individual (sex of participant) attributes that is important. Therefore, the finding that boys who worked on a collaborative task reported greater masculinity and girls who worked on a competitive task reported greater femininity can be explained. Work with college students (Wood, Christensen, 
Hebl, \& Rothgerber, 1997) and adolescents (Massad, 1981) suggests that individuals feel better about themselves and have higher peer acceptance when they exhibit sex congruent gender-typed behaviors. Perhaps these gender stereotypical behaviors are much more pronounced when individuals are working in a context designed to elicit either communal or agentic concerns. That is, boys may be more likely to act gender stereotypical when working on a communal task (i.e., collaborative) and girls may be more likely to act gender stereotypical when working on an agentic task (i.e., competitive). These findings may have implications for other contexts across the life-span. Girls' greater femininity in competitive situations may suggest that women exhibit feminine behaviors in other instrumental contexts (i.e., the workplace). Future researchers should continue to examine masculine and feminine behaviors in a number of different situations.

Measurement Issues. The two significant interactions for masculinity were consistent between the State Gender Role Inventory (SGRI) and the Children's State Gender Role Inventory (CSGRI). For example, on both the SGRI and the CSGRI, boys reported greater masculinity compared to girls (only on the collaborative task). Even though the significant findings were fairly consistent between the SGRI and the CSGRI for masculinity, there were differences between the two measures when femininity was examined. For instance, it was only on the Children's State Gender Role Inventory that boys reported greater femininity when interacting with a same-sex partner compared to an other-sex partner. Also, the finding that girls who worked with a same-sex partner first reported greater femininity than boys who worked with a same-sex partner first was qualified by a type of task (collaborative, competitive) effect on the CSGRI, but not on the SGRI. In addition, the greater number of significant findings on the Children's State Gender Role Inventory compared to the State Gender Role Inventory may 
suggest that the CSGRI is a more sensitive instrument for the early adolescent age period. Conversely, when examining college students, Pickard and Strough (2003) found that the State Gender Role Inventory yielded a greater number of significant results than the Children's State Gender Role Inventory. The BSRI (which the SGRI was derived from) was constructed for use with adults, whereas the CSRI (which the CSGRI was derived from) was constructed for use with $8-12$ year old children and early adolescents. Taken together, these studies suggest that it may be important to use a measure created specifically for the age group being examined when assessing masculine and feminine behaviors.

Summary. The current study highlights how masculine and feminine behaviors are constructed during social interactions. The results support a state-like component of masculinity and femininity in addition to a trait-like component. Individuals adapt their behaviors according to both individual and contextual attributes. In sum, the sex of the participants, the sex of their interactional partners and the types of tasks they were working on influenced displays of gendertyped behaviors with peers.

\section{Contextual Variability and Androgyny}

Bem's (1974) theory of androgynous flexibility states that, as a result of their more extensive behavioral repertoires, androgynous individuals' masculinity and femininity may vary more as a function of situational demands than individuals with traditional gender-typed behaviors. No significant differences were found in the contextual flexibility (defined as the change in masculine or feminine behaviors when working with same- versus other-sex peers) between individuals scoring high and individuals scoring low on androgyny. This finding is consistent with an earlier study with college students (e.g., Pickard \& Strough, 2003). However, there was a significant main effect for type of task (collaborative, competitive) when examining 
the change in participants' femininity from baseline to working with a same-sex partner. Participants who worked on a competitive task reported a greater change in femininity from baseline to the same-sex partner interaction than participants who worked on a collaborative task. Gender difference findings for state femininity were also specific to the competitive task, suggesting that competitive tasks may elicit greater variability and more change than do collaborative tasks. Also, the finding was specific to the same-sex context. When working with same-sex partners, participants reported higher expectations and perceptions for collaboration. Both collaboration and femininity are consistent with a communal orientation. Thus, participants' expectations for collaboration may have been reflected in their femininity when working with a same-sex partner.

The current study attempted to examine Bem's (1974) theory of androgynous flexibility by asking participants to report their feminine and masculine behaviors in different contexts (e.g., working with a same- and an other-sex partner, completing a collaborative or competitive task) However, very few studies have empirically examined androgynous individuals' observed behavioral changes. Research is needed in order to further test the theory. For example, future studies could focus on androgynous individuals and observe how their behaviors (rather than reported behaviors) change when interacting in communal and instrumental contexts.

\section{Contextual Variability in Peer Interactional Goals}

Sex of Partner. It was expected that both boys and girls would report greater control and task-performance goals when interacting with a same-sex peer than when interacting with an other-sex peer. This hypothesis was partially supported. On the Open-ended Goal Questionnaire, both boys and girls reported a greater proportion of task-performance goals when interacting with a same-sex peer compared to interactions with an other-sex peer. This finding is 
consistent with Pickard and Strough's (2003) work with college students suggesting that individuals are more likely to attend to how well they are doing on the task when working with same-sex peers than when working with other-sex peers. Early adolescents focused on task concerns when working with same-sex peers, regardless of the task structure (i.e., collaborative, competitive). During early adolescence, task-performance goals seem to be particularly important (Strough et al., 1996). Task concerns during this point in the life-span may result from an increase in academic concerns (Wentzel, 1993). As mentioned earlier, it is during early adolescence in which the frequency of other-sex peer interactions begins to increase (Buhrmester \& Furman, 1986; 1987; Maccoby, 1998); however, there may still be discomfort or anxiety when working with other-sex peers. Perhaps when working with same-sex peers, early adolescents feel comfortable and secure (Wentzel, 1991) and are able to focus on performing well on the task.

Type of Task. Previous studies have found differences in individuals' expressive and instrumental behaviors when completing collaborative or competitive tasks (e.g., Schmidt et al., 1988). The findings in the current study are consistent with the idea that collaborative contexts elicit communal concerns, whereas competitive contexts elicit agentic concerns. On the closedended assessment, among participants who interacted with a same-sex partner first, participants who worked on a competitive task reported greater control goals compared to participants who worked on a collaborative task. On the Open-ended Goals Questionnaire, participants who worked on a collaborative task reported greater task-performance goals and mutual-participation goals compared to participants who worked on a competitive task. These findings suggest that, during a competitive interaction, early adolescents were concerned with competing against their partner and attempting to control their partners' behaviors. During a collaborative interaction, 
early adolescents were concerned with working together with their partner and performing well on the task.

Type of Task and Sex of Participant. Figure 1 illustrates how contextual features such as type of task combine with individual attributes such as sex of participant to affect individuals' mutual-participation, control, and task-performance goals. Gender differences in males' and females' goals for a peer interaction were consistent with those found in the literature (Pickard \& Strough, 2003; Strough \& Berg, 2000; Swenson \& Strough, 2002). On the Closed-ended Goals Questionnaire, among participants who had worked with a same-sex partner first and on a competitive task, girls reported greater mutual-participation and task-performance goals than boys in the same condition. A similar effect was found for femininity in the current study. That is, among participants who had worked with a same-sex partner first and on a competitive task, girls reported greater femininity than boys in the same condition. On the Open-ended Goals Questionnaire, boys who worked on the competitive task reported a greater proportion of control goals compared to girls who worked on the competitive task. No gender differences in femininity, mutual-participation goals and control goals were found for participants who worked on a collaborative task. According to Sheldon (1990), mutual-participation goals reflect both communal and agentic orientations and task-performance and control goals reflect agentic orientations. Perhaps the instrumental nature of the competitive task elicited participants' agentic orientations. For girls, the agentic orientation was reflected in their reported mutualparticipation and task-performance goals. For boys, the agentic orientation was reflected in their control goals. These findings may suggest a gender difference in how agentic orientations are expressed when working with peers on a competitive task. 
Measurement Issues. The use of both open-ended and closed-ended questionnaires allowed the examination of differences between the two types of assessments. Only one significant finding was consistent between the Open-ended Goals Questionnaire and the Closedended Goals Questionnaire. On both types of assessments, the interaction between type of task and partner order was significant for control goals. Mutual-participation and control goals on the open-ended and closed-ended assessments were significantly correlated. However, correlations for task-performance goals between the two measures were not significant. As a result, many significant findings differed between the open-ended and closed-ended assessments. On the Open-ended Goals Questionnaire, there were a greater number of significant main effects and interactions than on the Closed-ended Goals Questionnaire. Perhaps the flexibility of the openended assessment encouraged participants to report a wider range of goals so that changes in goals were more evident across situations. In addition, partner order influenced early adolescents' reported goals on the closed-ended measure more so than the open-ended measure. Every significant effect on the Closed-ended Goals Questionnaire was qualified by an partner order (same-sex first) effect, whereas only one effect was qualified by a partner order effect on the Open-ended Goals Questionnaire.

Additional Considerations. Gender differences in goals for the peer interaction were more apparent in competitive situations than in collaborative situations. Differences between boys' and girls' mutual-participation goals (closed-ended assessment), control goals (open-ended assessment) and task-performance goals (closed-ended assessment) were found for the competitive task, but not for the collaborative task. This may suggest that researchers who examine gender differences in goals may want to consider using competitive rather than collaborative task structures. The manipulation check indicated that participants reported 
competitive expectations and perceptions for the competitive task, but participants did not report cooperative expectations and perceptions on the collaborative task. The lack of significant findings for the collaborative task may reflect the lack of salience of the cooperative task structure. Future research should create a clear distinction between collaborative and competitive tasks.

Partner order had a significant effect on participants' reported goals. The majority of partner order effects involved participants who had worked with a same-sex partner first rather than an other-sex partner first. The partner order effects in the current study suggest that gender acts as a social cue. Anecdotal evidence suggests that participants' initial interactions resulted in different behaviors during the study. Observations indicated that participants who worked with same-sex peers first enjoyed the study much more than participants who worked with other-sex peers first. In fact, when working with a same-sex partner, participants reported greater expectations and perceptions for collaboration than when working with an other-sex partner. In collaborative contexts, individuals are likely to trust each other and share their resources. Thus, participants may have expected and perceived trust more with a same-sex partner than with an other-sex partner. Perhaps participants' initial level of enjoyment and their expectations and perceptions for collaboration in the first peer interaction influenced how they completed subsequent questionnaires.

\section{Limitations and Future Directions}

When considering the findings of the present study, some limitations should be noted. First, even though playing games with friends is familiar to adolescents, the situation was still somewhat artificial. Second, gender-typed behaviors were assessed using self-report measures. Early adolescents may not have reported their actual masculine and feminine behaviors and 
goals, but may have been influenced by the social desirability of certain behaviors and concerns. Perhaps girls reported stereotypical feminine behaviors and boys reported stereotypical masculine behaviors because it was more socially desirable to have gender congruent behaviors than to have gender incongruent behaviors. Future research should utilize observational techniques to measure overt behaviors during peer interactions. Third, the study used a withinsubject design meaning that each participant completed the task twice. Therefore, practice effects for both the Jenga ${ }^{\circledR}$ game and completion of the measures may be a concern. For instance, participants may have been more comfortable playing the game the second time. Increased comfort may have either increased or decreased participants' reported gender-typed behaviors. For instance, participants reported a greater proportion of task-performance goals when working with a same-sex partner than when working with an other-sex partner. If comfort level with a same-sex partner lead to greater task-performance goals, than participants' comfort level during the second session may also have lead to greater task-performance goals.

Fourth, the current study instructed participants to compete against their partner. That is, intragroup (i.e., within group) competition was investigated. Future research should examine gender-typed behaviors in intergroup and interference competition to determine if gender-typed behaviors differ according to various types of cooperation and competition. Bornstein and Erev (1994) suggest that intergroup (i.e., between group) competition may lead to intragroup cooperation. Fifth, the current study used participants in the life-stage of early adolescence. Adolescence is a time in which identity formation is an important task (Erikson, 1950; Grotevant, 1998; Nurmi, 1993). Instability in identity may have led to an increased flexibility in a person's trait masculinity and femininity (which sets the range for variability in a person's state masculinity and femininity). Alfieri, Ruble, and Higgins (1996) suggest that gender stereotypes 
are flexible during early adolescence. However, their work indicates that it is during the transition from elementary to junior high in which gender stereotypes are the most flexible. The early adolescents in the current study were $7^{\text {th }}$ and $8^{\text {th }}$ graders and were not facing a recent transition. Perhaps gender stereotypes would be more flexible and reported gender-typed behaviors would be more variable in another sample. Future research should examine both younger and older early adolescents to assess changes in gender-typed behaviors during times of transition. Early adolescence was important to examine because it is at this point in the life-span in which individuals begin to interact frequently with other-sex peers (Maccoby, 1998). Future research should examine older adults to assess differences between individuals who are familiar and unfamiliar with other-sex interactions (e.g., romantic relationships). The current study has implications for romantic relationships and friendships between men and women later in life. The gender difference findings support the idea that males and females exhibit different orientations for viewing the world (i.e., communal and agentic) in different situations. These gender differences may make interactions between men and women difficult throughout the lifespan.

Sixth, many of the effects found in the current study were qualified by partner order (same-sex partner first, other-sex partner first). That is, early adolescents' goals and behaviors were affected by the sex of the partner they worked with first. The majority of significant partner order effects (all but one) occurred when participants worked with a same-sex partner first rather than an other-sex partner first. Future research should attempt to replicate the findings to determine if the effects were an artifact of sampling or methodological issues in the current study. If partner order effects were not an artifact of the sampling in the current study, it suggests that future research needs to analyze the order in which variables are presented. 
Perhaps researchers examining early adolescence in particular need to be sensitive to the presentation of variables related to peer social interactions.

Some additional future directions may be important to this particular line of research. The current study examined whether individuals change their gender-typed behaviors within social situations. However, the study did not examine the influence of one partner on another. Future research could investigate the degree of congruency between partners and how one partner (e.g., highly feminine, masculine, or androgynous) may affect another partners' behavioral change in different situations. It may be important to examine partner congruency in their gender-typed behaviors in order to assess whether gender differences in control and affiliation are a result of partners' sex (male, female) or their trait levels of masculinity, femininity, and androgyny. Also, the current study cannot address why participants changed their reported cognitions and behaviors according to the social situation. Future research should examine the mechanisms involved in behavioral change. Individuals' gender stereotypes may influence how their behaviors change in various social situations. For example, if individuals hold a gender stereotypical belief that females are more sensitive than males, they may be less aggressive during interactions with girls compared to interactions with boys.

\section{Conclusions}

The results of the current study highlight the importance of examining a combination of individual attributes (e.g., sex of participant) and contextual features (e.g., type of task, sex of partner, and partner order) when investigating issues related to early adolescence and gender. The study supports the contention that masculinity and femininity contain a state component of expressive and instrumental behaviors that varies according to aspects of the social context. The within-subject design furthers the belief that gender acts as a salient cue in social situations. In 
the current study, boys reported greater femininity when working with girls compared to interactions with same-sex peers. This finding suggests that it is not only girls who shift their behaviors when working with other-sex peers; during early adolescence, boys also attempt to change their behaviors in response to contextual demands. Previous studies have focused on gender-typed behaviors in childhood and adulthood. The current study adds to the gender literature by examining gender-typed behavior in early adolescence. The study also furthers the assertion that the type of task (e.g., collaborative, competitive) influences individuals' cognitions and behaviors. The current study adds to the literature by examining both collaborative and competitive tasks. The findings suggest that gender differences are more apparent (particularly for peer interaction goals) in competitive situations than in collaborative situations. Future research should continue to examine gender differences and similarities in competitive contexts, perhaps investigating various types of competition (e.g., intergroup, interference). Overall, this line of research may be important for examining gender differences and similarities in gendertyped social behaviors. 


\section{References}

Alfieri, T., Ruble, D. N., \& Higgins, E. T. (1996). Gender stereotypes during adolescence: Developmental changes and the transition to junior high school. Developmental Psychology, 32, 1129-1137.

Anselmi, D. L., \& Law, A. L. (1998). Questions of gender: Perspectives and paradoxes (pp. 113). Boston: McGraw Hill Companies, Inc.

Azmitia, M., \& Montgomery, R. (1993). Friendship, transactive dialogues, and the development of scientific reasoning. Social Development, 2, 202-221.

Bakan (1966). The duality of human existence: An essay on psychology and religion. Chicago: Ran McNally.

Bem, S. L. (1974). The measurement of psychological androgyny. Journal of Consulting and Clinical Psychology, 42, 155-162.

Bem, S. L. (1975). Sex role adaptability: One consequence of psychological androgyny. Journal of Personality and Social Psychology, 31, 634-643.

Block, J. H. (1983). Differential premises arising from differential socialization of the sexes: Some conjectures. Child Development, 54, 1335-1354.

Boldizar, J. P. (1991). Assessing sex typing and androgyny in children: The children's sex role inventory. Developmental Psychology, 27, 505-515.

Bornstein, G., \& Erev, I. (1994). The enhancing effect of intergroup competition on group performance. The International Journal of Conflict Management, 5, 271-283.

Brody, L. R., Lovas, G. S., \& Hay, D. H. (1995). Gender differences in anger and fear as a function of situational context. Sex Roles, 32, 47-78. 
Buhrmester, D., \& Furman, W. (1986). The changing function of friends in childhood: A NeoSullivanian perspective. In V. J. Derlega \& B. A. Winstead (Eds.), Friendship and social interaction (pp. 41-62). New York: Springer-Verlag.

Buhrmester, D., \& Furman, W. (1987). The development of companionship and intimacy. Child Development, 58, 1101-1113.

Carli, L. L. (1989). Gender differences in interaction style and influence. Journal of Personality and Social Psychology, 56, 565-576.

Carli, L. L. \& Bukatko, D. (2000). Gender, communication, and social influence: A developmental perspective. In T. Eckes \& H. M. Trautner (Eds.), The developmental social psychology of gender. (pp. 295-331). Mahwah, NJ: New Lawrence Erlbaum Associates, Publishers.

Constantinople, A. (1973). Masculinity-femininity: An exception to a famous dictum? Psychological Bulletin, 80, 389-407.

Craig, G. J. (1996). Human Development. Upper Saddle River, NJ: Prentice Hall.

Deaux, K., \& Major, B. (1987). Putting gender into context: An interactive model of genderrelated behavior. Psychological Review, 94, 369-389.

Dweck, C. S., \& Leggett, E. L. (1988). A social cognitive approach to motivation and personality. Psychological Review, 95, 256-273.

Erikson, E. H. (1950). Childhood and Society. New York, NY: W. W. Norton and Co, Inc.

Fagot, B. I. (1985). Beyond the reinforcement principle: Another step toward understanding sex roles. Developmental Psychology, 21, 1097-1104.

Fisher, B. A. (1983). Differential effects of sexual composition and interactional context on interaction patters in dyads. Human Communication Research, 9, 225-238. 
Flaherty, J. F., \& Dusek, J. B. (1980). An investigation of the relationship between psychological androgyny and components of self-concept. Journal of Personality and Social Psychology, 38, 984-992.

Furman (1987). Acquaintanceship in middle childhood. Developmental Psychology, 23, 563-570.

Galambos, N. L, Almeida, D. M., \& Peterson, A. C. (1990). Masculinity, femininity, and sex role attitudes in early adolescence: Exploring gender intensification. Child Development, 61, 1905-1914.

Gilligan, C. (1982). In A Different Voice: Psychological Theory and Women's Development. Cambridge, MA: Harvard University Press.

Goldman, M., Stockbauer, J. W., \& McAuliffe, T. G. (1977). Intergroup and intragroup competition and cooperation. Journal of Experimental Social Psychology, 13, 81-88.

Grotevant, H. D. (1998). Adolescent development in family contexts. In W. Damon (Series ed.) \& N. Eisenberg, (Vol. ed.), Handbook of child psychology. Vol. 3 Social, emotional, and personality development (5 ${ }^{\text {th }}$ ed., pp. 1097-1149). New York: Wiley.

Hannover, B. (2002). Development of the self in gendered contexts. In T. Eckes \& H. M. Trautner (Eds.), The developmental social psychology of gender. (pp. 177-205). Mahwah, NJ: New Lawrence Erlbaum Associates, Publishers.

Holt, C. L., \& Ellis, J. B. (1998). Assessing the current validity of the Bem Sex Role Inventory. Sex Roles, 39, 929-941.

Johnson, R. T., Johnson, D. W., \& Stanne, M. B. (1986). Comparison of computer-assisted cooperative, competitive, and individualistic learning. American Educational Research Journal, 23, 382-392. 
Kelly, J. R., \& Hutson-Comeaux, S. L. (1999). Gender-emotion stereotypes are context specific. Sex Roles, 40, 107-120.

Krauss, I. K. (1977). Some situational determinants of competitive performance on sexstereotyped tasks. Developmental Psychology, 13, 473-480.

Leaper, C. (1991). Influence and involvement in children's discourse: Age, gender, and partner effects. Child Development, 62, 797-811.

Leaper, C. (1994). Exploring the consequences of gender segregation on social relationships. New Directions for Child Development, 62, 797-811.

Maccoby, E. E. (1990). Gender and relationships: A developmental account. American Psychologist, 45, 513-520.

Maccoby, E. E. (1998). The two sexes: Growing up apart, coming together. Cambridge, MA: Harvard University Press.

Margrett, J. A., \& Marsiske, M. (2002). Gender differences in older adults' everyday cognitive collaboration. International Journal of Behavioral Development, 26(1), 45-59.

Marsh, H. W. (1987). Masculinity, femininity and androgyny: Their relations with multiple dimensions of self-concept. Multivariate Behavioral Research, 22, 91-118.

Massad, C. M. (1981). Sex role identity and adjustment during adolescence. Child Development, $52,1290-1298$.

Miller, J. B., Lewy, J., \& Peckham, E. (1997). Context effects on self-perceptions of feminine and masculine qualities. Sex Roles, 37, 723-750.

Moskowitz, D. S. (1993). Dominance and friendliness: On the interaction of gender and situation. Journal of Personality, 61, 387-409. 
Newcomb, A. F., \& Bagwell, C. L. (1995). Children's friendship relations: A meta-analytic review. Psychological Bulletin, 117, 306-347.

Newcomb, A. F., \& Brady, J. (1982). Mutuality in boys' friendship relations. Child Development, 53, 392-395.

Nurmi, J. E. (1993). Adolescent development in an age-graded context: The role of personal beliefs, goals, and strategies in the tackling of developmental tasks and standards. International Journal of Behavioral Development, 16, 169-189.

Oxford American Dictionary (1980). New York, NY: Oxford University Press, Inc.

Pepper, S. C. (1966). World Hypotheses. Berkely: University of California Press.

Pickard, J. \& Strough, J. (2003). The effects of same-sex and other-sex contexts on masculinity and femininity. Sex Roles, 48, 421-432.

Pickard, J., \& Strough, J. (2003). Variability in goals as a function of same-sex and other-sex contexts. Submitted for publication.

Porter, N., Geis, F. L., Cooper, E., \& Newman, E. (1985). Androgyny and leadership in mixedsex groups. Journal of Personality and Social Psychology, 49, 808-823.

Rose, A. J., \& Asher, S. R. (1999). Children's goals and strategies in response to conflicts within a friendship. Developmental Psychology, 35, 69-79.

Roy, R., \& Benenson, J. F. (2002). Sex and contextual effects on children's use of interference competition. Developmental Psychology, 38, 306-312.

Ruble, D. N., \& Martin, C. L. (1998). Gender development. In W. Damon (Series Ed.) \& N. Eisenberg, (Vol. Ed.), Handbook of child psychology. Vol. 3 Social, emotional, and personality development ( $5^{\text {th }}$ ed., pp. 933-1016). New York: Wiley. 
Sansone, C., \& Berg, C. A. (1993). Adapting to the environment across the life span: Different process or different inputs? International Journal of Behavioral Development, 16, 215-241.

Sansone, C., \& Harackiewicz, J. M. (1996). "I don't feel like it": The function of interest in selfregulation. In L. L. Martin \& A. Tesser (Eds.), Striving and feeling: Interactions among goals, affect, and self-regulation. (pp. 203-228). Hillsdale, NJ: Lawrence Erlbaum Associates.

Schmidt, C. R., Ollendick, T. H., \& Stanowicz, L. B. (1988). Developmental changes in the influence of assigned goals on cooperation and competition. Developmental Psychology, 24, 574-579.

Sheldon, A. (1990). Pickle fights: Gender talk in preschool disputes. Discourse Processes, 13, 5-31.

Smith, C. L., Noll, J. A., \& Becker-Bryant, J. (1999). The effect of social context on gender self-concept. Sex Roles, 40, 499-512.

Spence, J. T., \& Helmreich, R. L. (1981). Androgyny versus gender schema: A comment on Bem’s Gender Schema Theory. Psychological Review, 88, 365-368.

Stake, J. E., Zand, D., \& Smalley, R. (1996). The relation of instrumentality and expressiveness to self-concept and adjustment: A social context perspective. Journal of Social and Clinical Psychology, 15, 167-190.

Strough, J., \& Berg, C. A. (2000). Goals as a mediator of gender differences in high-affiliation dyadic conversations. Developmental Psychology, 36, 117-125. 
Strough, J., Berg, C. A., \& Meegan, S. P. (2000). Friendship and gender differences in task and social interpretations of peer collaborative problem solving. Social Development, $10,1-22$.

Strough, J., Berg, C. A. \& Sansone, C. (1996). Goals for solving everyday problems across the life span: Age and gender differences in the salience of interpersonal concerns. Developmental Psychology, 32, 1106-1115.

Strough, J., \& Cheng, S. (2000). Dyad gender and friendship differences in shared goals for mutual participation on a collaborative task. Child Study Journal, 30, 103-126.

Strough, J., \& Covatto, A. M. (2002). Context and age differences in same- and other-gender peer preferences. Social Development, 11, 346-361.

Strough, J., Swenson, L. M., \& Cheng, S. (2001). Friendship, gender, and preadolescents' representations of peer collaborative problem solving. Merrill Palmer Quarterly, 47, 475-499.

Strough, J., Swenson, L. M., Owens, R. A., \& Pickard, J. (2002). Developmental tasks from adolescence through early adulthood. Manuscript submitted for publication.

Strough, J., Swenson, L. M., Pickard, J. \& Owens, R. A. (2002). Dyadic interactions and young adults' performance on a collaborative task. Manuscript submitted for publication.

Swenson, L. M. \& Strough, J. (2002). The influence of friendship, friendship quality, and gender on collaborative processes and performance. Manuscript submitted for publication.

Taylor, M. C., \& Hall, J. A. (1982). Psychological androgyny: Theories, methods, and conclusions. Psychological Bulletin, 92, 347-366. 
Tjosvold, D. (1981). Unequal power relationships within a cooperative or competitive context. Journal of Applied Social Psychology, 11, 137-150.

Wentzel, K. R. (1991). Social and academic goals at school: Motivation and achievement in context. Review of Educational Research, 61, 1-24.

Wentzel, K. R. (1993). Motivation and achievement in early adolescence: The role of multiple classroom goals. Journal of Early Adolescence, 13, 4-20.

Wood, W., Christensen, P. N., Hebl, M. R., \& Rothgerber, H. (1997). Conformity to sex-typed norms, affect, and the self-concept. Journal of Personality and Social Psychology, 73, 523-535.

Wrosch, C., \& Heckhausen, J. (1999). Control processes before and after passing a developmental deadline: Activation and deactivation of intimate relationship goals. Journal of Personality and Social Psychology, 77, 415-427.

Zajac, R. J., \& Hartup, W. W. (1997). Friends as coworkers: Research review and classroom implications. Elementary School Journal, 98, 3-13.

Zirkel, S., \& Cantor, N. (1990). Personal construal of life tasks: Those who struggle for independence. Journal of Personality and Social Psychology, 58, 172-185. 


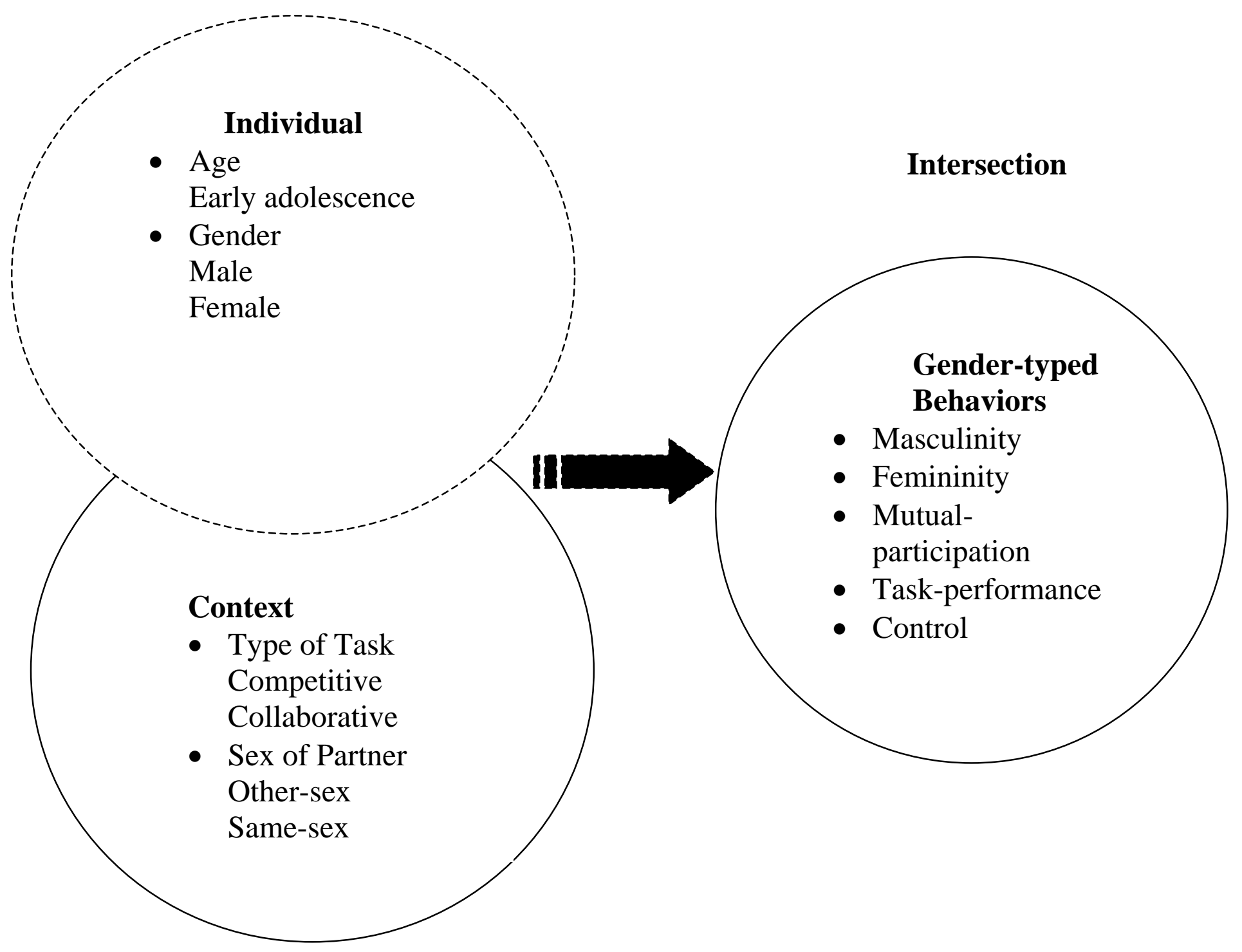

Figure 1. Conceptual model illustrating how contextual features and individual attributes intersect to influence gender as reflected through masculinity, femininity, and goals for the interaction. 


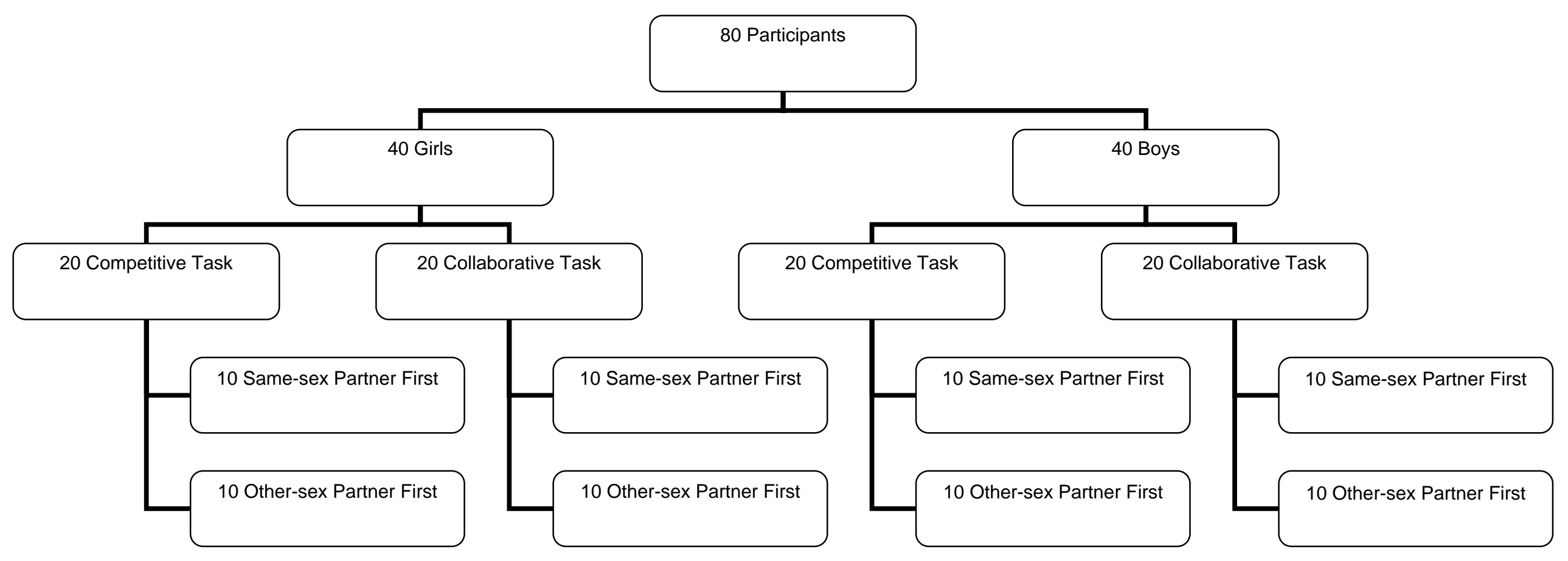

Figure 2. Outline of the number of participants in each condition by sex of participant, type of task and partner order. 
Table 1

Outline of the Procedure Used in the Study Including When Each Measure was Completed

Baseline Assessment

Prior to Interacting with a

Same-sex or an Other-sex Peer

\section{Expectations Questionnaire}

Trait Masculinity and Femininity

Bem Sex Role Inventory

Children's Sex Role Inventory
After Interacting with a

Same-sex or an Other-sex Peer

\section{Perceptions Questionnaire}

$\underline{\text { State Masculinity and Femininity }}$

State Gender Role Inventory

Children's State Gender Role Inventory

$\underline{\text { State Goals }}$

Open-ended Goals Questionnaire

Closed-ended Goals Questionnaire

$\underline{\text { Friendship (varying covariate) }}$

Friendship Questionnaire 
Table 2

Means and Standard Deviations for Baseline Masculinity and Femininity, and Androgyny Scores on the Bem Sex Role Inventory for Participants Who Worked with a Same- or an Other-sex Partner First on a Collaborative or a Competitive Task by Sex of Participant

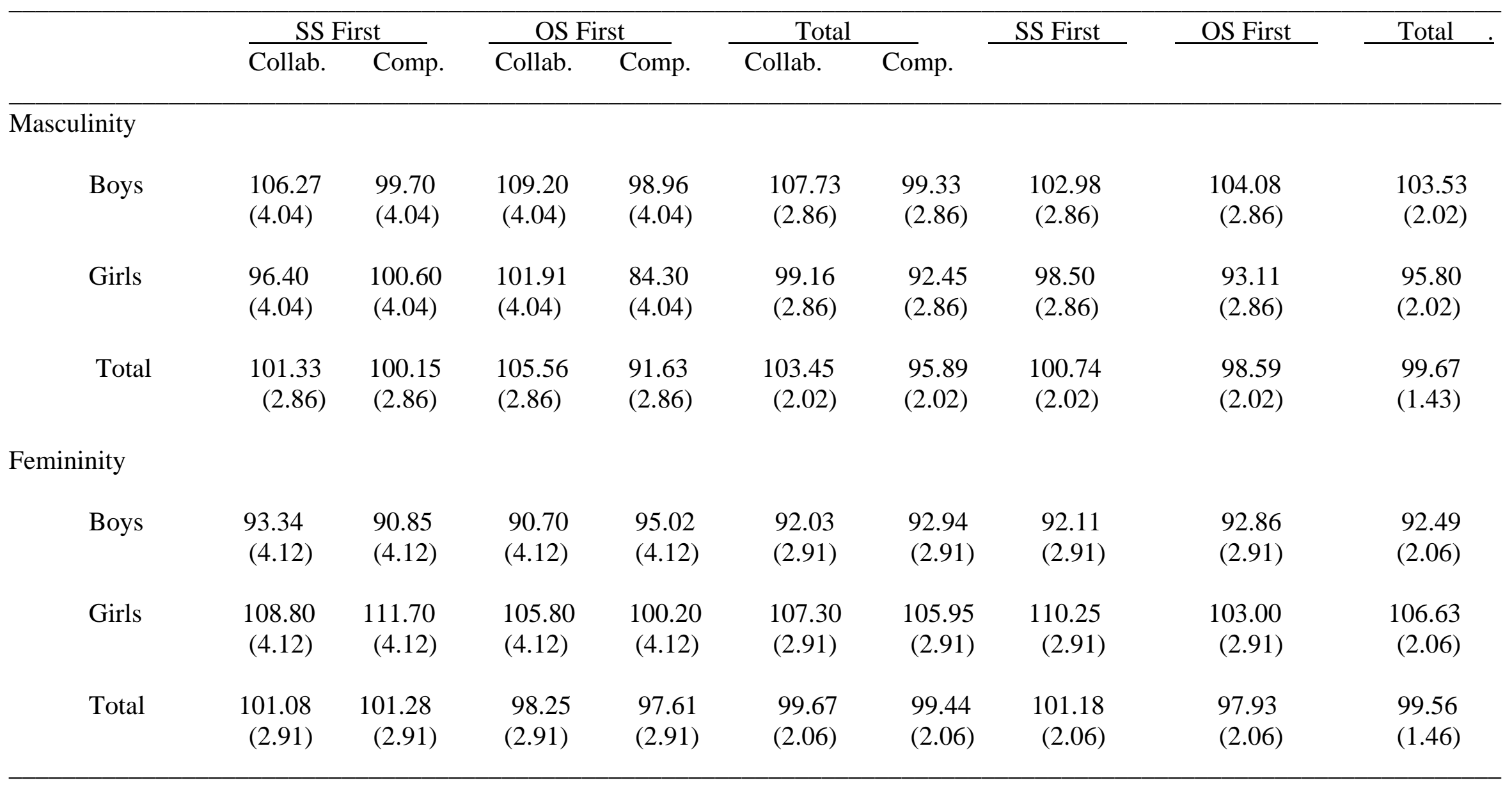


Table 2 Continued

Means and Standard Deviations for Baseline Masculinity and Femininity, and Androgyny Scores on the Bem Sex Role Inventory for Participants Who Worked with a Same- or an Other-sex Partner First on a Collaborative or a Competitive Task by Sex of Participant

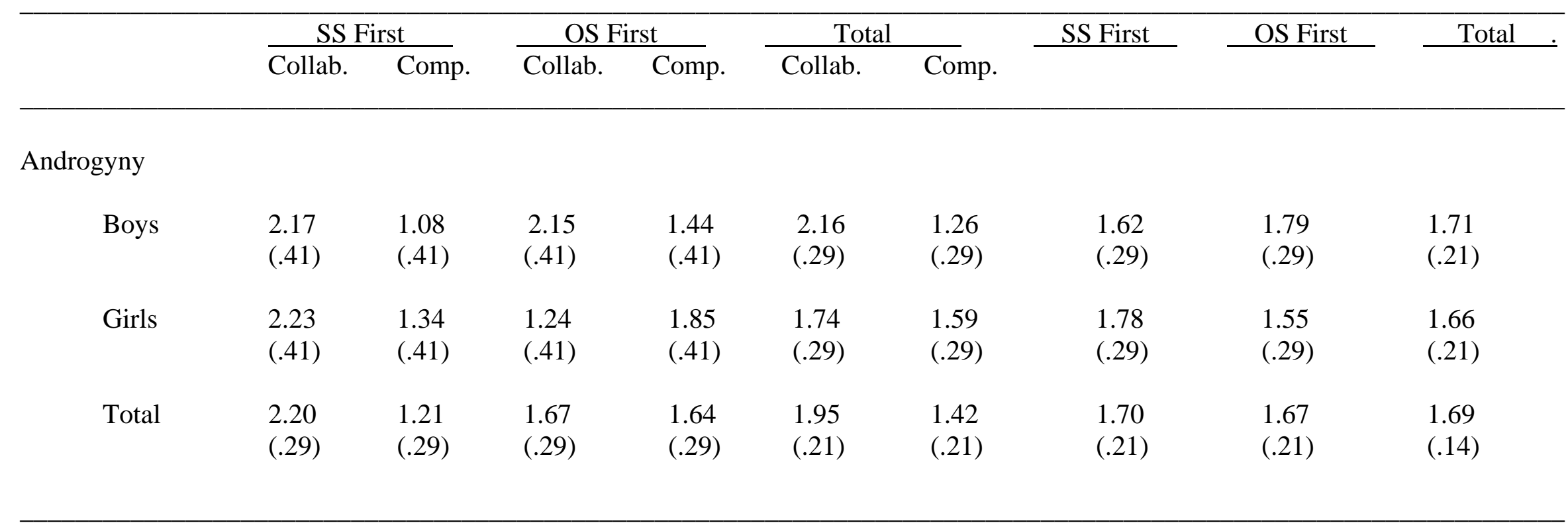

Note. $\quad$ SS First $=$ Same-sex partner first $;$ OS First $=$ Other-sex partner first Collab. $=$ Collaborative task $;$ Comp. $=$ Competitive task Masculinity and Femininity were computed as continuous variables, Androgyny was computed using Bem's (1974) formula 
Table 3

Means and Standard Errors for Cooperative and Competitive Expectations and Perceptions by Sex of Partner, Type of Task and Partner Order

\begin{tabular}{|c|c|c|c|c|c|c|c|c|c|}
\hline \multirow{2}{*}{$\begin{array}{l}\text { Sex of } \\
\text { Partner }\end{array}$} & \multicolumn{2}{|c|}{ SS First } & \multicolumn{2}{|c|}{ OS First } & \multicolumn{2}{|c|}{ Total } & \multirow{2}{*}{ SS First } & \multirow{2}{*}{ OS First } & \multirow{2}{*}{ Total } \\
\hline & Collab. & Comp. & Collab. & Comp. & Collab. & Comp. & & & \\
\hline
\end{tabular}

Coop. Expectations

$\begin{array}{lllllllllll}\text { Same-sex } & 3.85 & 3.95 & 4.25 & 4.15 & 4.05 & 4.05 & 3.90 & 4.20 & 4.05 * * \\ & (.21) & (.21) & (.21) & (.21) & (.15) & (.15) & (.15) & (.15) & (.10) \\ \text { Other-sex } & 3.65 & 3.55 & 4.00 & 3.30 & 3.83 & 3.43 & 3.60 & 3.65 & 3.63 * * \\ & (.21) & (.21) & (.21) & (.21) & (.15) & (.15) & (.15) & (.15) & (.10) \\ \text { Total } & 3.75 & 3.75 & 4.13 & 3.73 & 3.94 & 3.74 & 3.75 & 3.93 & 3.84 \\ & (.16) & (.16) & (.16) & (.16) & (.11) & (.11) & (.11) & (.11) & (.08)\end{array}$

Comp. Expectations

\begin{tabular}{|c|c|c|c|c|c|c|c|c|c|}
\hline Same-sex & $\begin{array}{l}2.70^{\mathrm{a}} \\
(.23)\end{array}$ & $\begin{array}{l}3.70 \\
(.23)\end{array}$ & $\begin{array}{l}1.80^{\mathrm{a}} \\
(.23)\end{array}$ & $\begin{array}{l}3.75 \\
(.23)\end{array}$ & $\begin{array}{l}2.25 \\
(.16)\end{array}$ & $\begin{array}{l}3.73 \\
(0.16)\end{array}$ & $\begin{array}{l}3.20 \\
(.16)\end{array}$ & $\begin{array}{l}2.78 \\
(.16)\end{array}$ & $\begin{array}{l}2.99 \\
(.11)\end{array}$ \\
\hline Other-sex & $\begin{array}{l}2.10 \\
(.24)\end{array}$ & $\begin{array}{l}3.95 \\
(.24)\end{array}$ & $\begin{array}{l}2.80 \\
(.24)\end{array}$ & $\begin{array}{l}3.75 \\
(.24)\end{array}$ & $\begin{array}{l}2.45 \\
(.17)\end{array}$ & $\begin{array}{l}3.85 \\
(.17)\end{array}$ & $\begin{array}{l}3.03 \\
(.17)\end{array}$ & $\begin{array}{l}3.28 \\
(.17)\end{array}$ & $\begin{array}{l}3.15 \\
(.12)\end{array}$ \\
\hline Total & $\begin{array}{l}2.40 \\
(.19)\end{array}$ & $\begin{array}{l}3.83 \\
(.19)\end{array}$ & $\begin{array}{l}2.30 \\
(.19)\end{array}$ & $\begin{array}{l}3.75 \\
(.19)\end{array}$ & $\begin{array}{l}2.35 \\
(.14)\end{array}$ & $\begin{array}{l}3.79 \\
(.14)\end{array}$ & $\begin{array}{l}3.11 \\
(.14)\end{array}$ & $\begin{array}{l}3.03 \\
(.14)\end{array}$ & $\begin{array}{l}3.07 \\
(.10)\end{array}$ \\
\hline
\end{tabular}


Table 3 Continued

Means and Standard Errors for Cooperative and Competitive Expectations and Perceptions by Sex of Partner, Type of Task and Partner Order

\begin{tabular}{|c|c|c|c|c|c|c|c|c|c|}
\hline Sex of & $\mathrm{SS}$ & & $\mathrm{OS} \mathrm{Fi}$ & & Total & & SS First & OS First & Total \\
\hline & Collab. & Comp. & Collab. & Comp. & Collab. & Comp. & & & \\
\hline
\end{tabular}

Coop. Perceptions

$\begin{array}{lllllllllll}\text { Same-sex } & 4.10 & 4.16 & 4.45 & 4.15 & 4.23 & 4.15 & 4.13 & 4.30 & 4.21^{*} \\ & (.22) & (.23) & (.22) & (.22) & (.16) & (.16) & (.16) & (.16) & \\ \text { Other-sex } & 4.00 & 3.70 & 4.25 & 3.80 & 4.13 & 3.75 & 3.85 & 4.03 & 3.94 * \\ & (.20) & (.20) & (.20) & (.20) & (.14) & (.14) & (.14) & (.14) & (.10) \\ \text { Total } & 4.05 & 3.92 & 4.35 & 3.98 & 4.20 & 3.95 & 3.99 & 4.16 & 4.07 \\ & (.16) & (.17) & (.16) & (.16) & (.12) & (.12) & (.12) & (.12)_{-} & (.08)\end{array}$

Comp. Perceptions

\begin{tabular}{|c|c|c|c|c|c|c|c|c|c|}
\hline Same-sex & $\begin{array}{l}2.20 \\
(.23)\end{array}$ & $\begin{array}{l}3.90 \\
(.24)\end{array}$ & $\begin{array}{l}1.65 \\
(.23)\end{array}$ & $\begin{array}{l}3.50 \\
(.23)\end{array}$ & $\begin{array}{l}1.93 \\
(.16)\end{array}$ & $\begin{array}{l}3.70 \\
(.16)\end{array}$ & $\begin{array}{l}3.05 \\
(.16)\end{array}$ & $\begin{array}{l}2.58 \\
(.16)\end{array}$ & $\begin{array}{l}2.81 \\
(.12)\end{array}$ \\
\hline Other-sex & $\begin{array}{l}1.90 \\
(.23)\end{array}$ & $\begin{array}{l}3.95 \\
(.23)\end{array}$ & $\begin{array}{l}1.95 \\
(.23)\end{array}$ & $\begin{array}{l}3.70 \\
(.23)\end{array}$ & $\begin{array}{l}1.93 \\
(.16)\end{array}$ & $\begin{array}{l}3.83 \\
(.16)\end{array}$ & $\begin{array}{l}2.93 \\
(.16)\end{array}$ & $\begin{array}{l}2.83 \\
(.16)\end{array}$ & $\begin{array}{l}2.88 \\
(.12)\end{array}$ \\
\hline Total & $\begin{array}{l}2.05 \\
(.20)\end{array}$ & $\begin{array}{c}3.92 \\
(.21)\end{array}$ & $\begin{array}{l}1.80 \\
(.20)\end{array}$ & $\begin{array}{l}3.60 \\
(.20)\end{array}$ & $\begin{array}{l}1.93^{b} \\
(.14)\end{array}$ & $\begin{array}{l}3.76^{\mathrm{b}} \\
(.15)\end{array}$ & $\begin{array}{l}2.99 \\
(.15)\end{array}$ & $\begin{array}{l}2.70 \\
(.14)\end{array}$ & $\begin{array}{l}2.84 \\
(.10)\end{array}$ \\
\hline
\end{tabular}


Note. $\quad$ SS First $=$ Same-sex partner first OS First $=$ Other-sex partner first Collab. $=$ Collaborative task $;$ Comp. $=$ Competitive task ${ }^{a}$ indicates means within a row that differ significantly, $p<.05$

${ }^{\mathrm{b}}$ indicates means within a row that differ significantly, $p<.01$

* indicates means within a column that differ significantly, $p<.01$

** indicates means with a column that differ significantly, $p<.01$ 
Table 4

Correlations Among Scores on the Bem Sex Role Inventory, the Children's Sex Role Inventory, the State Gender Role Inventory and the Children's State Gender Role Inventory

$\begin{array}{llllllllllll}1 & 2 & 3 & 4 & 5 & 6 & 7 & 8 & 9 & 10 & 11 & 12\end{array}$

Baseline

$\begin{array}{llllllllllllllll}\text { 1. } & \text { BSRI Masc. } & - & .17 & .82^{* *} & .00 & .66^{* *} & .10 & .51^{* *} & .12 & .70^{* *} & .18 & .48^{* *} & .25^{*} \\ \text { 2. } & \text { BSRI Fem. } & - & - & .05 & .77^{* *} & .18 & .51^{* *} & .15 & .40^{* *} & .18 & .46^{* *} & .08 & .20 \\ \text { 3. } & \text { CSRI Masc. } & - & - & - & .01 & .73^{* *} & .12 & .54^{* *} & .10 & .67^{* *} & .19 & .47^{* *} & .23^{*} \\ 4 . & \text { CSRI Fem. } & - & - & - & - & .12 & .54 * * & .03 & .45^{* *} & .12 & .50^{* *} & .03 & .24 *\end{array}$

Same-sex Partner

$\begin{array}{lllllllllllllll}\text { 5. } & \text { SGRI Masc. } & - & - & - & - & - & .33 * * & .71 * * & .18 & .74 * * & .29 * * & .49 * * & .19 \\ \text { 6. } & \text { SGRI Fem. } & - & - & - & - & - & - & .22 & .71 * * & .28 * & .67 * * & .05 & .44 * * \\ 7 . & \text { CSGRI Masc. } & - & - & - & - & - & - & - & .34 * * & .59 * * & .28 * & .63 * * & .32 * * \\ \text { 8. } & \text { CSGRI Fem. } & - & - & - & - & - & - & - & - & .20 & .60 * * & .07 & .59 * *\end{array}$


Table 4 Continued

Correlations Among Responses on the Bem Sex Role Inventory, the Children's Sex Role Inventory, the State Gender Role Inventory and the Children's State Gender Role Inventory

$\begin{array}{llllllllllll}1 & 2 & 3 & 4 & 5 & 6 & 7 & 8 & 9 & 10 & 11 & 12\end{array}$

Other-sex Partner

9. $\quad$ SGRI Masc.

10. SGRI Fem.

11. CSGRI Masc.

12. CSGRI Fem.

Note. $*$ indicates correlations significant at the $p<.05$ level

** indicates correlations significant at the $p<.01$ level 
Table 5

Correlations Between Responses on the Open-ended Goals Questionnaire and the Closed-ended Goals Questionnaire

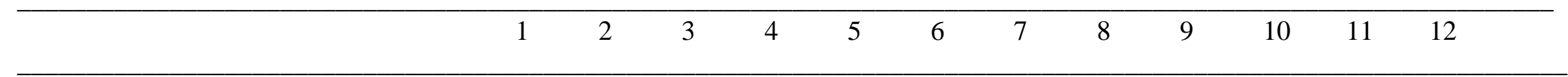

Same-sex Partner

Closed-ended Goals Questionnaire

1. Mutual-participation

2. Control

3. Task-performance

Open-ended Goals Questionnaire

4. Mutual-participation

5. Control

6. Task-performance

$\begin{array}{llllllllllll}- & -.33^{* *} & .72 * * & .33 * * & -.42 * * & -.02 & .44 * * & -.30^{* *} & .47 * * & .27 * & -.26 * & -.04 \\ - & - & .06 & -.08 & .43 * * & -.17 & -.15 & .79 * * & .04 & -.13 & .33 * * & -.31^{* *} \\ - & - & - & .18 & -.18 & .01 & .41 * * & .07 & .65^{* *} & .27 * & -.11 & -.12\end{array}$

$\begin{array}{llllllllllll}- & - & - & - & -.31 * * & -.47 * * & .23 & -.02 & .19 & .43 * * & -.08 & -.23 \\ - & - & - & - & - & -.40 * * & -.05 & .35 * * & -.13 & -.17 & .61 * * & -.30 * \\ - & - & - & - & - & - & -.08 & -.19 & .03 & -.14 & -.45 * * & .53 * *\end{array}$


Table 5 Continued

Correlations Between Responses on the Open-ended Goals Questionnaire and the Closed-ended Goals Questionnaire

$\begin{array}{llllllllllll}1 & 2 & 3 & 4 & 5 & 6 & 7 & 8 & 9 & 10 & 11 & 12\end{array}$

Other-sex Partner

Closed-ended Goals Questionnaire

7. Mutual-participation

8. Control

9. Task-performance

Open-ended Goals Questionnaire
10. Mutual-participation
11. Control
12. Task-performance

Note. * indicates correlations significant at the $p<.05$ level

$* *$ indicates correlations significant at the $p<.01$ level 
Table 6

Adjusted Means and Standard Errors for Femininity on the State Gender Role Inventory for Participants Who Worked with a Same- or an Other-sex Partner First on a Collaborative or a Competitive Task by Sex of Participant and Sex of Partner

\begin{tabular}{|c|c|c|c|c|c|c|c|c|c|c|}
\hline \multirow{2}{*}{\multicolumn{2}{|c|}{$\begin{array}{l}\text { Sex of } \\
\text { Partner }\end{array}$}} & \multicolumn{2}{|c|}{ SS First } & \multicolumn{2}{|c|}{ OS First } & \multicolumn{2}{|c|}{ Total } & \multirow[t]{2}{*}{ SS First } & \multirow[t]{2}{*}{ OS First } & \multirow[t]{2}{*}{ Total } \\
\hline & & Collab. & Comp. & Collab. & Comp. & Collab. & Comp. & & & \\
\hline & Same-sex & $\begin{array}{l}88.66 \\
(5.28)\end{array}$ & $\begin{array}{l}76.93 \\
(5.28)\end{array}$ & $\begin{array}{l}87.92 \\
(5.29)\end{array}$ & $\begin{array}{l}81.32 \\
(5.37)\end{array}$ & $\begin{array}{l}88.29 \\
(3.73)\end{array}$ & $\begin{array}{l}79.12 \\
(3.78)\end{array}$ & $\begin{array}{l}82.80 \\
(3.73)\end{array}$ & $\begin{array}{l}84.62 \\
(3.75)\end{array}$ & $\begin{array}{l}83.71 \\
(2.65)\end{array}$ \\
\hline & Other-sex & $\begin{array}{l}89.77 \\
(5.55)\end{array}$ & $\begin{array}{l}77.57 \\
(5.55)\end{array}$ & $\begin{array}{l}89.61 \\
(5.46)\end{array}$ & $\begin{array}{l}86.52 \\
(5.47)\end{array}$ & $\begin{array}{l}89.69 \\
(3.89)\end{array}$ & $\begin{array}{l}82.04 \\
(3.92)\end{array}$ & $\begin{array}{l}83.67 \\
(3.98)\end{array}$ & $\begin{array}{l}88.07 \\
(3.87)\end{array}$ & $\begin{array}{l}85.87 \\
(2.79)\end{array}$ \\
\hline & Total & $\begin{array}{l}89.22 \\
(3.82)\end{array}$ & $\begin{array}{l}77.25 \\
(3.82)\end{array}$ & $\begin{array}{l}88.77 \\
(3.80)\end{array}$ & $\begin{array}{l}83.92 \\
(3.81)\end{array}$ & $\begin{array}{l}88.99 \\
(2.70)\end{array}$ & $\begin{array}{l}80.58 \\
(2.69)\end{array}$ & $\begin{array}{l}83.23 * * \\
(2.72)\end{array}$ & $\begin{array}{l}86.34 \\
(2.69)\end{array}$ & $\begin{array}{l}84.79 \\
(1.91)\end{array}$ \\
\hline \multirow{3}{*}{ Girls } & Same-sex & $\begin{array}{r}103.50 \\
(5.30)\end{array}$ & $\begin{array}{r}106.82 \\
(5.37)\end{array}$ & $\begin{array}{c}94.78 \\
(5.28)\end{array}$ & $\begin{array}{l}86.83 \\
(5.49)\end{array}$ & $\begin{array}{l}99.14 \\
(3.75)\end{array}$ & $\begin{array}{r}96.82 \\
(3.94)\end{array}$ & $\begin{array}{r}105.16 \\
(3.81)\end{array}$ & $\begin{array}{l}90.80 \\
(3.83)\end{array}$ & $\begin{array}{l}97.98 \\
(2.76)\end{array}$ \\
\hline & Other-sex & $\begin{array}{l}96.24 \\
(5.50)\end{array}$ & $\begin{array}{r}102.02 \\
(5.47)\end{array}$ & $\begin{array}{l}92.92 \\
(5.47)\end{array}$ & $\begin{array}{l}91.64 \\
(5.50)\end{array}$ & $\begin{array}{l}94.58 \\
(3.89)\end{array}$ & $\begin{array}{l}96.83 \\
(3.89)\end{array}$ & $\begin{array}{l}99.13 \\
(3.89)\end{array}$ & $\begin{array}{l}92.28 \\
(3.89)\end{array}$ & $\begin{array}{l}95.71 \\
(2.77)\end{array}$ \\
\hline & Total & $\begin{array}{l}99.87 \\
(3.80)\end{array}$ & $\begin{array}{r}104.42 \\
(3.81)\end{array}$ & $\begin{array}{l}93.85 \\
(3.80)\end{array}$ & $\begin{array}{l}89.24 \\
(3.82)\end{array}$ & $\begin{array}{l}96.86 \\
(2.69)\end{array}$ & $\begin{array}{l}96.83 \\
(2.71)\end{array}$ & $\begin{array}{c}102.15^{* *} \\
(2.69)\end{array}$ & $\begin{array}{l}91.54 \\
(2.69)\end{array}$ & $\begin{array}{l}96.84 \\
(1.91)\end{array}$ \\
\hline
\end{tabular}


Table 6 Continued

Adjusted Means and Standard Errors for Femininity on the State Gender Role Inventory for Participants Who Worked with a Same- or an Other-sex Partner First on a Collaborative or a Competitive Task by Sex of Participant and Sex of Partner

\begin{tabular}{|c|c|c|c|c|c|c|c|c|c|}
\hline \multirow{2}{*}{$\begin{array}{l}\text { Sex of } \\
\text { Partner }\end{array}$} & \multicolumn{2}{|c|}{ SS First } & \multicolumn{2}{|c|}{ OS First } & \multicolumn{2}{|c|}{ Total } & \multirow[t]{2}{*}{ SS First } & \multirow[t]{2}{*}{ OS First } & \multirow[t]{2}{*}{ Total } \\
\hline & Collab. & Comp. & Collab. & Comp. & Collab. & Comp. & & & \\
\hline \multicolumn{10}{|l|}{ All Participants } \\
\hline Same-sex & $\begin{array}{l}96.08 \\
(3.74)\end{array}$ & $\begin{array}{l}91.87 \\
(3.78)\end{array}$ & $\begin{array}{l}91.35 \\
(3.73)\end{array}$ & $\begin{array}{l}84.07 \\
(3.94)\end{array}$ & $\begin{array}{l}93.72 \\
(2.64)\end{array}$ & $\begin{array}{l}87.97 \\
(2.80)\end{array}$ & $\begin{array}{l}93.98 \\
(2.68)\end{array}$ & $\begin{array}{l}87.71 \\
(2.71)\end{array}$ & $\begin{array}{l}90.84 \\
(1.94)\end{array}$ \\
\hline Other-sex & $\begin{array}{l}93.01 \\
(3.95)\end{array}$ & $\begin{array}{l}89.79 \\
(3.92)\end{array}$ & $\begin{array}{l}91.27 \\
(3.87)\end{array}$ & $\begin{array}{l}89.08 \\
(3.89)\end{array}$ & $\begin{array}{l}92.14 \\
(2.77)\end{array}$ & $\begin{array}{l}89.44 \\
(2.79)\end{array}$ & $\begin{array}{l}91.40 \\
(2.83)\end{array}$ & $\begin{array}{l}90.17 \\
(2.75)\end{array}$ & $\begin{array}{l}90.79 \\
(2.00)\end{array}$ \\
\hline Total & $\begin{array}{l}94.55 \\
(2.70)\end{array}$ & $\begin{array}{l}90.83 \\
(2.69)\end{array}$ & $\begin{array}{l}91.31 \\
(2.69)\end{array}$ & $\begin{array}{l}86.58 \\
(2.71)\end{array}$ & $\begin{array}{l}92.93 \\
(1.91)\end{array}$ & $\begin{array}{l}88.71 \\
(1.91)\end{array}$ & $\begin{array}{l}92.69 \\
(1.90)\end{array}$ & $\begin{array}{l}88.94 \\
(1.90)\end{array}$ & $\begin{array}{l}90.82 \\
(1.34)\end{array}$ \\
\hline
\end{tabular}

Note. $\quad$ SS First $=$ Same-sex partner first OS First $=$ Other-sex partner first Collab. $=$ Collaborative task $;$ Comp. $=$ Competitive task $* *$ indicates means within a column that differ significantly, $p<.01$ 
Table 7

Adjusted Means and Standard Errors for Masculinity on the State Gender Role Inventory for Participants Who Worked with a Same- or an Other-sex Partner First on a Collaborative or a Competitive Task by Sex of Participant and Sex of Partner

\begin{tabular}{|c|c|c|c|c|c|c|c|c|c|c|}
\hline \multirow{3}{*}{ Boys } & \multirow{2}{*}{$\begin{array}{l}\text { Sex of } \\
\text { Partner }\end{array}$} & \multicolumn{2}{|c|}{ SS First } & \multicolumn{2}{|c|}{ OS First } & \multicolumn{2}{|l|}{ Total } & \multirow[t]{2}{*}{ SS First } & \multirow[t]{2}{*}{ OS First } & \multirow[t]{2}{*}{ Total } \\
\hline & & Collab. & Comp. & Collab. & Comp. & Collab. & Comp. & & & \\
\hline & & & & & & & & & & \\
\hline & Same-sex & $\begin{array}{l}99.82 \\
(5.58)\end{array}$ & $\begin{array}{r}101.23 \\
(5.59)\end{array}$ & $\begin{array}{r}105.21 \\
(5.59)\end{array}$ & $\begin{array}{l}93.16 \\
(5.68)\end{array}$ & $\begin{array}{r}102.52 \\
(3.95)\end{array}$ & $\begin{array}{l}97.19 \\
(3.99)\end{array}$ & $\begin{array}{r}100.52 \\
(3.95)\end{array}$ & $\begin{array}{l}99.19 \\
(3.96)\end{array}$ & $\begin{array}{l}99.86 \\
(2.80)\end{array}$ \\
\hline & Other-sex & $\begin{array}{r}101.99 \\
(5.45)\end{array}$ & $\begin{array}{r}88.09 \\
(5.45)\end{array}$ & $\begin{array}{r}106.96 \\
(5.36)\end{array}$ & $\begin{array}{l}94.21 \\
(5.37)\end{array}$ & $\begin{array}{r}104.48 \\
(3.82)\end{array}$ & $\begin{array}{l}91.15 \\
(3.85)\end{array}$ & $\begin{array}{l}95.04 \\
(3.92)\end{array}$ & $\begin{array}{r}100.59 \\
(3.79)\end{array}$ & $\begin{array}{l}97.81 \\
(2.74)\end{array}$ \\
\hline & Total & $\begin{array}{r}100.90 \\
(3.90)\end{array}$ & $\begin{array}{l}94.66 \\
(3.89)\end{array}$ & $\begin{array}{r}106.09 \\
(3.87)\end{array}$ & $\begin{array}{l}93.69 \\
(3.89)\end{array}$ & $\begin{array}{l}103.50 * * \\
(2.75)\end{array}$ & $\begin{array}{r}94.17 \\
(2.74)\end{array}$ & $\begin{array}{l}97.78 \\
(2.77)\end{array}$ & $\begin{array}{l}99.89 \\
(2.74)\end{array}$ & $\begin{array}{l}98.83 \\
(1.94)\end{array}$ \\
\hline U & Same-sex & $\begin{array}{l}89.34 \\
(5.61)\end{array}$ & $\begin{array}{r}107.26 \\
(5.68)\end{array}$ & $\begin{array}{l}89.53 \\
(5.59)\end{array}$ & $\begin{array}{l}84.58 \\
(5.79)\end{array}$ & $\begin{array}{l}89.44 \\
(3.96)\end{array}$ & $\begin{array}{r}95.92 \\
(4.15)\end{array}$ & $\begin{array}{l}98.30 \\
(4.02)\end{array}$ & $\begin{array}{l}87.05 \\
(4.04)\end{array}$ & $\begin{array}{l}92.68 \\
(2.91)\end{array}$ \\
\hline & Other-sex & $\begin{array}{l}85.00 \\
(5.40)\end{array}$ & $\begin{array}{r}99.61 \\
(5.37)\end{array}$ & $\begin{array}{l}91.31 \\
(5.37)\end{array}$ & $\begin{array}{l}84.10 \\
(5.40)\end{array}$ & $\begin{array}{l}88.16 \\
(3.82)\end{array}$ & $\begin{array}{r}91.86 \\
(3.82)\end{array}$ & $\begin{array}{l}92.31 \\
(3.82)\end{array}$ & $\begin{array}{l}87.71 \\
(3.82)\end{array}$ & $\begin{array}{l}90.01 \\
(2.72)\end{array}$ \\
\hline & Total & $\begin{array}{l}87.17 \\
(3.87)\end{array}$ & $\begin{array}{r}103.44 \\
(3.89)\end{array}$ & $\begin{array}{l}90.42 \\
(3.87)\end{array}$ & $\begin{array}{l}84.34 \\
(3.89)\end{array}$ & $\begin{array}{c}88.80 * * \\
(2.74)\end{array}$ & $\begin{array}{l}93.89 \\
(2.77)\end{array}$ & $\begin{array}{l}95.30 \\
(2.74)\end{array}$ & $\begin{array}{l}87.38 \\
(2.74)\end{array}$ & $\begin{array}{l}91.34 \\
(1.94)\end{array}$ \\
\hline
\end{tabular}


Table 7 Continued

Adjusted Means and Standard Errors for Masculinity on the State Gender Role Inventory for Participants Who Worked with a Same- or an Other-sex Partner First on a Collaborative or a Competitive Task by Sex of Participant and Sex of Partner

\begin{tabular}{|c|c|c|c|c|c|c|c|c|c|}
\hline \multirow{2}{*}{$\begin{array}{l}\text { Sex of } \\
\text { Partner }\end{array}$} & \multicolumn{2}{|c|}{ SS First } & \multicolumn{2}{|c|}{ OS First } & \multicolumn{2}{|c|}{ Total } & \multirow[t]{2}{*}{ SS First } & \multirow[t]{2}{*}{ OS First } & \multirow[t]{2}{*}{ Total } \\
\hline & Collab. & Comp. & Collab. & $\overline{\text { Comp. }}$ & Collab. & Comp. & & & \\
\hline \multicolumn{10}{|l|}{ All participants } \\
\hline Same-sex & $\begin{array}{l}94.58 \\
(3.96)\end{array}$ & $\begin{array}{c}104.24 \\
(3.99)\end{array}$ & $\begin{array}{l}97.37 \\
(3.95)\end{array}$ & $\begin{array}{l}88.87 \\
(4.15)\end{array}$ & $\begin{array}{l}95.98 \\
(2.79)\end{array}$ & $\begin{array}{l}96.56 \\
(2.95)\end{array}$ & $\begin{array}{l}99.41 \\
(2.83)\end{array}$ & $\begin{array}{l}93.12 \\
(2.86)\end{array}$ & $\begin{array}{l}96.27 \\
(2.05)\end{array}$ \\
\hline Other-sex & $\begin{array}{l}93.50 \\
(3.88)\end{array}$ & $\begin{array}{l}93.85 \\
(3.85)\end{array}$ & $\begin{array}{l}99.14 \\
(3.79)\end{array}$ & $\begin{array}{l}89.16 \\
(3.82)\end{array}$ & $\begin{array}{l}96.32 \\
(2.73)\end{array}$ & $\begin{array}{l}91.50 \\
(2.74)\end{array}$ & $\begin{array}{l}93.67 \\
(2.78)\end{array}$ & $\begin{array}{l}94.15 \\
(2.70)\end{array}$ & $\begin{array}{l}93.91 \\
(1.97)\end{array}$ \\
\hline Total & $\begin{array}{l}94.04 \\
(2.75)\end{array}$ & $\begin{array}{r}99.05 \\
(2.74)\end{array}$ & $\begin{array}{l}98.25^{\mathrm{a}} \\
(2.74)\end{array}$ & $\begin{array}{l}89.01^{\mathrm{a}} \\
(2.77)\end{array}$ & $\begin{array}{l}96.15 \\
(1.94)\end{array}$ & $\begin{array}{l}94.03 \\
(1.94)\end{array}$ & $\begin{array}{l}96.54 \\
(1.94)\end{array}$ & $\begin{array}{l}93.63 \\
(1.94)\end{array}$ & $\begin{array}{l}95.09 \\
(1.37)\end{array}$ \\
\hline
\end{tabular}

Note. $\quad$ SS First $=$ Same-sex partner first OS First $=$ Other-sex partner first Collab. $=$ Collaborative task Comp. $=$ Competitive task

${ }^{\mathrm{a}}$ indicates means within a row that differ significantly, $p<.05$

** indicates means within a column that differ significantly, $p<.01$ 
Table 8

Adjusted Means and Standard Errors for Femininity on the Children's State Gender Role Inventory for Participants Who Worked with a Same- or an Other-sex Partner First on a Collaborative or a Competitive Task by Sex of Participant and Sex of Partner

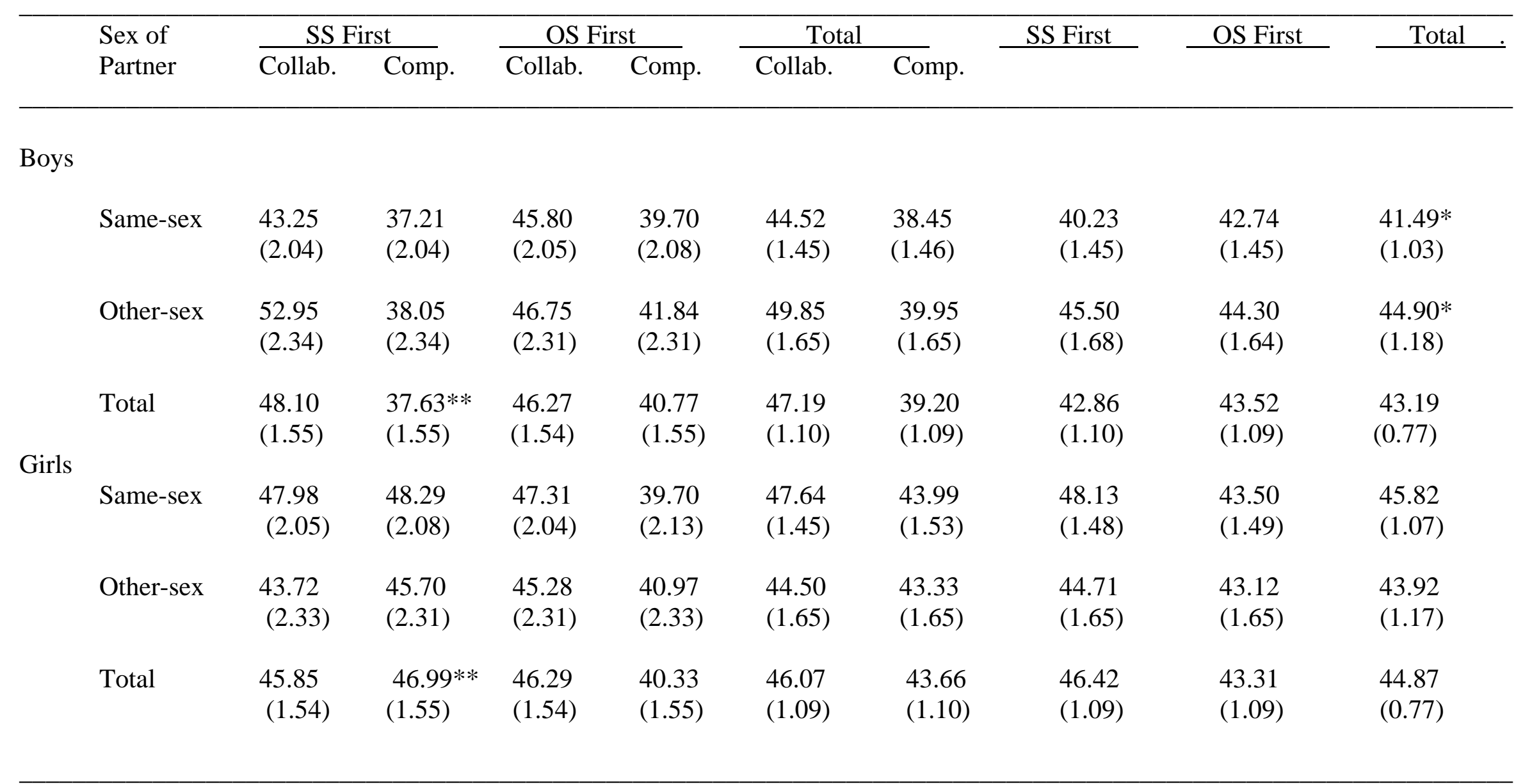


Table 8 Continued

Adjusted Means and Standard Errors for Femininity on the Children's State Gender Role Inventory for Participants Who Worked with a Same- or an Other-sex Partner First on a Collaborative or a Competitive Task by Sex of Participant and Sex of Partner

\begin{tabular}{|c|c|c|c|c|c|c|c|c|c|}
\hline \multirow{2}{*}{$\begin{array}{l}\text { Sex of } \\
\text { Partner }\end{array}$} & \multicolumn{2}{|c|}{ SS First } & \multicolumn{2}{|c|}{ OS First } & \multicolumn{2}{|c|}{ Total } & \multirow[t]{2}{*}{ SS First } & \multirow[t]{2}{*}{ OS First } & \multirow[t]{2}{*}{ Total } \\
\hline & Collab. & $\overline{\text { Comp. }}$ & Collab. & Comp. & Collab. & Comp. & & & \\
\hline Same-sex & $\begin{array}{l}45.61 \\
(1.45)\end{array}$ & $\begin{array}{l}42.75 \\
(1.46)\end{array}$ & $\begin{array}{l}46.55 \\
(1.44)\end{array}$ & $\begin{array}{l}39.69 \\
(1.53)\end{array}$ & $\begin{array}{l}46.08 \\
(1.02)\end{array}$ & $\begin{array}{l}41.22 \\
(1.09)\end{array}$ & $\begin{array}{l}44.18 \\
(1.04)\end{array}$ & $\begin{array}{l}43.12 \\
(1.05)\end{array}$ & $\begin{array}{l}43.65 \\
(0.75)\end{array}$ \\
\hline Total & $\begin{array}{c}46.98 \\
(1.10)\end{array}$ & $\begin{array}{l}42.31 \\
(1.09)\end{array}$ & $\begin{array}{l}46.28 \\
(1.09)\end{array}$ & $\begin{array}{l}40.55 \\
(1.10)\end{array}$ & $\begin{array}{l}46.63 \\
(0.77)\end{array}$ & $\begin{array}{l}41.43 \\
(0.77)\end{array}$ & $\begin{array}{l}44.64 \\
(0.77)\end{array}$ & $\begin{array}{l}43.42 \\
(0.77)\end{array}$ & $\begin{array}{l}44.03 \\
(0.55)\end{array}$ \\
\hline
\end{tabular}

Note. $\quad$ SS First $=$ Same-sex partner first OS First $=$ Other-sex partner first Collab. $=$ Collaborative task $;$ Comp. $=$ Competitive task

* indicates means within a column that differ significantly, $p<.05$

** indicates means within a column that differ significantly, $p<.01$ 
Table 9

Adjusted Means and Standard Errors for Masculinity on the Children's State Gender Role Inventory for Participants Who Worked with a Same- or an Other-sex Partner First on a Collaborative or a Competitive Task by Sex of Participant and Sex of Partner

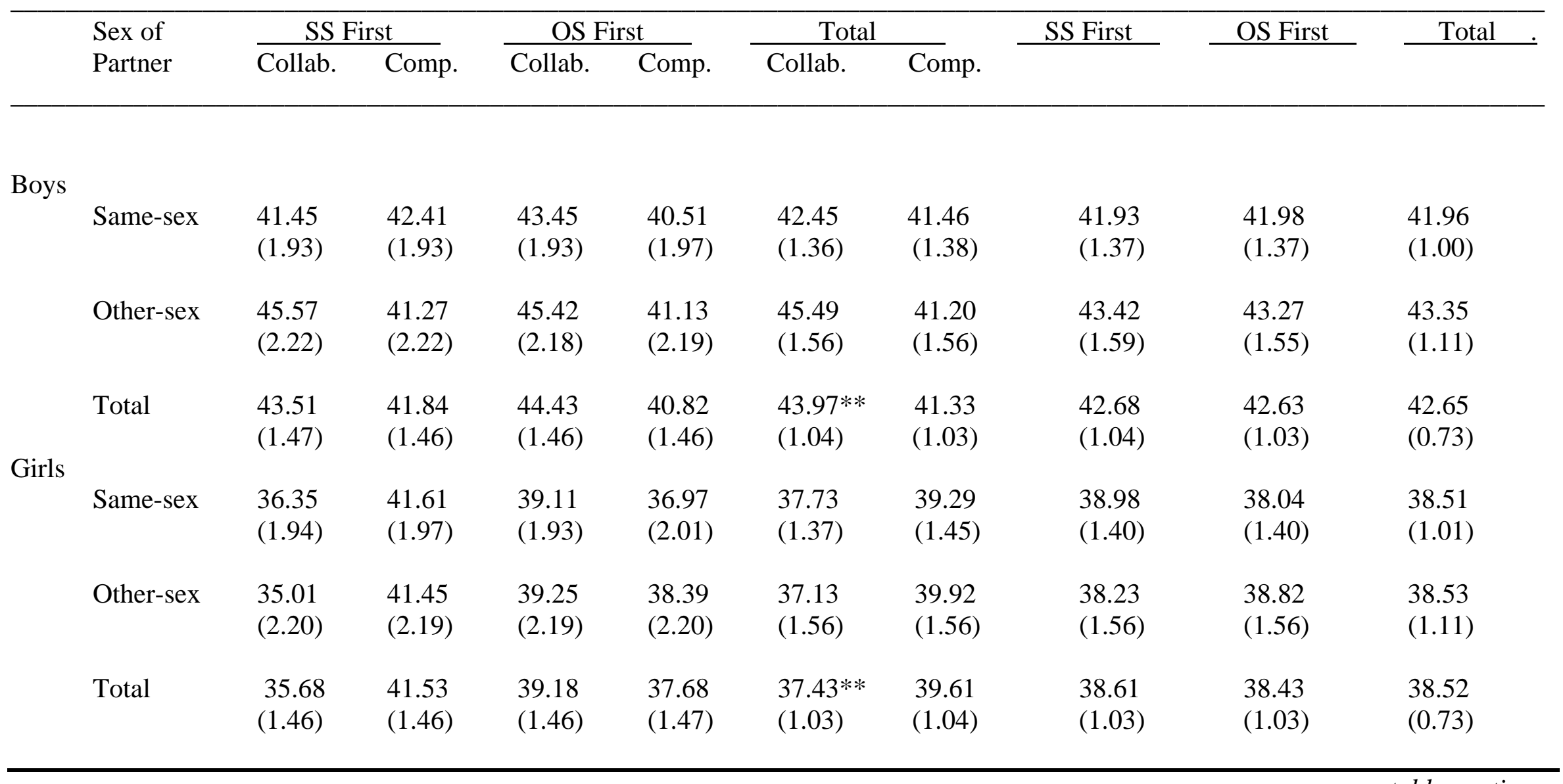


Table 9 Continued

Adjusted Means and Standard Errors for Masculinity on the Children's State Gender Role Inventory for Participants Who Worked with a Same- or an Other-sex Partner First on a Collaborative or a Competitive Task by Sex of Participant and Sex of Partner

\begin{tabular}{|c|c|c|c|c|c|c|c|c|c|}
\hline \multirow{2}{*}{$\begin{array}{l}\text { Sex of } \\
\text { Partner }\end{array}$} & \multicolumn{2}{|c|}{ SS First } & \multicolumn{2}{|c|}{ OS First } & \multicolumn{2}{|c|}{ Total } & \multirow[t]{2}{*}{ SS First } & \multirow[t]{2}{*}{ OS First } & \multirow[t]{2}{*}{ Total } \\
\hline & Collab. & Comp. & Collab. & Comp. & Collab. & Comp. & & & \\
\hline \multicolumn{10}{|l|}{ All participants } \\
\hline Same-sex & $\begin{array}{l}38.90 \\
(1.37)\end{array}$ & $\begin{array}{l}42.01 \\
(1.38)\end{array}$ & $\begin{array}{l}41.28 \\
(1.36)\end{array}$ & $\begin{array}{l}38.74 \\
(1.45)\end{array}$ & $\begin{array}{r}40.09 \\
(0.97)\end{array}$ & $\begin{array}{l}40.38 \\
(1.03)\end{array}$ & $\begin{array}{l}40.46 \\
(0.98)\end{array}$ & $\begin{array}{l}40.01 \\
(0.99)\end{array}$ & $\begin{array}{l}40.24 \\
(0.71)\end{array}$ \\
\hline Other-sex & $\begin{array}{l}40.29 \\
(1.58)\end{array}$ & $\begin{array}{l}41.36 \\
(1.56)\end{array}$ & $\begin{array}{l}42.33 \\
(1.55)\end{array}$ & $\begin{array}{r}39.76 \\
(1.55)\end{array}$ & $\begin{array}{r}41.31 \\
(1.11)\end{array}$ & $\begin{array}{l}40.56 \\
(1.11)\end{array}$ & $\begin{array}{l}40.83 \\
(1.13)\end{array}$ & $\begin{array}{l}41.05 \\
(1.10)\end{array}$ & $\begin{array}{l}40.94 \\
(0.80)\end{array}$ \\
\hline Total & $\begin{array}{l}39.60 \\
(1.03)\end{array}$ & $\begin{array}{l}41.69 \\
(1.03)\end{array}$ & $\begin{array}{l}41.81 \\
(1.03)\end{array}$ & $\begin{array}{r}39.25 \\
(1.04)\end{array}$ & $\begin{array}{l}40.70 \\
(0.73)\end{array}$ & $\begin{array}{l}40.47 \\
(0.73)\end{array}$ & $\begin{array}{l}40.64 \\
(0.73)\end{array}$ & $\begin{array}{l}40.53 \\
(0.73)\end{array}$ & $\begin{array}{l}40.59 \\
(0.52)\end{array}$ \\
\hline
\end{tabular}

Note. $\quad$ SS First $=$ Same-sex partner first OS First $=$ Other-sex partner first Collab. $=$ Collaborative task Comp. $=$ Competitive task

** indicates means within a column that differ significantly, $p<.01$ 
Table 10

Adjusted Means and Standard Errors for Mutual-Participation Goals on the Closed-ended Goal Questionnaire for Participants Who Worked with a Same- or an Other-sex Partner First on a Collaborative or a Competitive Task by Sex of Participant and Sex of Partner

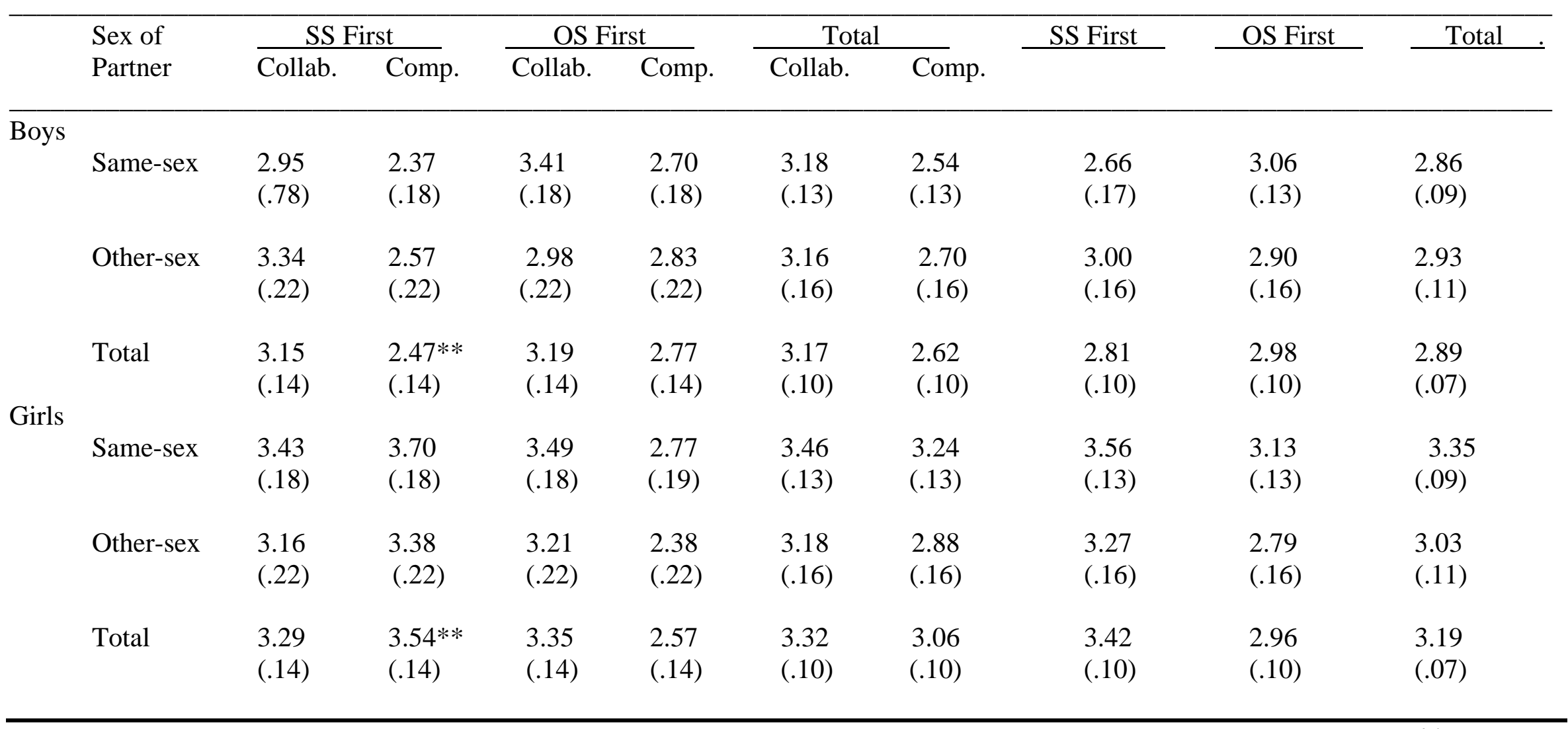


Table 10 Continued

Adjusted Means and Standard Errors for Mutual-Participation Goals on the Closed-ended Goal Questionnaire for Participants Who Worked with a Same- or an Other-sex Partner First on a Collaborative or a Competitive Task by Sex of Participant and Sex of Partner

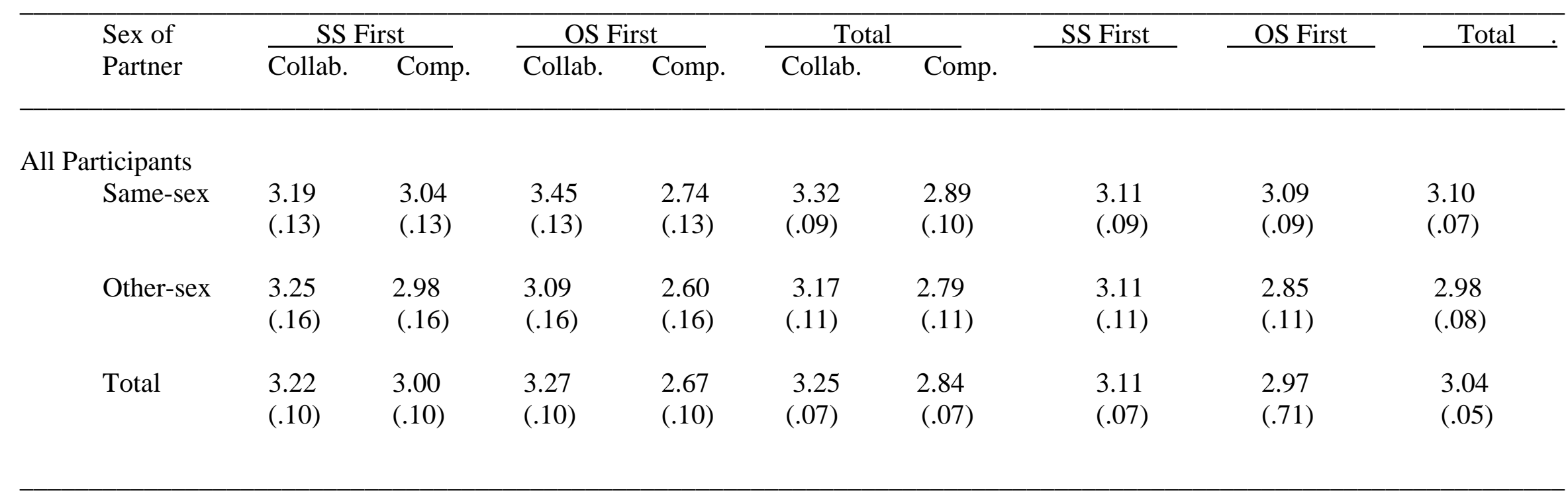

Note. SS First $=$ Same-sex partner first OS First $=$ Other-sex partner first Collab. $=$ Collaborative task Comp. $=$ Competitive task ** indicates means within a column that differ significantly, $p<.01$ 
Table 11

Adjusted Means and Standard Errors for Control Goals on the Closed-ended Goal Questionnaire for Participants Who Worked with a Same- or an Other-sex Partner First on a Collaborative or a Competitive Task by Sex of Participant and Sex of Partner

\begin{tabular}{|c|c|c|c|c|c|c|c|c|c|c|}
\hline \multirow{2}{*}{\multicolumn{2}{|c|}{$\begin{array}{l}\text { Sex of } \\
\text { Partner } \\
\end{array}$}} & \multicolumn{2}{|c|}{ SS First } & \multicolumn{2}{|c|}{ OS First } & \multicolumn{2}{|c|}{ Total } & \multirow[t]{2}{*}{ SS First } & \multirow[t]{2}{*}{ OS First } & \multirow[t]{2}{*}{ Total } \\
\hline & & Collab. & Comp. & Collab. & Comp. & Collab. & Comp. & & & \\
\hline \multicolumn{11}{|l|}{ Boys } \\
\hline & Other-sex & $\begin{array}{l}1.68 \\
(.25)\end{array}$ & $\begin{array}{l}2.35 \\
(.25)\end{array}$ & $\begin{array}{l}1.78 \\
(.25)\end{array}$ & $\begin{array}{l}1.62 \\
(.25)\end{array}$ & $\begin{array}{l}1.73 \\
(.18)\end{array}$ & $\begin{array}{l}1.98 \\
(.18)\end{array}$ & $\begin{array}{l}2.01 \\
(.18)\end{array}$ & $\begin{array}{l}1.70 \\
(.18)\end{array}$ & $\begin{array}{l}1.86 \\
(.13)\end{array}$ \\
\hline & Total & $\begin{array}{l}1.66 \\
(.17)\end{array}$ & $\begin{array}{l}2.39 \\
(.17)\end{array}$ & $\begin{array}{l}1.73 \\
(.17)\end{array}$ & $\begin{array}{l}1.64 \\
(.17)\end{array}$ & $\begin{array}{l}1.69 \\
(.12)\end{array}$ & $\begin{array}{l}2.01 \\
(.12)\end{array}$ & $\begin{array}{l}2.03^{\mathrm{a}} \\
(.12)\end{array}$ & $\begin{array}{l}1.68^{\mathrm{a}} \\
(.12)\end{array}$ & $\begin{array}{l}1.85 \\
(.09)\end{array}$ \\
\hline Girls & Same-sex & $\begin{array}{l}0.65 \\
(.24)\end{array}$ & $\begin{array}{l}1.21 \\
(.24)\end{array}$ & $\begin{array}{l}1.26 \\
(.24)\end{array}$ & $\begin{array}{l}1.34 \\
(.25)\end{array}$ & $\begin{array}{l}0.96 \\
(.17)\end{array}$ & $\begin{array}{l}1.28 \\
(.18)\end{array}$ & $\begin{array}{l}0.93 \\
(.17)\end{array}$ & $\begin{array}{l}1.30 \\
(.17)\end{array}$ & $\begin{array}{l}1.12 \\
(.12)\end{array}$ \\
\hline & Total & $\begin{array}{l}0.60 \\
(.17)\end{array}$ & $\begin{array}{l}1.32 \\
(.17)\end{array}$ & $\begin{array}{l}1.29 \\
(.17)\end{array}$ & $\begin{array}{l}1.31 \\
(.17)\end{array}$ & $\begin{array}{c}0.94 \\
(.12)\end{array}$ & $\begin{array}{l}1.31 \\
(.12)\end{array}$ & $\begin{array}{l}0.96 \\
(.12)\end{array}$ & $\begin{array}{l}1.30 \\
(.12)\end{array}$ & $\begin{array}{l}1.13 \\
(.09)\end{array}$ \\
\hline
\end{tabular}


Table 11 Continued

Adjusted Means and Standard Errors for Control Goals on the Closed-ended Goal Questionnaire for Participants Who Worked with a Same- or an Other-sex Partner First on a Collaborative or a Competitive Task by Sex of Participant and Sex of Partner

\begin{tabular}{|c|c|c|c|c|c|c|c|c|c|}
\hline \multirow{2}{*}{$\begin{array}{l}\text { Sex of } \\
\text { Partner }\end{array}$} & \multicolumn{2}{|c|}{ SS First } & \multicolumn{2}{|c|}{ OS First } & \multicolumn{2}{|c|}{ Total } & \multirow[t]{2}{*}{ SS First } & \multirow[t]{2}{*}{ OS First } & \multirow[t]{2}{*}{ Total } \\
\hline & Collab. & Comp. & Collab. & Comp. & Collab. & Comp. & & & \\
\hline \multicolumn{10}{|l|}{ All Participants } \\
\hline Same-sex & $\begin{array}{l}1.15 \\
(.17)\end{array}$ & $\begin{array}{l}1.82 \\
(.17)\end{array}$ & $\begin{array}{l}1.47 \\
(.17)\end{array}$ & $\begin{array}{l}1.50 \\
(.18)\end{array}$ & $\begin{array}{l}1.31 \\
(.12)\end{array}$ & $\begin{array}{l}1.66 \\
(.13)\end{array}$ & $\begin{array}{l}1.49 \\
(.12)\end{array}$ & $\begin{array}{l}1.49 \\
(.12)\end{array}$ & $\begin{array}{l}1.49 \\
(.09)\end{array}$ \\
\hline Other-sex & $\begin{array}{c}1.11 \\
(.18)\end{array}$ & $\begin{array}{l}1.88 \\
(.18)\end{array}$ & $\begin{array}{l}1.54 \\
(.18)\end{array}$ & $\begin{array}{l}1.45 \\
(.18)\end{array}$ & $\begin{array}{l}1.33 \\
(.13)\end{array}$ & $\begin{array}{l}1.66 \\
(.13)\end{array}$ & $\begin{array}{l}1.50 \\
(.13)\end{array}$ & $\begin{array}{l}1.50 \\
(.13)\end{array}$ & $\begin{array}{c}1.50 \\
(.09)\end{array}$ \\
\hline Total & $\begin{array}{c}1.13^{\mathrm{b}} \\
(.12)\end{array}$ & $\begin{array}{l}1.85^{\mathrm{b}} \\
(.12)\end{array}$ & $\begin{array}{l}1.51 \\
(.12)\end{array}$ & $\begin{array}{l}1.47 \\
(.12)\end{array}$ & $\begin{array}{l}1.32 \\
(.09)\end{array}$ & $\begin{array}{l}1.66 \\
(.09)\end{array}$ & $\begin{array}{l}1.49 \\
(.09)\end{array}$ & $\begin{array}{l}1.49 \\
(.09)\end{array}$ & $\begin{array}{l}1.49 \\
(.06)\end{array}$ \\
\hline
\end{tabular}

Note. $\quad$ SS First $=$ Same-sex partner first OS First $=$ Other-sex partner first Collab. $=$ Collaborative task $;$ Comp. $=$ Competitive task

${ }^{a}$ indicates means within a row that differ significantly, $p<.05$

${ }^{\mathrm{b}}$ indicates means within a row that differ significantly, $p<.01$ 
Table 12

Adjusted Means and Standard Errors for Task-Performance Goals on the Closed-ended Goal Questionnaire for Participants Who Worked with a Same- or an Other-sex Partner First on a Collaborative or a Competitive Task by Sex of Participant and Sex of Partner

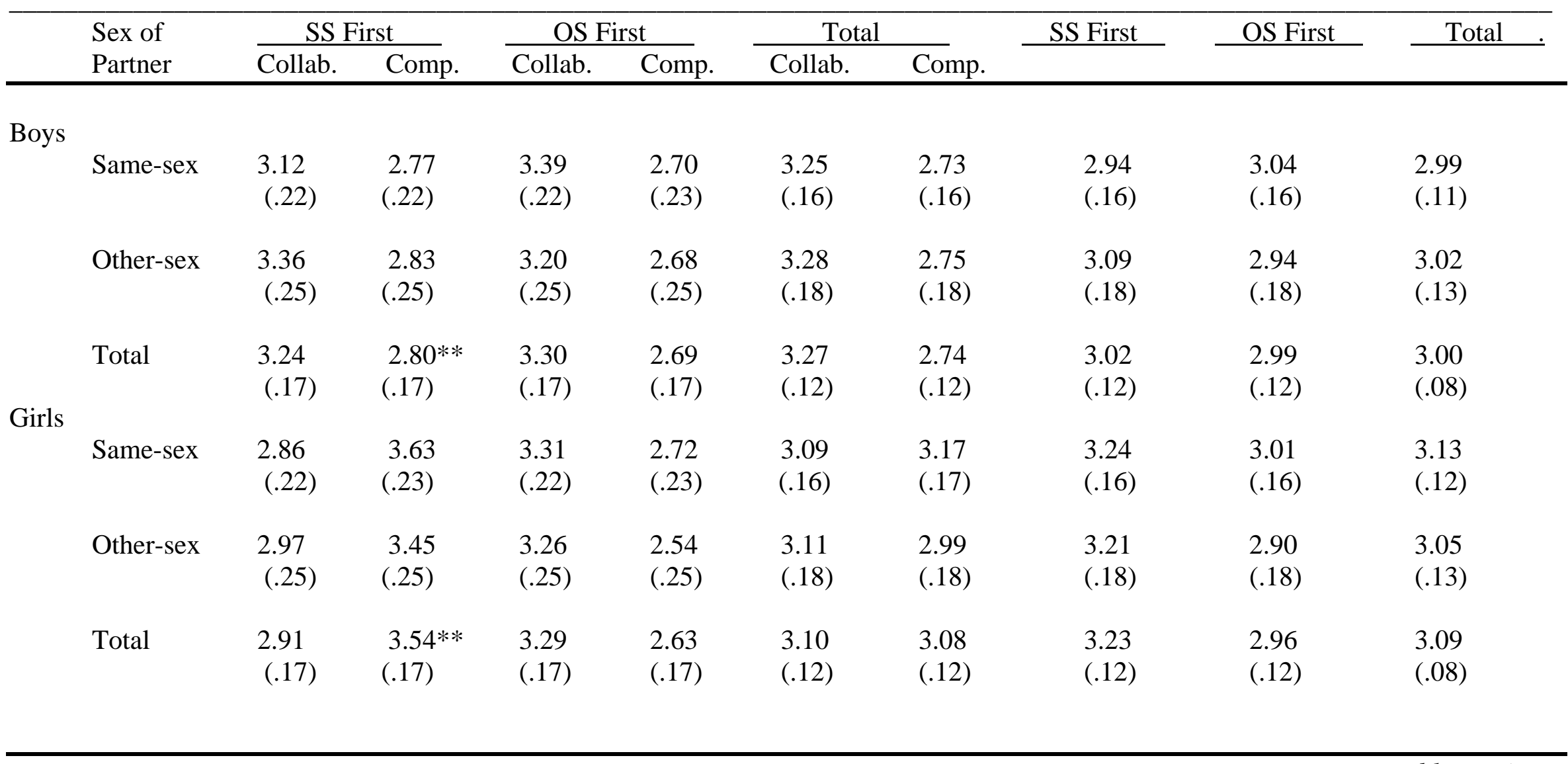


Table 12 Continued

Adjusted Means and Standard Errors for Task-Performance Goals on the Closed-ended Goal Questionnaire for Participants Who Worked with a Same- or an Other-sex Partner First on a Collaborative or a Competitive Task by Sex of Participant and Sex of Partner

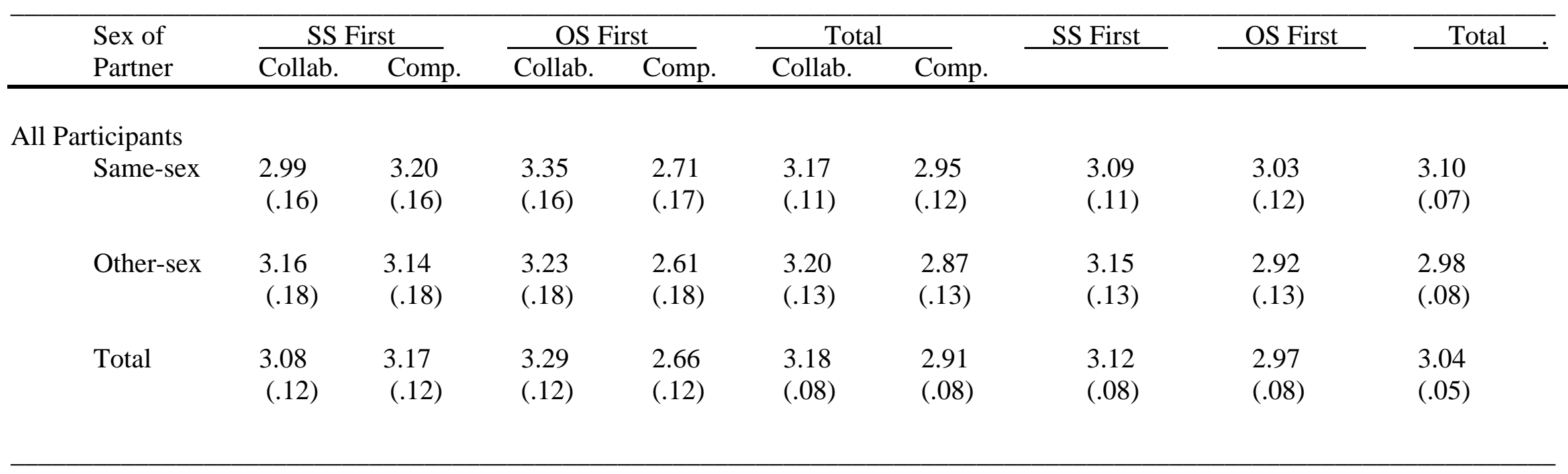

Note. $\quad$ SS First $=$ Same-sex partner first OS First $=$ Other-sex partner first Collab. $=$ Collaborative task Comp. $=$ Competitive task

** indicates means within a column that differ significantly, $p<.01$ 
Table 13

Adjusted Means and Standard Errors for Mutual-Participation Goals on the Open-ended Goal Questionnaire for Participants Who Worked with a Same- or an Other-sex Partner First on a Collaborative or a Competitive Task by Sex of Participant and Sex of Partner

\begin{tabular}{|c|c|c|c|c|c|c|c|c|c|c|}
\hline & \multirow{2}{*}{$\begin{array}{l}\text { Sex of } \\
\text { Partner }\end{array}$} & \multicolumn{2}{|c|}{ SS First } & \multicolumn{2}{|c|}{ OS First } & \multicolumn{2}{|c|}{ Total } & \multirow[t]{2}{*}{ SS First } & \multirow[t]{2}{*}{ OS First } & \multirow[t]{2}{*}{ Total } \\
\hline & & Collab. & Comp. & Collab. & Comp. & Collab. & Comp. & & & \\
\hline \multicolumn{11}{|l|}{$\overline{\text { Boys }}$} \\
\hline & Same-sex & $\begin{array}{l}.23 \\
(.11)\end{array}$ & $\begin{array}{c}.03 \\
(.11)\end{array}$ & $\begin{array}{c}.36 \\
(.11)\end{array}$ & $\begin{array}{l}.15 \\
(.11)\end{array}$ & $\begin{array}{l}.29 \\
(.08)\end{array}$ & $\begin{array}{c}.09 \\
(.08)\end{array}$ & $\begin{array}{c}.13 \\
(.08)\end{array}$ & $\begin{array}{c}.26 \\
(.08)\end{array}$ & $\begin{array}{l}.19 \\
(.05)\end{array}$ \\
\hline & Other-sex & $\begin{array}{l}.14 \\
(.08)\end{array}$ & $\begin{array}{c}.01 \\
(.08)\end{array}$ & $\begin{array}{c}.27 \\
(.08)\end{array}$ & $\begin{array}{l}.04 \\
(.08)\end{array}$ & $\begin{array}{l}.20 \\
(.05)\end{array}$ & $\begin{array}{c}.02 \\
(.05)\end{array}$ & $\begin{array}{l}.07 \\
(.06)\end{array}$ & $\begin{array}{l}.15 \\
(.05)\end{array}$ & $\begin{array}{l}.11 \\
(.04)\end{array}$ \\
\hline \multicolumn{11}{|l|}{ Girls } \\
\hline & Same-sex & $\begin{array}{l}.35 \\
(.11)\end{array}$ & $\begin{array}{c}.27 \\
(.11)\end{array}$ & $\begin{array}{c}.32 \\
(.11)\end{array}$ & $\begin{array}{l}.04 \\
(.11)\end{array}$ & $\begin{array}{l}.34 \\
(.08)\end{array}$ & $\begin{array}{r}.15 \\
(.08)\end{array}$ & $\begin{array}{c}.31 \\
(.08)\end{array}$ & $\begin{array}{c}.18 \\
(.08)\end{array}$ & $\begin{array}{c}.24 \\
(.06)\end{array}$ \\
\hline & Total & $\begin{array}{l}.36 \\
(.07)\end{array}$ & $\begin{array}{c}.16 \\
(.07)\end{array}$ & $\begin{array}{r}.34 \\
(.07)\end{array}$ & $\begin{array}{c}.02 \\
(.07)\end{array}$ & $\begin{array}{c}.35 \\
(.05)\end{array}$ & $\begin{array}{r}.09 \\
(.05)\end{array}$ & $\begin{array}{c}.26 \\
(.05)\end{array}$ & $\begin{array}{l}.18 \\
(.05)\end{array}$ & $\begin{array}{c}.22 \\
(.03)\end{array}$ \\
\hline
\end{tabular}


Table 13 Continued

Adjusted Means and Standard Errors for Mutual-Participation Goals on the Open-ended Goal Questionnaire for Participants Who Worked with a Same- or an Other-sex Partner First on a Collaborative or a Competitive Task by Sex of Participant and Sex of Partner

\begin{tabular}{|c|c|c|c|c|c|c|c|c|c|}
\hline \multirow{2}{*}{$\begin{array}{l}\text { Sex of } \\
\text { Partner }\end{array}$} & \multicolumn{2}{|c|}{ SS First } & \multicolumn{2}{|c|}{ OS First } & \multicolumn{2}{|c|}{ Total } & \multirow[t]{2}{*}{ SS First } & \multirow[t]{2}{*}{ OS First } & \multirow[t]{2}{*}{ Total } \\
\hline & Collab. & Comp. & Collab. & Comp. & Collab. & Comp. & & & \\
\hline \multicolumn{10}{|l|}{ All Participants } \\
\hline Same-sex & $\begin{array}{c}.29 \\
(.08)\end{array}$ & $\begin{array}{c}.15 \\
(.08)\end{array}$ & $\begin{array}{l}.34 \\
(.08)\end{array}$ & $\begin{array}{c}.09 \\
(.08)\end{array}$ & $\begin{array}{c}.31 \\
(.05)\end{array}$ & $\begin{array}{l}.12 \\
. .06\end{array}$ & $\begin{array}{l}.22 \\
(.06)\end{array}$ & $\begin{array}{c}.22 \\
(.06)\end{array}$ & $\begin{array}{c}.22 \\
(.04)\end{array}$ \\
\hline Other-sex & $\begin{array}{c}.25 \\
(.06)\end{array}$ & $\begin{array}{c}.03 \\
(.05)\end{array}$ & $\begin{array}{c}.32 \\
(.05)\end{array}$ & $\begin{array}{c}.02 \\
(.05)\end{array}$ & $\begin{array}{l}.29 \\
(.04)\end{array}$ & $\begin{array}{r}.02 \\
(.04\end{array}$ & $\begin{array}{l}.14 \\
(.04\end{array}$ & $\begin{array}{l}.17 \\
(.04)\end{array}$ & $\begin{array}{r}.16 \\
(.03)\end{array}$ \\
\hline Total & $\begin{array}{c}.27 \\
(.05)\end{array}$ & $\begin{array}{c}.09 \\
(.05)\end{array}$ & $\begin{array}{c}.33 \\
(.05)\end{array}$ & $\begin{array}{r}.06 \\
(.06)\end{array}$ & $\begin{array}{l}.30 * * \\
(.03)\end{array}$ & $\begin{array}{l}.07 * * \\
(.03)\end{array}$ & $\begin{array}{c}.18 \\
(.03)\end{array}$ & $\begin{array}{c}.19 \\
(.03)\end{array}$ & $\begin{array}{c}.19 \\
(.02)\end{array}$ \\
\hline
\end{tabular}

Note. $\quad$ SS First $=$ Same-sex partner first OS First $=$ Other-sex partner first Collab. $=$ Collaborative task $;$ Comp. $=$ Competitive task

** indicates means within a column that differ significantly, $p<.01$ 
Table 14

Adjusted Means and Standard Errors for Control Goals on the Open-ended Goal Questionnaire for Participants Who Worked with a Sameor an Other-sex Partner First on a Collaborative or a Competitive Task by Sex of Participant and Sex of Partner

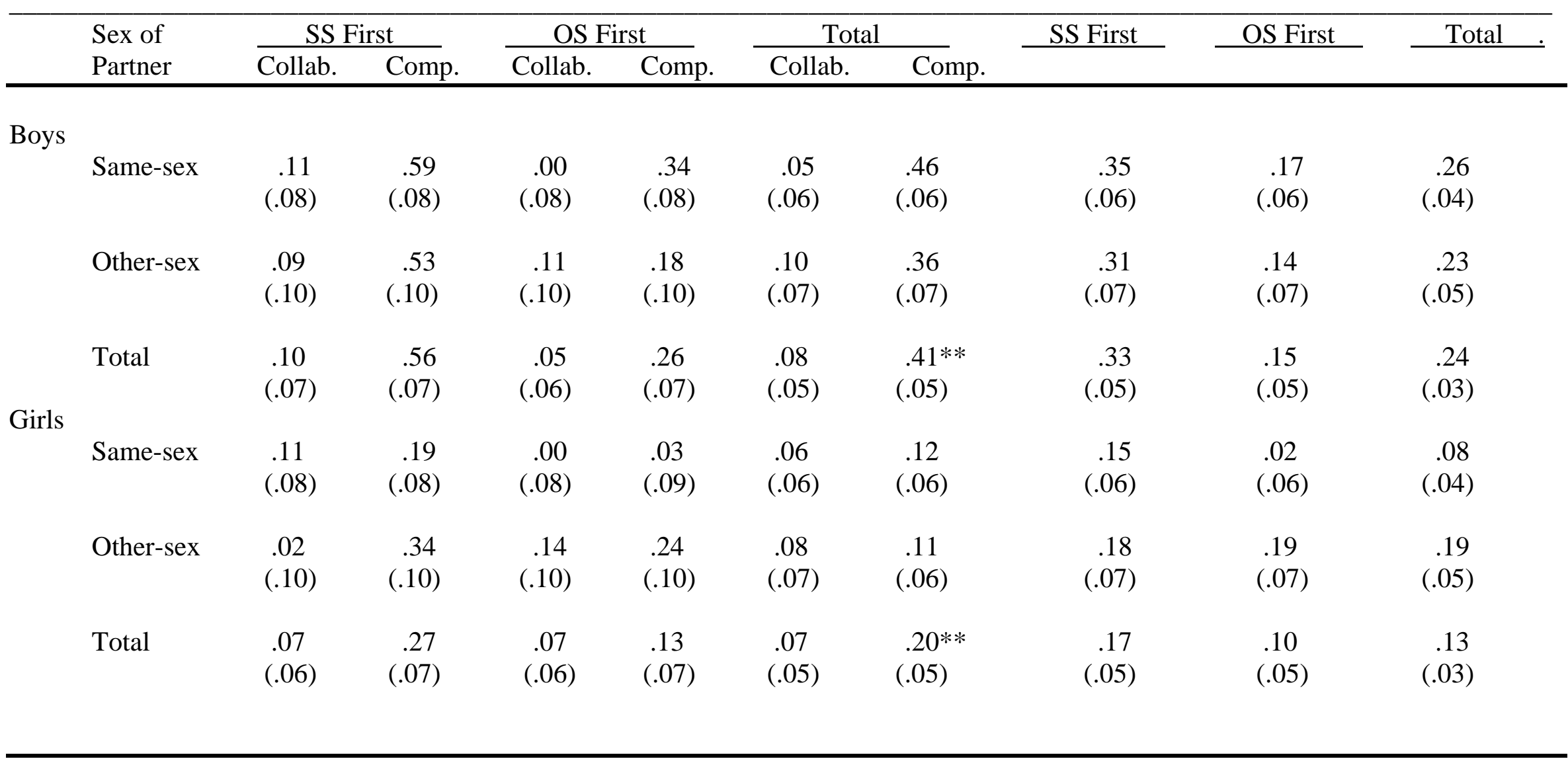


Table 14 Continued

Adjusted Means and Standard Errors for Control Goals on the Open-ended Goal Questionnaire for Participants Who Worked with a Sameor an Other-sex Partner First on a Collaborative or a Competitive Task by Sex of Participant and Sex of Partner

\begin{tabular}{|c|c|c|c|c|c|c|c|c|c|}
\hline \multirow{2}{*}{$\begin{array}{l}\text { Sex of } \\
\text { Partner }\end{array}$} & \multicolumn{2}{|c|}{ SS First } & \multicolumn{2}{|c|}{ OS First } & \multicolumn{2}{|c|}{ Total } & \multirow[t]{2}{*}{ SS First } & \multirow[t]{2}{*}{ OS First } & \multirow[t]{2}{*}{ Total } \\
\hline & Collab. & Comp. & Collab. & Comp. & Collab. & Comp. & & & \\
\hline All Participants & & & & & & & & & \\
\hline Other-sex & $\begin{array}{l}.06 \\
(.07)\end{array}$ & $\begin{array}{c}.44 \\
(.07)\end{array}$ & $\begin{array}{c}.13 \\
(.07)\end{array}$ & $\begin{array}{l}.21 \\
(.07)\end{array}$ & $\begin{array}{l}.09 \\
(.05)\end{array}$ & $\begin{array}{r}.32 \\
(.05)\end{array}$ & $\begin{array}{c}.25 \\
(.05)\end{array}$ & $\begin{array}{c}.17 \\
(.05)\end{array}$ & $\begin{array}{c}.21 \\
(.04)\end{array}$ \\
\hline Total & $\begin{array}{l}.08 \\
(.05)\end{array}$ & $\begin{array}{c}.41^{\mathrm{b}} \\
(.05)\end{array}$ & $\begin{array}{c}.06 \\
(.05)\end{array}$ & $\begin{array}{c}.20^{\mathrm{b}} \\
(.05)\end{array}$ & $\begin{array}{l}.07 \\
(.03)\end{array}$ & $\begin{array}{r}.30 \\
(.03)\end{array}$ & $\begin{array}{c}.25 \\
(.03)\end{array}$ & $\begin{array}{r}.13 \\
(.03)\end{array}$ & $\begin{array}{c}.19 \\
(.02)\end{array}$ \\
\hline
\end{tabular}

Note. $\quad$ SS First $=$ Same-sex partner first; OS First $=$ Other-sex partner first Collab. $=$ Collaborative task; Comp. $=$ Competitive task

${ }^{\mathrm{b}}$ indicates means within a row that differ significantly, $p<.01$ 
Table 15

Adjusted Means and Standard Errors for Task-Performance Goals on the Open-ended Goal Questionnaire for Participants Who Worked with a Same- or an Other-sex Partner First on a Collaborative or a Competitive Task by Sex of Participant and Sex of Partner

\begin{tabular}{|c|c|c|c|c|c|c|c|c|c|c|}
\hline \multirow{2}{*}{\multicolumn{2}{|c|}{$\begin{array}{ll}\text { Sex of } \\
\text { Partner } \\
\end{array}$}} & \multicolumn{2}{|c|}{ SS First } & \multicolumn{2}{|c|}{ OS First } & \multicolumn{2}{|c|}{ Total } & \multirow[t]{2}{*}{ SS First } & \multirow{2}{*}{ OS First } & \multirow[t]{2}{*}{ Total } \\
\hline & & Collab. & Comp. & Collab. & Comp. & Collab. & Comp. & & & \\
\hline \multicolumn{11}{|l|}{ Boys } \\
\hline & Same-sex & $\begin{array}{r}.52 \\
(.13)\end{array}$ & $\begin{array}{c}.35 \\
(.13)\end{array}$ & $\begin{array}{c}.62 \\
(.13)\end{array}$ & $\begin{array}{l}.30 \\
(.13)\end{array}$ & $\begin{array}{c}.57 \\
(.09)\end{array}$ & $\begin{array}{l}.32 \\
(.09)\end{array}$ & $\begin{array}{l}.44 \\
(.09)\end{array}$ & $\begin{array}{l}.46 \\
(.09)\end{array}$ & $\begin{array}{l}.45 \\
(.06)\end{array}$ \\
\hline & Other-sex & $\begin{array}{l}.07 \\
(.04)\end{array}$ & $\begin{array}{c}.01 \\
(.04)\end{array}$ & $\begin{array}{l}.15 \\
(.04)\end{array}$ & $\begin{array}{c}.03 \\
(.04)\end{array}$ & $\begin{array}{l}.11 \\
(.03)\end{array}$ & $\begin{array}{l}.01 \\
(.03)\end{array}$ & $\begin{array}{l}.03 \\
(.03)\end{array}$ & $\begin{array}{l}.09 \\
(.03)\end{array}$ & $\begin{array}{l}.06 \\
(.02)\end{array}$ \\
\hline & Total & $\begin{array}{c}.30 \\
(.07)\end{array}$ & $\begin{array}{l}.17 \\
(.16)\end{array}$ & $\begin{array}{c}.38 \\
(.07)\end{array}$ & $\begin{array}{c}.16 \\
(.07)\end{array}$ & $\begin{array}{c}.34 \\
(.05)\end{array}$ & $\begin{array}{l}.17 \\
(.05)\end{array}$ & $\begin{array}{l}.23 \\
(.05)\end{array}$ & $\begin{array}{l}.27 \\
(.05)\end{array}$ & $\begin{array}{l}.25 \\
(.03)\end{array}$ \\
\hline Girls & Same-sex & $\begin{array}{l}.32 \\
(.13)\end{array}$ & $\begin{array}{l}.35 \\
(.13)\end{array}$ & $\begin{array}{l}.60 \\
(.13)\end{array}$ & $\begin{array}{r}.42 \\
(.13)\end{array}$ & $\begin{array}{c}.46 \\
(.09)\end{array}$ & $\begin{array}{l}.38 \\
(.09)\end{array}$ & $\begin{array}{l}.33 \\
(.09)\end{array}$ & $\begin{array}{l}.51 \\
(.09)\end{array}$ & $\begin{array}{l}.42 \\
(.07)\end{array}$ \\
\hline & Other-sex & $\begin{array}{l}.20 \\
(.04)\end{array}$ & $\begin{array}{c}.02 \\
(.04)\end{array}$ & $\begin{array}{l}.22 \\
(.04)\end{array}$ & $\begin{array}{r}.04 \\
(.04)\end{array}$ & $\begin{array}{l}.21 \\
(.03)\end{array}$ & $\begin{array}{l}.03 \\
(.03)\end{array}$ & $\begin{array}{l}.11 \\
(.03)\end{array}$ & $\begin{array}{l}.13 \\
(.03)\end{array}$ & $\begin{array}{l}.12 \\
(.02)\end{array}$ \\
\hline & Total & $\begin{array}{c}.26 \\
(.07)\end{array}$ & $\begin{array}{l}.18 \\
(.07)\end{array}$ & $\begin{array}{l}.41 \\
(.07)\end{array}$ & $\begin{array}{c}.23 \\
(.07)\end{array}$ & $\begin{array}{l}.34 \\
(.05)\end{array}$ & $\begin{array}{l}.21 \\
(.05)\end{array}$ & $\begin{array}{l}.22 \\
(.05)\end{array}$ & $\begin{array}{l}.32 \\
(.05)\end{array}$ & $\begin{array}{l}.27 \\
(.03)\end{array}$ \\
\hline
\end{tabular}


Table 15 Continued

Adjusted Means and Standard Errors for Task-Performance Goals on the Open-ended Goal Questionnaire for Participants Who Worked with a Same- or an Other-sex Partner First on a Collaborative or a Competitive Task by Sex of Participant and Sex of Partner

\begin{tabular}{|c|c|c|c|c|c|c|c|c|c|}
\hline \multirow{2}{*}{$\begin{array}{l}\text { Sex of } \\
\text { Partner }\end{array}$} & \multicolumn{2}{|c|}{ SS First } & \multicolumn{2}{|c|}{ OS First } & \multicolumn{2}{|c|}{ Total } & \multirow[t]{2}{*}{ SS First } & \multirow[t]{2}{*}{ OS First } & \multirow[t]{2}{*}{ Total } \\
\hline & Collab. & Comp. & Collab. & Comp. & Collab. & Comp. & & & \\
\hline \multicolumn{10}{|l|}{ All Participants } \\
\hline Same-sex & $\begin{array}{c}.42 \\
(.09)\end{array}$ & $\begin{array}{c}.35 \\
(.09)\end{array}$ & $\begin{array}{c}.61 \\
(.09)\end{array}$ & $\begin{array}{c}.36 \\
(.09)\end{array}$ & $\begin{array}{r}.52 \\
(.06)\end{array}$ & $\begin{array}{c}.35 \\
(.07)\end{array}$ & $\begin{array}{l}.38 \\
(.06)\end{array}$ & $\begin{array}{l}.48 \\
(.07)\end{array}$ & $\begin{array}{l}.43 * * \\
(.05)\end{array}$ \\
\hline Other-sex & $\begin{array}{c}.14 \\
(.03)\end{array}$ & $\begin{array}{c}.01 \\
(.03)\end{array}$ & $\begin{array}{l}.18 \\
(.03)\end{array}$ & $\begin{array}{c}.03 \\
(.03)\end{array}$ & $\begin{array}{c}.16 \\
(.02)\end{array}$ & $\begin{array}{c}.02 \\
(.02)\end{array}$ & $\begin{array}{l}.07 \\
(.02)\end{array}$ & $\begin{array}{l}.11 \\
(.02)\end{array}$ & $\begin{array}{l}.09 * * \\
(.02)\end{array}$ \\
\hline Total & $\begin{array}{c}.28 \\
(.05)\end{array}$ & $\begin{array}{c}.18 \\
(.05)\end{array}$ & $\begin{array}{l}.40 \\
(.05)\end{array}$ & $\begin{array}{c}.20 \\
(.05)\end{array}$ & $\begin{array}{l}.34^{\mathrm{b}} \\
(.03)\end{array}$ & $\begin{array}{c}.19^{\mathrm{b}} \\
(.03)\end{array}$ & $\begin{array}{l}.23 \\
(.03)\end{array}$ & $\begin{array}{l}.30 \\
(.03)\end{array}$ & $\begin{array}{c}.26 \\
(.02)\end{array}$ \\
\hline
\end{tabular}

Note. $\quad$ SS First $=$ Same-sex partner first OS First $=$ Other-sex partner first Collab. $=$ Collaborative task $;$ Comp. $=$ Competitive task

** indicates means within a column that differ significantly, $p<.01$

${ }^{\mathrm{b}}$ indicates means within a row that differ significantly, $p<.01$ 
Appendix A

\section{Demographic Questionnaire}

1. Sex (circle one)

Male

Female

2. Age

years

3. Race

\section{African American}

Asian

Caucasian

Hispanic

Other

4. Grade in school

5. What grades do you usually get in your classes?
Mostly A's
Mostly B's
Mostly C's
Mostly D's
Mostly F's

6. Current overall g.p.a.

7. What city/town and state do you live in?

City/town

State

8. Parent's combined yearly income

$$
\begin{array}{ll}
\text { Less than } \$ 10,000 & \\
\$ 10,001-\$ 20,000 & \\
\$ 20,001-\$ 30,000 & \\
\$ 30,001-\$ 40,000 & \\
\$ 40,001-\$ 50,000 & \\
\$ 50,001-\$ 60,000 & - \\
\text { More than } \$ 60,000 & -
\end{array}
$$

9. Number of siblings

10. How many of your siblings are male?

How many of your siblings are female? 
11. What order were you born in relation to your siblings? (check one)

First

Second

Third

Fourth

Other

Specify

12. Religion

Jewish

Protestant

Roman Catholic

Other

13. List the extra-curricular activities you are involved with:

14. Have you ever played the game Jenga ${ }^{\circledR}$ before today?

Yes

No

If Yes, how many times?

Less than 5

5-10

10-20

More than 20 
INSTRUCTIONS: $\quad$ Read each adjective or statement. Place a number from 1 (Not at all true of me) to 7 (Very true of me) on the line according to how true the adjective or statement was about yourself while you were working on the Jenga ${ }^{\circledR}$ task.

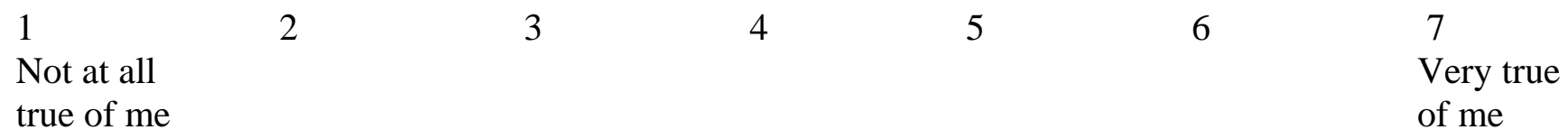

1.

2.

3.

4.

5.

6.

7.

8.

9.

10.

11.

12.

13.

14.

15.

16.

17.

18.

Self-reliant - Relying on your own abilities; independent

Yielding - doing what is requested or ordered of you

Helpful - giving help to others

Defends own beliefs - standing up for what you believe in

Cheerful - happy; having a positive mood

Moody - having a changing mood; grumpy

Independent - your behavior and thoughts are not controlled by another person

Shy - lacking self confidence around other people; timid

Conscientious - doing things with careful attention

Athletic - physically strong or active

Affectionate - showing affection; loving

Theatrical - having dramatic and exaggerated behaviors

Assertive - using your authority; to insist on your rights

Flatterable - to enjoy receiving compliments

Happy - feeling or showing pleasure and contentment

Strong personality - having definite or distinct behaviors and thoughts

Loyal - faithful to a person, idea etc.

Unpredictable - impossible to predict your behaviors/thoughts 
4

5

6

7

Not at all

true of me

Very true

of me

19.

Forceful - aggressive and influential

20.

Feminine - having the qualities associated with women

21.

Reliable - consistently good in performance

22.

Analytical - thinking deeply about a situation or problem

23.

Sympathetic - feelings of understanding towards another person

24.

Jealous - wanting something that another person has

25.

Has leadership abilities - able to guide a group of people

26.

Sensitive to the needs of others - aware of other people's needs

27.

Truthful - telling the truth often

28.

Willing to take risks - putting yourself in a situation with potential for injury/loss

29.

Understanding - having sympathy for others' views or feelings

30.

Secretive - keeping things to yourself

31.

Makes decisions easily - finding it easy to decide what to do in situations

32.

Compassionate - feelings of pity that makes you want to help others

33.

Sincere - not deceiving other people

34.

Self-sufficient - able to get what you need without help

35.

Eager to soothe hurt feelings - want to make others feel better

36.

Conceited - too proud of yourself

37.

Dominant - to have control and influence over other people

38.

Soft spoken - having a soft voice

39.

Likable - easily liked by others 
4

5

6

7

Not at all

true of me

Very true

of me

40.

Masculine - having the qualities associated with men

41.

Warm - kind

42.

Solemn - not smiling or not being cheerful

43.

Willing to take a stand - standing up for what you believe in

44.

Tender - sensitive, loving, gentle

45.

Friendly - kind and helpful to other people

46.

Aggressive - forceful

47.

Gullible - easily deceived

48.

Inefficient - wasteful with time and resources

49.

Acts as a leader - acts self-confident and assertive with others

50.

Childlike - acts like a child

51.

Adaptable - changes in response to situations

52.

Individualistic - independent in what you think and do

53.

Does not use harsh language - does not swear

54.

Unsystematic - acts randomly; not according to a plan

55.

Competitive - enjoying a contest between yourself and others

56.

Loves children - loves children

57.

Tactful - avoids offending other people

58.

Ambitious - desire to achieve things

59.

Gentle - mild; not rough or mean

60.

Conventional - traditional attitude 
INSTRUCTIONS: Read each statement. Place a number from 1 (not at all true of me) to 4 (very true of me) on the line according to how true the statement was about yourself while you were working on the Jenga ${ }^{\circledR}$ task. 1 not at all true of me

1.

2.

3.

4.

5.

6.

7.

8.

9.

10.

11.

12.

13.

14.

15.

16.

17.

18.

19. 2 a little true of me 3 mostly true of me 4 very true of me

It was easy for me to make up my mind about things.

I I cared about what happened to my partner.

I was honest.

.

I thought I was better than my partner.

I could control my partner.

I spoke softly.

My partner liked me.

I was a warm person.

I was a serious person.

When a decision had to be made, it was easy for me to take a stand.

_ I I was a kind and caring person.

13. _ I got pretty angry when my partner got in my way.

_ _ It was easy for my partner to get me to believe what they told me.

I5. I was the leader during the task.

6. _ It was easy for me to fit into the new situation.

I I did not swear.

When I did the task, I really wanted to win.

If my partner's feelings were hurt, I tried to make my partner feel better.

7. I I would have rather done things my own way than take directions from my partner. 
1

not at all true

of me

20.

21.

22.

23.

24.

25.

26.

27.

28.

29.

30.

31.

32.

33.

34.

35.

36.

37.

38.

39.

.
2

a little true

of me
3

mostly true

of me
4

very true

of me

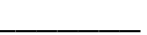

I was careful not to say things that would hurt my partner's feelings.

I was a gentle person.

I liked to do things my partner did.

I was sure of my abilities.

When there was a disagreement, I usually gave in and let my partner have his/her way.

I liked to help my partner.

I stood up for what I believed in.

I was a cheerful person.

I was a moody person.

I would rather have done the task on my own than ask my partner for help.

I felt shy around my partner.

My partner could depend on me.

I liked my partner so I did nice things to show him/her how I felt.

I liked working on the task in front of my partner.

It was easy for me to tell my partner what I thought, even when I knew he/she probably disagreed with me.

I felt good when my partner said nice things about me.

I was a happy person.

I made a strong impression on my partner.

I never knew what I was going to do from one minute to the next.

I could get my partner to do what I wanted him/her to do most of the time. 
1

not at all true

of me

40.

41.

42.

43.

44.

45.

46.

47.

48.

.

2.

.

.

46

.
2

a little true

of me
3

mostly true

of me
4

very true

of me

I always did what I said I would do.

I liked to think about and solve problems.

It made me feel bad when my partner was feeling bad.

I felt bad when my partner had some skill/idea that I didn't have.

I was good at taking charge of things.

I usually could tell when my partner needed help.

I tried to tell the truth.

I was willing to take risks.

I was good at understanding my partner's problems. 
INSTRUCTIONS: Read each question. Answer the question by choosing a number from the scale. Circle the number. There are no right or wrong answers, we are just interested in your opinion.

1. How well do you think you will do on the task?

$\begin{array}{lllll}1 & 2 & 3 & 4 & 5 \\ \text { Poor } & \text { O.k. } & \text { Not sure } & \text { Good } & \text { Excellent }\end{array}$

2. How much will you like doing the task?

$\begin{array}{lllll}1 & 2 & 3 & 4 & 5 \\ \text { Really } & \text { Kind of } & \text { In the } & \text { Will kind } & \text { Will really } \\ \text { won't like } & \text { won't like } & \text { middle } & \text { of like } & \text { like }\end{array}$

3. How much will you like doing the task with a partner?

$\begin{array}{lllll}1 & 2 & 3 & 4 & 5 \\ \text { Really } & \text { Kind of } & \text { In the } & \text { Will kind } & \text { Will really like } \\ \text { won't like } & \text { won't like } & \text { middle } & \text { of like } & \end{array}$

4. How much do you think you will compete against your partner so you can win the game?

$\begin{array}{lllll}1 & 2 & 3 & 4 & 5 \\ \text { Not at all } & \text { A little } & \text { In the } & \text { A lot } & \text { Very much } \\ & \text { middle } & & \end{array}$

5. How much do you think that you will cooperate (work together) to build the highest tower possible?

$\begin{array}{lllll}1 & 2 & 3 & 4 & 5 \\ \text { Not at all } & \text { A little } & \text { In the } & \text { A lot } & \text { Very much } \\ & \text { middle } & & \end{array}$


PART I.

INSTRUCTIONS: In about a paragraph, describe in your own words, what happened today when you worked on the task.

\section{PART II.}

INSTRUCTIONS: Read each question. Answer the question by choosing a number from the scale. Circle the number. There are no right or wrong answers, we are just interested in your opinion.

1. How well do you think you did on the task?

$\begin{array}{lllll}1 & 2 & 3 & 4 & 5 \\ \text { Very } & \text { Poor } & \text { OK } & \text { Good } & \text { Excellent } \\ \text { Poor } & & & \end{array}$

2. How much did you like doing the task?

$\begin{array}{lllll}1 & 2 & 3 & 4 & 5 \\ \text { Really } & \text { Kind of } & \text { In the } & \text { Kind of } & \text { Really } \\ \text { didn't like } & \text { didn't like } & \text { middle } & \text { liked } & \text { liked }\end{array}$

3. How much did you like doing the task with a partner?

$\begin{array}{lllll}1 & 2 & 3 & 4 & 5 \\ \text { Really } & \text { Kind of } & \text { In the } & \text { Kind of } & \text { Really } \\ \text { didn't like } & \text { didn't like } & \text { middle } & \text { liked } & \text { liked }\end{array}$

4. How much did you compete against your partner so you could win the game?

$\begin{array}{lllll}1 & 2 & 3 & 4 & 5 \\ \text { Not at all } & \text { A little } & \text { In the } & \text { A lot } & \text { Very much } \\ & & \text { middle } & \end{array}$

5. How much did you cooperate (work together) to build the highest tower possible ?

$\begin{array}{lllll}1 & 2 & 3 & 4 & 5 \\ \text { Not at all } & \text { A little } & \text { In the } & \text { A lot } & \text { Very much } \\ & & \text { middle } & \end{array}$




\section{Appendix F Closed-ended Goals Questionnaire}

PART II.

INSTRUCTIONS: Read each sentence below. Use the five-point scale to indicate how true the statement is for what you wanted to happen today while you were completing the task. Circle the number that describes how true the statement was for you today while completing the Jenga® task. There are no right or wrong answers.

1. I wanted to make the highest tower possible.

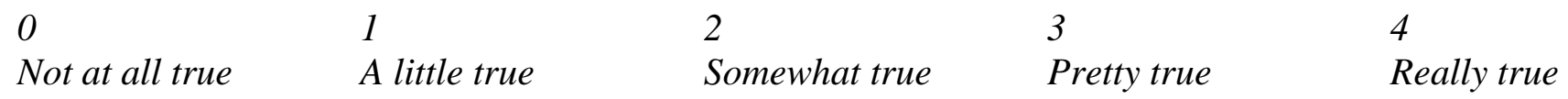

2. I wanted to work together with my partner to come up with the best way to do the task.

$\begin{array}{lllll}0 & 1 & 2 & 3 & 4 \\ \text { Not at all true } & \text { A little true } & \text { Somewhat true } & \text { Pretty true } & \text { Really true }\end{array}$

3. I wanted to figure out the best way to do the task and tell my partner it was the best.

$\begin{array}{lllll}0 & 1 & 2 & 3 & 4 \\ \text { Not at all true } & \text { A little true } & \text { Somewhat true } & \text { Pretty true } & \text { Really true }\end{array}$

4. I wanted to win.

$\begin{array}{lllll}0 & 1 & 2 & 3 & 4 \\ \text { Not at all true } & \text { A little true } & \text { Somewhat true } & \text { Pretty true } & \text { Really true }\end{array}$

5. I wanted to get my partner to do what I wanted to do.

$\begin{array}{lllll}0 & 1 & 2 & 3 & 4 \\ \text { Not at all true } & \text { A little true } & \text { Somewhat true } & \text { Pretty true } & \text { Really true }\end{array}$

6. I wanted us to help each other figure out the best way to do the task.

$\begin{array}{lllll}0 & 1 & 2 & 3 & 4 \\ \text { Not at all true } & \text { A little true } & \text { Somewhat true } & \text { Pretty true } & \text { Really true }\end{array}$

7. I wanted to be the best.

$\begin{array}{lllll}0 & 1 & 2 & 3 & 4 \\ \text { Not at all true } & \text { A little true } & \text { Somewhat true } & \text { Pretty true } & \text { Really true }\end{array}$

8. I wanted to do well on the task.

$\begin{array}{lllll}0 & 1 & 2 & 3 & 4 \\ \text { Not at all true } & \text { A little true } & \text { Somewhat true } & \text { Pretty true } & \text { Really true }\end{array}$


9. I wanted both mine and my partner's ideas to contribute to doing the task.

$\begin{array}{lllll}0 & 1 & 2 & 3 & 4 \\ \text { Not at all true } & \text { A little true } & \text { Somewhat true } & \text { Pretty true } & \text { Really true }\end{array}$

10. I wanted to be better than my partner.

$\begin{array}{lllll}0 & 1 & 2 & 3 & 4 \\ \text { Not at all true } & \text { A little true } & \text { Somewhat true } & \text { Pretty true } & \text { Really true }\end{array}$

11. I wanted to avoid arguing with my partner.

$\begin{array}{lllll}0 & 1 & 2 & 3 & 4\end{array}$

Not at all true Alittle true Somewhat true Pretty true Really true

12. I wanted to listen to my partner's ideas and feelings.

$\begin{array}{lllll}0 & 1 & 2 & 3 & 4\end{array}$

Not at all true Alittle true Somewhat true Pretty true Really true

13. I wanted my partner to do all the work.

$\begin{array}{lllll}0 & 1 & 2 & 3 & 4\end{array}$

Not at all true Alittle true Somewhat true Pretty true Really true

14. I wanted to make my partner to feel good about his or her ideas.

$\begin{array}{lllll}0 & 1 & 2 & 3 & 4 \\ \text { Not at all true } & \text { A little true } & \text { Somewhat true } & \text { Pretty true } & \text { Really true }\end{array}$

15. I wanted to prove I was the best at the game.

$\begin{array}{lllll}0 & 1 & 2 & 3 & 4 \\ \text { Not at all true } & \text { A little true } & \text { Somewhat true } & \text { Pretty true } & \text { Really true }\end{array}$

16. I wanted my partner to listen to me.

$\begin{array}{lllll}0 & 1 & 2 & 3 & 4 \\ \text { Not at all true } & \text { A little true } & \text { Somewhat true } & \text { Pretty true } & \text { Really true }\end{array}$

17. I wanted to get my partner to help me with the task.

$\begin{array}{lllll}0 & 1 & 2 & 3 & 4 \\ \text { Not at all true } & \text { A little true } & \text { Somewhat true } & \text { Pretty true } & \text { Really true }\end{array}$


18. I wanted to work together with my partner to make decisions about the best way to do the task.

0

Not at all true

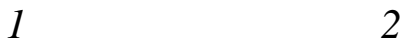

A little true
2

Somewhat true
3

Pretty true
4

Really true

19. I wanted to figure out with the best way to do the task.

0

Not at all true

\section{1}

A little true
2

Somewhat true
3

Pretty true
4

Really true

20. I wanted to get my partner to do his or her fair share.

0

Not at all true

\section{1}

A little true
2

Somewhat true
3

Pretty true
4

Really true

21. I wanted to get my way.

0

Not at all true

\section{1}

A little true
2

Somewhat true
3

Pretty true
4

Really true

22. I wanted to stack the blocks so the tower would not fall.

0

Not at all true
1

A little true
2

Somewhat true
3

Pretty true
4

Really true

23. I wanted to get along with my partner.

$\begin{array}{lllll}0 & 1 & 2 & 3 & 4 \\ \text { Not at all true } & \text { A little true } & \text { Somewhat true } & \text { Pretty true } & \text { Really true }\end{array}$

24. I wanted to get my partner to pay attention to me.

$\begin{array}{lllll}0 & 1 & 2 & 3 & 4 \\ \text { Not at all true } & \text { A little true } & \text { Somewhat true } & \text { Pretty true } & \text { Really true }\end{array}$

25. I wanted my partner to lose.

$\begin{array}{lllll}0 & 1 & 2 & 3 & 4 \\ \text { Not at all true } & \text { A little true } & \text { Somewhat true } & \text { Pretty true } & \text { Really true }\end{array}$

26. I wanted us to work together to do the best job we could.

$\begin{array}{lllll}0 & 1 & 2 & 3 & 4 \\ \text { Not at all true } & \text { A little true } & \text { Somewhat true } & \text { Pretty true } & \text { Really true }\end{array}$


27. I wanted my partner to cooperate with me.

$\begin{array}{lllll}0 & 1 & 2 & 3 & 4 \\ \text { Not at all true } & \text { A little true } & \text { Somewhat true } & \text { Pretty true } & \text { Really true }\end{array}$

28. I wanted my partner to do what I said.

$\begin{array}{lllll}0 & 1 & 2 & 3 & 4 \\ \text { Not at all true } & \text { A little true } & \text { Somewhat true } & \text { Pretty true } & \text { Really true }\end{array}$

29. I wanted my partner to know I was better at the task than he/she was.

$\begin{array}{lllll}\text { Not at all true } & 1 & 2 & 3 & 4 \\ \text { A little true } & \text { Somewhat true } & \text { Pretty true } & \text { Really true }\end{array}$

30. I wanted to build a tall tower that would not fall down.

$\begin{array}{lllll}0 & 1 & 2 & 3 & 4 \\ \text { Not at all true } & \text { A little true } & \text { Somewhat true } & \text { Pretty true } & \text { Really true }\end{array}$


Appendix G

\section{Open-ended Goals Questionnaire}

PART I.

INSTRUCTIONS: In about a paragraph, describe in your own words, what your goal was for completing the Jenga ${ }^{\circledR}$ task. 


\section{Appendix H Coding Scheme for Open-ended Goals Questionnaire}

Based on Pickard and Strough (2002)

\section{Goal Codes}

Since participants will not be given a limited area in which to write, they may report several goals concerning the task. First, the coder must determine whether more than one goal is

present. Separate goals may be indicated by conjunctions such as "and", "but", "or", spaces, numbering systems, commas, or may be placed into separate sentences. Each goal will be separated by a " $/$ ".

Each goal will then be coded into one of the following categories

1) Mutual-participation goal - A goal statement will be categorized as a mutualparticipation goal if it describes a collaborative interaction. Some examples are: "I want(ed) to work together with my partner" "I want(ed) to use both mine and my partners ideas (strategies) in doing the task" "I want(ed) my partner to work together with me to complete the highest tower possible" or "...so that the tower would not fall".

2) Authority goal - A goal statement will be categorized as an authority goal if it describes an interaction in which the participant wants to take over (or control) the interaction. Some examples are:

"I want(ed) my partner to do the task by following my suggestions" "I want(ed) to get my partner to do what I wanted to do"

3) Competitive goal - A goal statement will be categorized as a competitive goal if participants describe competitiveness between themselves and their partners. This will be used if the participant compares his/her performance to that of implied or explicitly mentioned others (partner). Some examples are: 
"I want(ed) to do better on the task than my partner"

"I want(ed) my partner to make the tower fall"

"I want(ed) to win the game"

4) Task-completion goal - A goal statement will be categorized as a task-completion goal if it describes a general completion of the task. This involves goals concerning an absolute measure of performance. Some examples are:

"I want(ed) to build a tower"

"I want(ed) to complete the study"

5) Task-quality goal - A goal statement will be categorized as a task-quality goal if it describes doing well on the task (w/o competition or help from others). Some examples are:

"I want(ed) to build the highest tower possible"

"I want(ed) to come up with the best strategy"

"I want(ed) to do well on the task"

6) Other - This category will be reserved for any statement that does not fit into the other 8 categories.

7) None - A statement will be categorized as none if the participant states explicitly that there was no goal for the interaction. Some examples are:

"I didn't have a goal"

"No goal"

8) Missing - This category will be reserved for when the participant does not complete the questionnaire. 


\section{Appendix I}

\section{Friendship Questionnaire}

INSTRUCTIONS: Please circle the number that best matches your relationship with your partner.

1) How well do you know your partner?

\begin{tabular}{|c|c|c|c|c|}
\hline 0 & 1 & 2 & 3 & 4 \\
\hline $\begin{array}{c}\text { I have never } \\
\text { met this person }\end{array}$ & $\begin{array}{c}\text { I have met them } \\
\text { before but don't } \\
\text { really know } \\
\text { them }\end{array}$ & I know them & $\begin{array}{c}\text { I know them } \\
\text { well }\end{array}$ & $\begin{array}{c}\text { I know them } \\
\text { very well. }\end{array}$ \\
\hline
\end{tabular}

2) Before today, how often have you talked to your partner?

\begin{tabular}{|c|c|c|c|c|}
\hline 0 & 1 & 2 & 3 & 4 \\
\hline $\begin{array}{c}\text { I Have Never } \\
\begin{array}{c}\text { Talked To } \\
\text { Them }\end{array}\end{array}$ & $\begin{array}{c}\text { I have talked to } \\
\text { them only once } \\
\text { or twice }\end{array}$ & $\begin{array}{c}\text { I talk to them } \\
\text { almost } \\
\text { everyday }\end{array}$ & $\begin{array}{c}\text { I talk to them } \\
\text { everyday }\end{array}$ & $\begin{array}{c}\text { I talk to them } \\
\text { several times } \\
\text { each day }\end{array}$ \\
\hline
\end{tabular}

3) How would you describe your relationship with your partner?

\begin{tabular}{|c|c|c|c|c|}
\hline 0 & 1 & 2 & 3 & 4 \\
\hline $\begin{array}{l}\text { We really don't } \\
\text { like each other }\end{array}$ & $\begin{array}{c}\text { We kind of } \\
\text { don't like each } \\
\text { other. }\end{array}$ & $\begin{array}{c}\text { We like each } \\
\text { other. }\end{array}$ & We are friends. & $\begin{array}{c}\text { We are best } \\
\text { friends. }\end{array}$ \\
\hline
\end{tabular}

4) How long have you known your partner? Circle the number of years you have been friends.

$\begin{array}{llllllllllll}\text { Less than } & 1 & 2 & 3 & 4 & 5 & 6 & 7 & 8 & 9 & 10 & \text { More than } 10\end{array}$

1 year $\quad$ years

5) If you know your partner, where did you meet? 
Appendix $\mathbf{J}$

\section{Instructions}

1) The object of the task is to work together with your partner so that the Jenga® tower does not fall.

2) You and your partner will take turns removing the blocks.

3) You and your partner need to decide together on the strategy of the game and agree on each move of a block.

4) If the tower falls, work together with your partner to rebuild the tower and begin another game.

5) Record the height of the tower after each turn by using the sheet provided. If it is your turn, you will record the height of the tower, if it is your partners turn, he/she will record the height of the tower.

\section{Remember, you want to work together with your partner so that the tower does not fall!}

To play:

- On your turn, carefully remove a block from anywhere below the highest completed story. Then stack it on top of the tower, at right angles to the blocks just below it.

- Remove and stack one block per turn.

Use one hand at a time to remove a block. You can switch hands whenever you wish.

- You can touch blocks to find a loose one - but if you move a block out of place, you must fix it before touching another block. 


\section{Instructions}

1) The object of the task is to compete against your partner so that your partner knocks down the Jenga ${ }^{\circledR}$ tower.

2) You and your partner will take turns removing the blocks.

3) You need to figure out how to make your partner lose.

4) If the tower falls, the loser rebuilds the tower to begin another game.

5) Record the height of the tower after each turn by using the sheets provided. You will be given a separate sheet from your partner and should only record the height of the tower on your turn.

Remember, you do not want to make the tower fall! Whoever makes the tower fall loses the game!

To play:

- On your turn, carefully remove a block from anywhere below the highest completed story. Then stack it on top of the tower, at right angles to the blocks just below it.

- Remove and stack one block per turn.

Use one hand at a time to remove a block. You can switch hands whenever you wish.

- You can touch blocks to find a loose one - but if you move a block out of place, you must fix it before touching another block 